\title{
LONG-TERM LIME PRETREATMENT \\ OF POPLAR WOOD
}

\author{
A Thesis \\ by \\ ROCIO SIERRA RAMIREZ
}

\begin{abstract}
Submitted to the Office of Graduate Studies of
Texas A\&M University

in partial fulfillment of the requirements for the degree of

MASTER OF SCIENCE
\end{abstract}

December 2005

Major Subject: Chemical Engineering 


\title{
LONG-TERM LIME PRETREATMENT \\ OF POPLAR WOOD
}

\author{
A Thesis \\ by \\ ROCIO SIERRA RAMIREZ
}

\begin{abstract}
Submitted to the Office of Graduate Studies of
Texas A\&M University

in partial fulfillment of the requirements for the degree of

MASTER OF SCIENCE
\end{abstract}

Approved by:

Chair of Committee, Mark Holtzapple

Committee Members, Charles Glover

Richard Davison

Cady Engler

Head of Department, Kenneth Hall

December 2005

Major Subject: Chemical Engineering 


\author{
ABSTRACT \\ Long- Term Lime Pretreatment of Poplar Wood. (December 2005) \\ Rocio Sierra Ramirez, B.S., Universidad de America, Colombia; \\ M.S., Universidad de los Andes, Colombia \\ Chair of Advisory Committee: Dr. Mark T. Holtzapple
}

Lignocellulosic biomass (e.g., poplar wood) provides a unique and sustainable resource for environmentally safe organic fuels and chemicals. The core of this study is the pretreatment step involved in bioconversion processes. Pretreatment is required to realize high yields vital to commercial success. The focus of the pretreatment step is to methodically change key features of the biomass to favor enzymatic hydrolysis.

This work assesses the compositional changes due to oxidative and non-oxidative longterm lime pretreatment of poplar wood (up to 4 weeks of pretreatment) at mild temperatures $\left(25^{\circ} \mathrm{C}\right.$ to $\left.65^{\circ} \mathrm{C}\right)$, and their effect on the enzymatic yield of glucan and xylan.

The most important pretreatment yield of lignin was $54 \mathrm{~g}$ lignin remaining/100 g lignin in raw biomass, and was accomplished for 4-week lime pretreatment at $65^{\circ} \mathrm{C}$ in oxidative conditions. The corresponding pretreatment yields of glucan and xylan were 85.9 g glucan recovered/100 g glucan in raw biomass and $80.2 \mathrm{~g}$ xylan recovered/100 $\mathrm{g}$ xylan in raw biomass respectively.

For poplar wood oxidatively pretreated with lime for 4 weeks at $65^{\circ} \mathrm{C}$ and enzymatically hydrolyzed with an enzyme loading of $15 \mathrm{FPU} / \mathrm{g}$ glucan in raw biomass during a 3-day period, the best overall yields of glucan and xylan, were $80.7 \mathrm{~g}$ glucan hydrolyzed/100 g glucan in raw biomass and $66.9 \mathrm{~g}$ xylan hydrolyzed/100 g xylan in raw biomass respectively. The corresponding hydrolysis yields were $94.0 \mathrm{~g}$ glucan hydrolyzed/100 g glucan in treated biomass and $83.5 \mathrm{~g}$ xylan hydrolyzed/100 $\mathrm{g}$ xylan in treated biomass respectively.

Because there is a previous study of long-term lime pretreatment of corn stover (Kim, 2004), the data obtained in this work show the effect of using woody lignocellulose as substrate. 
From the comparison, resulted that in the case of poplar wood oxidatively pretreated at $65^{\circ} \mathrm{C}$ for 4 weeks, less lignin was removed and more carbohydrates were solubilized, however the hydrolysis yield of glucan was almost equal and the hydrolysis yield of xylan was higher than the reported by Kim for corn stover oxidatively pretreated at $55^{\circ} \mathrm{C}$ for 4 weeks. The overall yield of glucan resulted lower in the case of poplar wood because of the lower pretreatment yield of glucan. Thus, it is important to complete the mass balances including an analysis on the pretreatment liquor to determine if the solubilized glucan was degraded. 
To God from whom all goods come.

To my husband Gerardo and beloved children Angela, Juan, and Maria for their unconditional love.

To my parents for their love and continuous encouragement. 


\section{ACKNOWLEDGEMENTS}

Many people contributed in one way or another to the success of this work. Without them it would not have been possible. I express my most sincere gratitude to all of them.

First of all, I would like to thank Dr. Mark T. Holtzapple for believing in me and giving me the opportunity to work on this very challenging and rewarding project. His continuous encouragement and patience were of great importance and prevented me from giving up in the hardest moments. His profound knowledge and ideas made it a pleasure to work with him.

I would like to thank my committee members - Dr. Richard Davison, Dr. Charles Glover, and Dr. Cady Engler - for their helpful comments and suggestions.

I thank Dr. Jose Rafael Toro, Provost at Universidad de los Andes for supporting me and believing in me.

I thank my husband Gerardo Gordillo who encouraged me in so many ways. The hardest problems were half as hard when considered from his point of view. I also thank my dearly loved children Angela, Juan, and Maria for understanding and even giving me a helping hand when I needed.

I would like to thank all the members of my lab group. Their help was fundamental in its moment: Dr. Sehoon Kim, Mr. Zhihong Fu, Ms. Maxine Jones, Dr. Li Zhu, and Mr. Stanley Coleman. I specifically thank Dr. Cesar Granda, Dr. Jonathan O’Dwyer, and Dr. Frank Agbogbo for their technical support, availability, ideas and encouragement.

I would like to thank Mr. Randy Marek for his capability, good will, and efficiency. No trouble in the equipment building up, repair or maintenance was overwhelming with his help.

I thank Dr. Nathan Mosier, from Purdue University; Dr. Y.Y. Lee from Auburn University, Dr. Richard Elander form NREL laboratory and all other members of the CAFI group (Consortium for Applied Fundamentals and Innovation) for their helpful comments and suggestions.

Last but not least, I would like to especially thank my parents for their love and support throughout graduate school. 


\section{TABLE OF CONTENTS}

Page

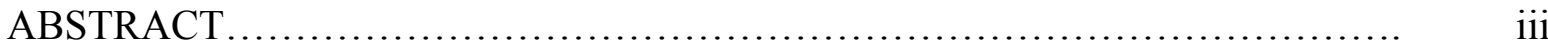

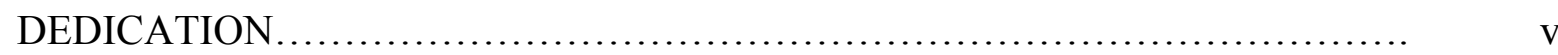

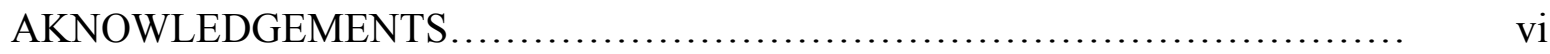

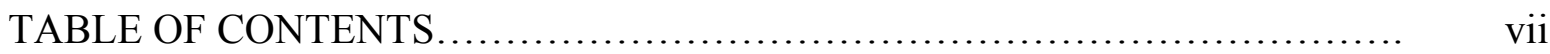

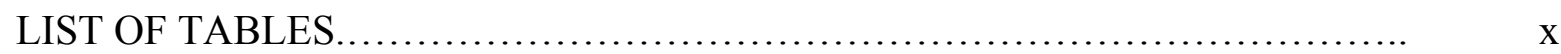

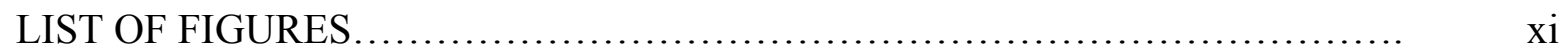

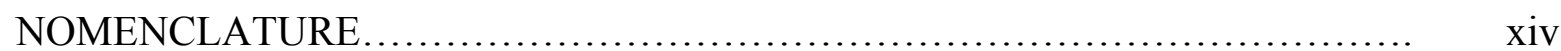

\section{CHAPTER}

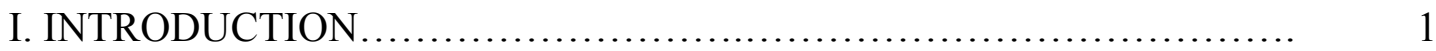

1.1. Poplar wood as a renewable energy source....................... 1

1.2. Structure of lignocellulosic biomass.............................. 2

1.3. Biomass conversion processes................................. 3

1.4. Pretreatments.................................................. 5

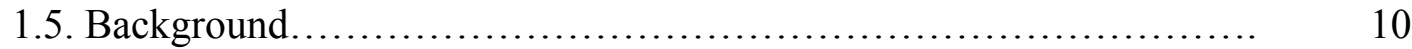

1.6. Objective................................................... 15

II. FEEDSTOCK .................................................... 16

2.1. Preparation, storage and handling .............................. $\quad 16$

2.2. Composition of poplar wood feedstock........................... 18

2.3. Results and discussion...................................... 20

2. 4. Conclusion................................................... 21

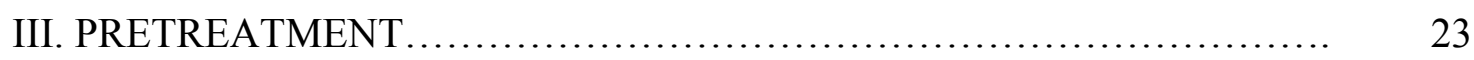

3.1. Experimental design.......................................... 23

3.2. Reactor system............................................ 26

3.3. Pretreatment method .......................................... 30

IV. PRETREATMENT YIELD, HYDROLYSIS YIELD, AND OVERALL

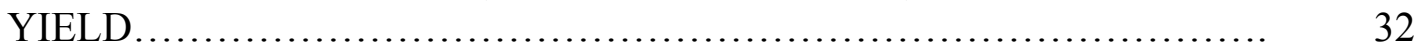


CHAPTER

V. LIME CONSUMPTION ............................................... 37

5.1. Lime mode of action............................................. 37

5.2. Materials and methods........................................ 37

5.3. Results and discussion......................................... 39

5.4. Conclusions...................................................... 44

VI. CHANGES IN COMPOSITION OF POPLAR WOOD CAUSED BY LIME PRETREATMENT ............................................ 45

6.1. Introduction....................................................... 45

6.2. Materials and methods.......................................... 46

6.3. Recovery yield of total mass.................................... 46

6.4. Mass balances.................................................. 48

6.5. Pretreatment yields of cellulose $\left(\mathrm{Y}_{\mathrm{G}}\right)$ and hemicellulose $\left(\mathrm{Y}_{\mathrm{X}}\right) \ldots \ldots \ldots \ldots . . \ldots 5$

6.6. Delignification............................................... 55

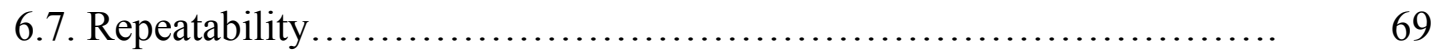

6.8. Conclusion................................................... 72

VII. ENZYMATIC HYDROLYSIS...................................... 73

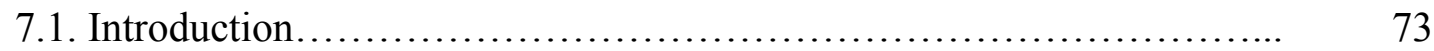

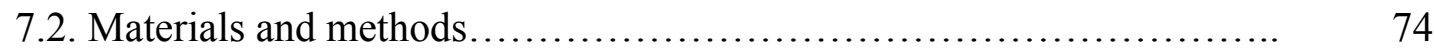

7.3. Total yield and hydrolysis yield................................. $\quad 75$

7.3. Results and discussions......................................... 76

7.4. Conclusion................................................. 87

VIII. CONCLUSION AND FUTURE STUDIES $\ldots \ldots \ldots \ldots \ldots \ldots \ldots \ldots \ldots \ldots \ldots \ldots \ldots \ldots$

REFERENCES..................................................... 92

APPENDIX A............................................................... 100

APPENDIX B....................................................... 103

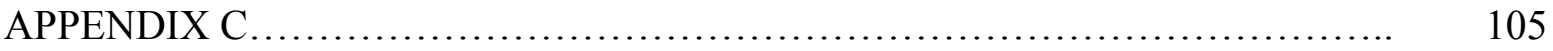

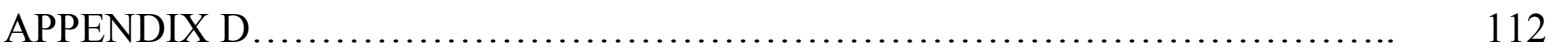

APPENDIX E....................................................... 114

APPENDIX F....................................................... 115 


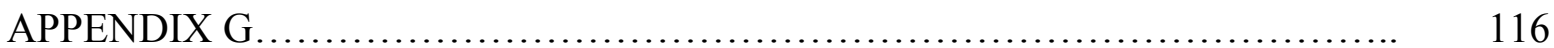

APPENDIX H....................................................... 118

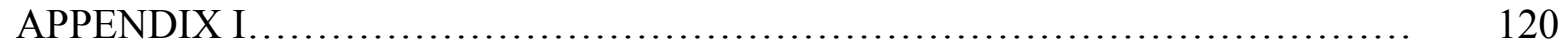

APPENDIX J............................................................ 124

APPENDIX K...................................................... 125

APPENDIX L.......................................................... 126

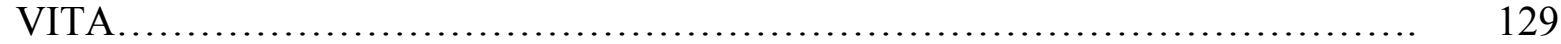




\section{LIST OF TABLES}

TABLE

Page

1 Effect of several different pretreatment methods on digestibility.........

2 Yields of xylose and glucose for each pretreatment system studied followed by enzymatic hydrolysis with a loading of $15 \mathrm{FPU} / \mathrm{g}$ glucan in the original corn stover............................................

3 Particle size distribution of poplar wood........................... 17

4 Composition of poplar wood feedstock.............................

5 Percentage of decrease of oxygen concentration in the air at temperature $T\left({ }^{\circ} \mathrm{C}\right)$ compared to what it would be if it was at $25^{\circ} \mathrm{C}$

6 Experimental conditions for pretreatment.........................

7 Variation of the recovery yield of total mass with pretreatment time for all temperatures, oxidative and non-oxidative condition..................

8 Comparation between this study and a previous study on long term

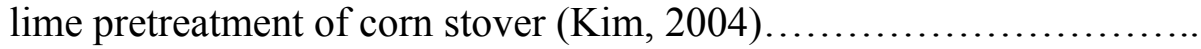




\section{LIST OF FIGURES}

FIGURE

Page

1 Process routes for converting biomass to liquid fuels............... 4

2 Schematic of goals of pretreatment on lignocellulosic material.......

6

3 Average particle size distribution. a) After grinding and sieving. b) Used in pretreatment............................................

4 Chromatograms to interpret results on xylan and arabinan concentration. a) All carbohydrate components in a single standard. b) Xylan and arabinan appear as a single peak....................

5 Schematic Diagram of the lime pretreatment reactor.

6 Schematic diagram of a set of eight reactors in the reactor system for lime pretreatment........................................

7 Reactor system. a) Complete system. b) Reactors at 55 and $65^{\circ} \mathrm{C}$ were coated with insulating material. c) Temperature controller. d) Flow rate of gasses measured as bubbles per second. d) Bottle with a water and lime slurry to scrub $\mathrm{CO}_{2}$ in the air...

8 Schematic definitions of pretreatment yield, hydrolysis yield and overall yield.................................................

9 Nomenclature and definition of fractions used to calculate pretreatment yield, hydrolysis yield and overall yield................

10 The salient chemical structural units associated with lignin in woody tissue.

11 Lime consumption as a function of pretreatment time and temperature. a) Oxidative. b) Non-oxidative.......................

12 Lime consumption along pretreatment time at a) 25, b) 35 c) 45 d) 55 and e) $65^{\circ} \mathrm{C}$ in the oxidative and non-oxidative condition.

13 Delignification as a function of lime consumption in the oxidative and non-oxidative conditions

14 Summative mass closure for poplar wood pretreated at $25^{\circ} \mathrm{C}$, a) oxidative, b) non-oxidative 
15 Summative mass closure for poplar wood pretreated at $35^{\circ} \mathrm{C}$ a) oxidative b) non-oxidative.

16 Summative mass closure for poplar wood pretreated at $45^{\circ} \mathrm{C}$, a) oxidative, b) non-oxidative..

17 Summative mass closure for poplar wood pretreated at $55^{\circ} \mathrm{C}$, a) oxidative, b) non-oxidative

18 Summative mass closure for poplar wood pretreated at $65^{\circ} \mathrm{C}$ a) oxidative b) non-oxidative

19 a) Cellulose and b) hemicellulose yields of poplar wood pretreated at $25^{\circ} \mathrm{C}$.

20 a) Cellulose and b) hemicellulose yields of poplar wood pretreated at $35^{\circ} \mathrm{C}$

21 a) Cellulose and b) hemicellulose yields of poplar wood pretreated at $45^{\circ} \mathrm{C}$

22 a) Cellulose and b) hemicellulose yields of poplar wood pretreated at $55^{\circ} \mathrm{C}$.

23 a) Cellulose and b) hemicellulose yields of poplar wood pretreated at $65^{\circ} \mathrm{C}$

24 Fraction of lignin remained after pretreatement (yield of lignin) a) 25 b) 35 c) 45 d) 55 e) $65^{\circ} \mathrm{C}$.

25 Calculation of delignification selectivity at $25^{\circ} \mathrm{C}$. a) Oxidative b) Non-oxidative.

26 Calculation of delignification selectivity at $35^{\circ} \mathrm{C}$. a) Oxidative b) Non-oxidative

27 Calculation of delignification selectivity at $45^{\circ} \mathrm{C}$. a) Oxidative b) Non-oxidative.

28 Calculation of delignification selectivity at $55^{\circ} \mathrm{C}$. a) Oxidative b) Non-oxidative 
29 Calculation of delignification selectivity at $65^{\circ} \mathrm{C}$. a) Oxidative b)

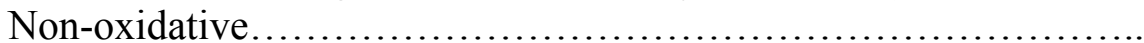

30 Selectivity as a function of temperature and oxidative condition......

31 Relation between pretreatment yield of lignin and pretreatment yield of carbohydrates. a) Cellulose case. b) Hemicellulose case.............

32 Hydrolysis yields of a) glucan and b) xylan for pretreated poplar wood in oxidative and non-oxidative condition at $25^{\circ} \mathrm{C}$.....

33 Hydrolysis yields of a) glucan and b) xylan for pretreated poplar wood in oxidative and non-oxidative condition at $35^{\circ} \mathrm{C}$

34 Hydrolysis yields of a) glucan and b) xylan for pretreated poplar wood in oxidative and non-oxidative condition at $45^{\circ} \mathrm{C}$

35 Hydrolysis yields of a) glucan and b) xylan for pretreated poplar wood in oxidative and non-oxidative condition at $55^{\circ} \mathrm{C}$

36 Hydrolysis yields of a) glucan and b) xylan for pretreated poplar wood in oxidative and non-oxidative condition at $65^{\circ} \mathrm{C}$

37 Overall yields of a) glucan and b) xylan for pretreated poplar wood

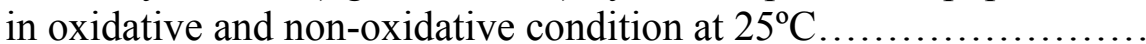

38 Overall yields of a) glucan and b) xylan for pretreated poplar wood in oxidative and non-oxidative condition at $35^{\circ} \mathrm{C}$

39 Overall yields of a) glucan and b) xylan for pretreated poplar wood in oxidative and non-oxidative condition at $45^{\circ} \mathrm{C}$

40 Overall yields of a) glucan and b) xylan for pretreated poplar wood

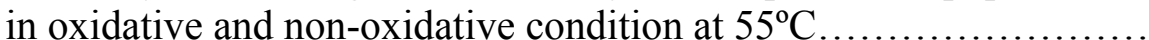

41 Overall yields of a) glucan and b) xylan for pretreated poplar wood in oxidative and non-oxidative condition at $65^{\circ} \mathrm{C}$ 


\section{NOMENCLATURE}

$\begin{array}{ll}Y_{g} & \text { Hydrolysis yield of glucan } \\ Y_{G} & \text { Pretreatment yield of glucan } \\ Y_{L} & \text { Pretreatment yield of lignin } \\ Y_{p} & \text { Pretreatment yield } \\ Y_{g}^{T} & \text { Overall yield of glucan } \\ Y_{X}^{T} & \text { Overall yield of xylan } \\ Y_{X} & \text { Hydrolysis yield of xylan } \\ Y_{X} & \text { Pretreatment yield of xylan }\end{array}$




\section{CHAPTER I \\ INTRODUCTION}

Over the last 25 years, depletion of global fossil fuels, increasing energy demand, progressive environmental quality decay, and national security concerns have motivated research into renewable, domestic sources of fuels and chemicals to replace petroleum.

Lignocellulosic biomass (e.g., poplar wood) provides a unique and sustainable resource for environmentally safe organic fuels and chemicals. Furthermore, due to its abundance and immense potential, the conversion of lignocellulosic biomass to ethanol is considered one of the most important uses of biomass as an energy source in the United States (DOA, Office of Energy Efficiency and Renewable Energy; Kheshgi et al., 2000; Colin, 2003; Eaglesham et al., 2000; Lightfoot, 2004; Ranney and Mann, 1994; Smil 1994; Spath and Mann, 2004).

Ethanol produced from biomass would be of great benefit to the transportation sector, where about two thirds of U.S petroleum is consumed (Wyman, 1999). Futhermore "no major infrastructure barriers exist" for producing over 5 billion gallons of ethanol in the United States each year (Reynolds, 2002; Mosier et al., 2005).

\subsection{Poplar wood as a renewable energy source}

Forestry is a major industry encompassing nearly 559 million acres in publicly and privately held forest lands in the continental United States (USDA, 1997). Nearly 16 million cubic feet of roundwood are harvested and processed annually to produce sawlogs, paper, veneers, composites, and other fiber products (USDA, 1998).

The extensive forest acreage and roundwood harvest generate logging residues and provide the potential to harvest non-merchantable wood for energy. Additionally, processing wood into fiber products creates substantial quantities of mill residues that could potentially be used for energy. However, because primary mill residues are clean, concentrated at one source, and relatively homogeneous, nearly $98 \%$ of all residues genera-

This thesis follows the style and format of Bioresource Technology. 
ted in the United States are currently used as fuel or to produce other fiber products (Walsh, 2000). Dedicated energy crops are currently not produced in the United States, but they could be if sold at a price that ensures the producer a profit at least as high as could be earned using the land for alternative uses. The development of dedicated feedstock supply systems has focused on several hardwood species, including poplar (Wright, 1994). Hybrid poplar is rated among the most promising species for the United States because it easily grows on marginal lands requiring minimal fertilization, it may be mechanically harvested, it exhibits high growth rates (average 10 to $17 \mathrm{Mg} /(\mathrm{ha} \cdot \mathrm{yr})$ ), and it is easily propagated from either stem cuttings or tissue culture (Wright, 1994; Wayman, 1990).

\subsection{Structure of lignocellulosic biomass}

Lignocellulose is the three-dimensional polymeric composite formed by plants as structural material. It consists of variable amounts of cellulose, hemicellulose, and lignin. Cellulose is a homopolysaccharide with building blocks of glucose molecules connected by $\beta-1,4$ linkages. The cellulose degree of polymerization (DP) is about 10,000 , although chemical pulping reduces this greatly. Cellulose molecules form intra- and inter-molecular hydrogen bonds that result in highly ordered crystalline cellulose. Cellulose is relatively inert to chemical treatment and insoluble in most solvents (Holtzapple, 1993a).

Hemicellulose is a short, highly branched chain of heteropolysaccharides (DP 100-200) built from hexoses (D-glucose, D-mannose, and D-galactose), pentoses (D-xylose, Larabionose, and D-arabionse), and deoxyhexoses (L-rhamnose or 6-deoxy-L-mannose and rare L-fucose or 6-deoxy-L-galactose). Small amounts of uronic acids (4-O-methyl-Dglucoronic acid, D-galacturonic acid, and D-glucuronic acid) are also present (Holtzapple, 1993b). The monosaccharides released upon hemicellulose hydrolysis include a large fraction of pentoses. The chemical and thermal stability of hemicellulose is lower than cellulose, due to its lack of crystallinity and lower DP.

Lignin is a phenylpropane-based polymer and is the largest non-carbohydrate fraction of lignocellulose. It is constructed of three monomers: coniferyl alcohol, sinapyl alcohol, and coumaryl alcohol. Each has an aromatic ring with different substituents. Unlike cellulose, lignin cannot be depolymerized to its original monomers. Lignin and 
hemicellulose form a sheath that surrounds the cellulosic portion of the biomass (Holtzapple, 1993c). Lignin protects lignocellulose against insect attack.

\subsection{Biomass conversion processes}

Using proper processes, lignocellulosic biomass (e.g., poplar wood) can be converted to a wide variety of fuels and chemicals. With this purpose, many processes have been developed. These include the following: fermentation of sugars and starches, fast pyrolysis, direct liquefaction of biomass by thermal processes, and indirect liquefaction of biomassderived syngas. The full range is shown in Fig. 1 (Double, 1987).

A major emphasis in the fermentation industry is ethanol production (Chadha et al., 1995; Holtzapple et al., 1999). Fermentation is a biological process in which enzymes produced by microorganisms catalyze energy-releasing reactions that break down complex organic substrates. Besides ethanol, fermentation can also produce chemicals such as carboxylic acids (Blasig et al., 1992; Loescher, 1996) in addition to nearly 40 other chemicals and chemical feedstocks (Ladish et al., 1979; Voloch et al., 1985; Landucci et al., 1996; Ladish, 2002).

Lignocellulose fermentation to alcohols requires four major unit operations in either of the two currently available approaches: the traditional process and the MixAlco process developed by Holtzapple et al., (1997). These two processes are illustrated in Fig. 1.

In both or these processes, the first step is pretreatment. It is required to realize high yields vital to commercial success in biological conversion to ethanol and chemicals (Chang et al., 2000; Mosier et al., 2005). It is due to lignocellulose structural characteristics, such as its lignin barrier, cellulose crystallinity, and hemicellulose acetylation. The goal is to break the lignin seal, remove the acetyl groups, and disrupt the crystalline structure of cellulose. After an appropriate pretreatment, the cellulose is more accessible to hydrolysis in which fermentable sugars are released. 
Thermochemical routes

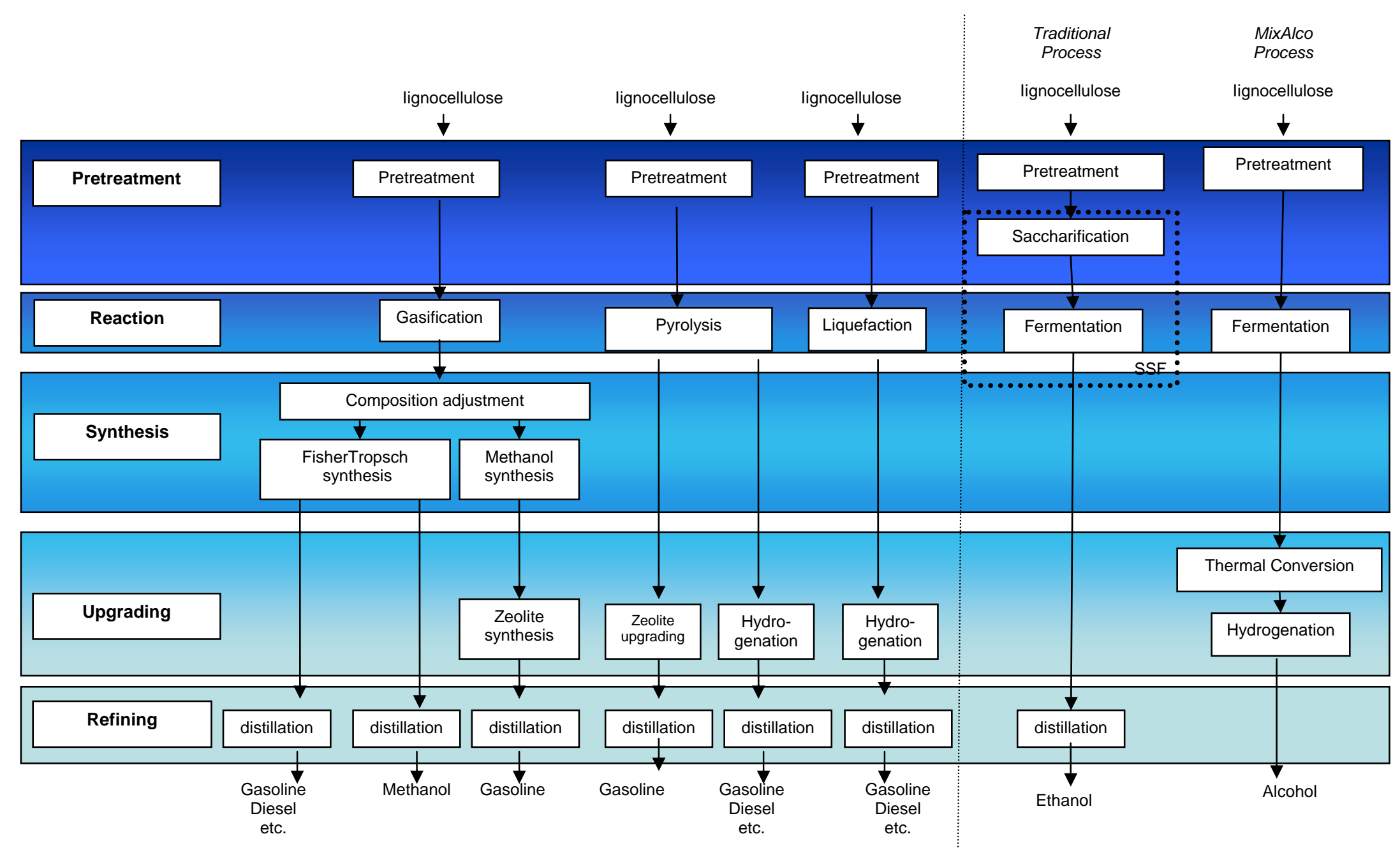

Fig. 1. Process routes for converting biomass to liquid fuels 
In the traditional process, once pretreatment is completed, cellulase enzyme complexes (the system includes $\beta$-glucosidase, cellobiase, exoglucanase, and endoglucanase) saccharifies carbohydrate polymers into monomeric sugars. This step can alternatively be executed chemically by dilute sulfuric or other acids.

Enzymatic saccharification is advantageous because it is very selective, it can achieve high yields, and the formation of inhibitory by-products is avoided. Cellulose hydrolysis performed in the presence of fermentative microorganisms is termed simultaneous saccharification and fermentation (SSF). Simultaneous saccharification of both cellulose (to glucose) and hemicellulose (to xylose and arabinose) and co-fermentation of both glucose and xylose (SSCF) would be performed by genetically engineered microbes that ferment glucose and xylose in the same broth. More research is needed to achieve this goal. Finally, ethanol is recovered from the fermentation broth by distillation, or distillation combined with adsorption.

In the MixAlco process, after pretreatment, an anaerobic fermentation is performed using a mixed culture of microorganisms to produce carboxylic acids. The carboxylic acids are converted to their salts in the presence of $\mathrm{CaCO}_{3}$ buffer. The carboxylate salts are then dried, converted to ketones, and further hydrogenated to alcohol fuels. The MixAlco process has advantages such as no sterility requirement, adaptability to many feedstocks, and no enzyme addition.

\subsection{Pretreatments}

An effective pretreatment is characterized by several criteria: it avoids the need for reducing the size of biomass particles, preserves the cellulose and hemicellulose fractions, limits the formation of degradation products that may inhibit fermentative microorganisms, minimizes energy demand, is effective on multiple lignocellulose feedstocks, and limits costs. Pretreatment has a major influence on the process cost due to its own cost and because it directly affects prior and subsequent operations (Wooley et al., 1999; Lynd et al., 1996). Consequently, over the past 25 years, numerous pretreatment approaches have been investigated at many laboratories, universities, and industrial locations. 


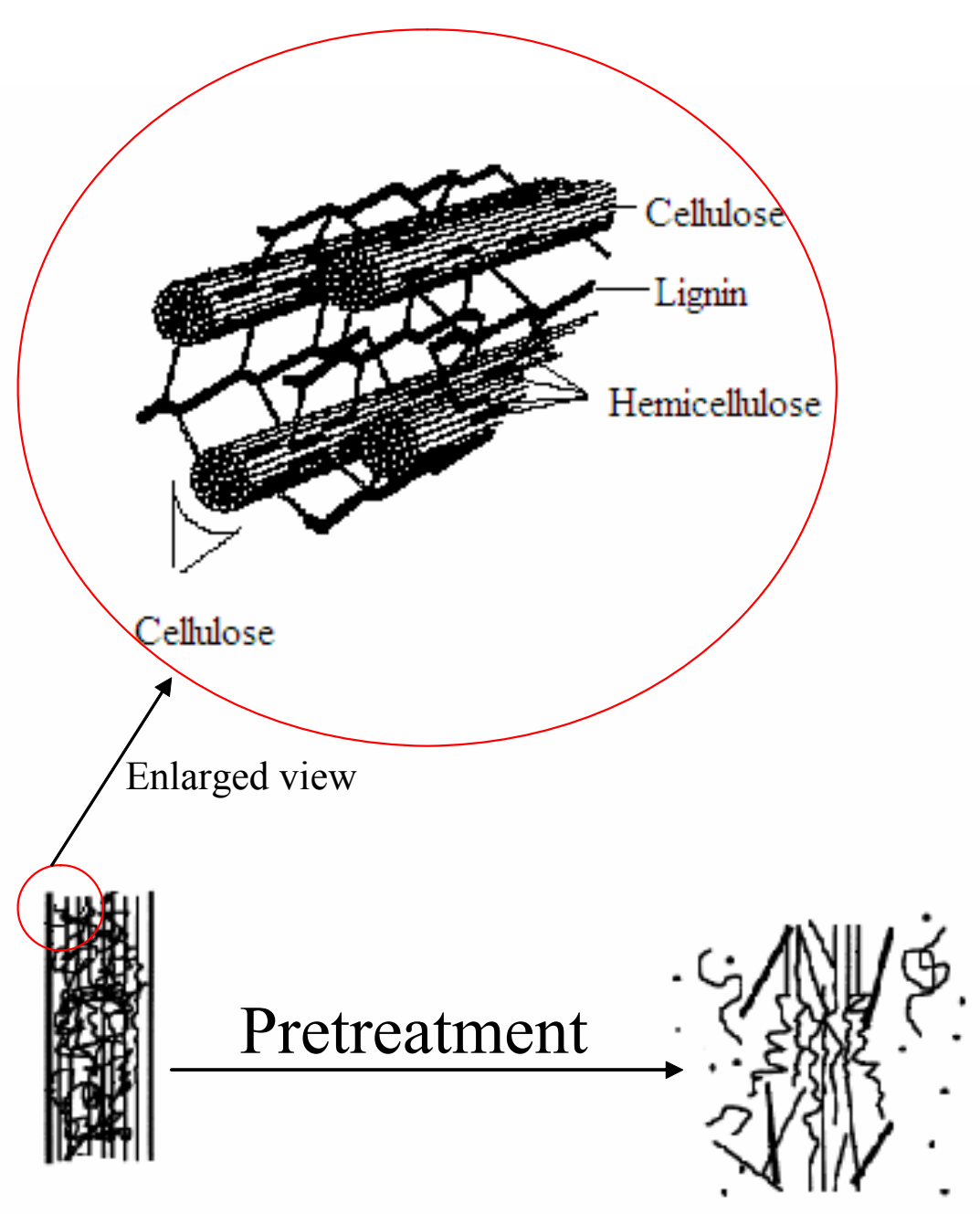

Fig. 2. Schematic of goals of pretreatment of lignocellulosic biomass. (Adapted from Mosier et al., 2005) 
However, the mechanisms by which pretreatments improve lignocellulose digestibility are not well understood. In fact, different pretreatments can affect biomass in very different ways (Wyman et al., 2005a, 2005b, Aden et al., 2002). Nevertheless, pretreatment effectiveness has been correlated with removing hemicellulose and lignin. It is believed that pretreatment creates numerous large pores in hardwoods and herbaceous biomass, which allows cellulase penetration to the cellulose fibers (Fig. 2). Hemicellulose hydrolysis yields mostly xylan, which is soluble in the pretreatment liquid phase. Lignin solubilization is benefical for subsequent hydrolysis, but may also produce derivatives that inhibit enzyme activity. Thus, the assessment of a pretreatment technology must include not only its ability to remove lignin, but also its potential ethanol yield.

Currently available pretreatment methods are biological, chemical (cellulose solvents, acids or bases), or physical (mechanical size reduction, comminution, steam explosion, vibratory ball milling, compression milling, and hydrothermolysis).

Biological pretreatments employ microorganisms that produce lignin-degrading enzymes (ligninase). As lignin is decomposed, cellulose and hemicellulose are released from the lignocellulosic matrix. The exploitation of ligninase-producing microorganisms has been little developed and faces several hurdles. These include the fact that many ligninolytic microorganism grow on the resulting sugars and produce cellulases and hemicellulases, thus degrading yields (Brown, 2003).

Some physical pretreatments (size reduction or comminution) are needed to make material handling easier through subsequent steps and increase the surface area of the lignocellulosic material to be pretreated by other means. Primary size reduction employs hammer mills to produce particles that can pass through 3-mm screen openings (Brown, 2003). High energy requirements, low yields, and long times requirements are some of the drawbacks of mechanical pretreatments. Furthermore, recent research suggests that more important than the mechanical disruption, are the chemical changes that occur during pretreatment (Mosier et al., 2005). Chemical pretreatments using cellulose solvents (e.g., glycerol, dioxane, ozone, phenol, and ethylene glycol) are too expensive to be practical when measured against the value of glucose, approximately $5 \not / \mathrm{lb}$ (Mosier, 2005). Among a vast number of possibilities, a few pretreatments are potentially cost-effective and a brief review of them follows: 


\subsubsection{Dilute acid}

This pretreatment is also known as prehydrolysis, or acid-catalyzed steam explosion. The comminuted biomass is treated with sulfuric acid $(\sim 0.5-1.0 \%)$ at moderate temperatures $\left(\sim 140-190^{\circ} \mathrm{C}\right)$ for 5 to 30 minutes. This pretreatment effectively retains most of the cellulose, but hemicellulose is recovered as dissolved sugars. Although little lignin is dissolved, data suggest that lignin is disrupted thereby increasing cellulose susceptibility to enzymes (Knappert et al., 1981). Nonetheless, dilute acid pretreatment results in costly materials of construction, high pressures, neutralization and conditioning of hydrolyzate prior to enzymatic hydrolysis, slow cellulose digestion, and non-productive binding of enzymes to lignin (Wyman, 1999; Hsu, 1980).

\subsection{2. pH-controlled liquid hot water pretreatment}

In this pretreatment, high-pressure water penetrates the cell structure of biomass, hydrates cellulose, and removes hemicellulose. The preferred temperature is $180-190^{\circ} \mathrm{C}$. The benefit of using just water is that an extraneous reagent is not needed. The goal is to minimize degradation by avoiding the formation of monosaccharides that degrade to aldehydes during the high-temperature pretreatment. Enzymes can be added at lower temperatures for hydrolysis of the resulting cellulose and hemicellulose oligomers (Ladish et al., 1983; Lynd et al., 1991; Holtzapple, 1993b; Mosier et al., 1999).

\subsubsection{Ammonia Fiber Explosion (AFEX)}

In AFEX pretreatment, biomass is treated with liquid anhydrous ammonia at moderate temperatures $\left(60-100^{\circ} \mathrm{C}\right)$ and high pressure $(250-300 \mathrm{psi})$ for $5 \mathrm{~min}$. Then the pressure is rapidly released. In this process, the combined chemical and physical effects of lignin solubilization, hemicellulose hydrolysis, cellulose decrystallization, and increased surface area, enables nearly complete enzymatic conversion of cellulose and hemicellulose to fermentable sugars (Mosier et al., 2005). In this process, nearly all of the ammonia can be

recovered and reused whereas the remaining serves as nitrogen source for microbes in 
downstream processes (Dale et al., 1982). It is also characterized by high yields and no need of neutralization after pretreatment.

\subsubsection{Ammonia Recycled Percolation (ARP)}

An ammonia solution $(\sim 15 \%)$ is fed to a column reactor packed with biomass at temperatures of 160 to $180^{\circ} \mathrm{C}$ and fluid velocity of $1 \mathrm{~mL} /\left(\mathrm{cm}^{2} \cdot \min \right)$ with residence times of 14 min. Aqueous ammonia reacts primarily with lignin (but not cellulose), which causes depolymerization of lignin and cleaves lignin-carbohydrate linkages. A large and adjustable degree of delignification has been reported in tests with hardwood (Yoon et al., 1995).

\subsection{5. $\mathrm{SO}_{2}$ steam explosion pretreatment}

$\mathrm{SO}_{2}$ gas is added in the amount of $2-3 \%$ to moist biomass chips and heated to $150^{\circ} \mathrm{C}$ for 20 minutes to hydrolyze hemicellulose. The sulfur dioxide rapidly diffuses into biomass pores before it is converted into $\mathrm{H}_{2} \mathrm{SO}_{4}$, providing superior performance compared to the direct use of an acid catalyst.

\subsubsection{Lime pretreatment}

Calcium hydroxide, water, and an oxidizing agent (air or $\mathrm{O}_{2}$ ) are mixed with the biomass at temperatures ranging from 40 to $150^{\circ} \mathrm{C}$ for a period ranging from hours to weeks. The major effect is the removal of lignin from the biomass, thus improving the reactivity of the remaining polysaccharides. In addition, this pretreatment removes acetyl and the various uronic acid substitutions on hemicellulose that lower the accessibility of the enzyme to the hemicellulose and cellulose surface (Chang and Holtzapple, 2000; Kaar and Holtzapple, 2000). 


\subsection{Background}

Acid pretreatment as described before, has been implemented for commercial development because it is considered very promising. However, compared with acid processes, alkaline processes have shown better possibilities of recovery and/or regeneration. The most widely used bases are urea, sodium, potassium, calcium, and ammonium hydroxide. Among all of these, the pretreatment with calcium hydroxide (lime) is the least expensive per kilogram of agent. The price of lime, $\$ 0.06 / \mathrm{kg}$ (Miller, 2001) is a third that of the second least expensive alkali, urea.

Alkali delignification of lignocellulosic biomass is an important part of industrial processes known as soda and kraft pulping, and the chemistry of this delignification has been extensively discussed (Alén, 2000; Lai, 2001; Klinkle et al., 2002; Kleinert, 1966; Montgomery, 1953). Studies in this context show that during oxidative alkali treatment, biomass delignification occurs by oxidation of the phenolic groups in lignin. Due to the low activity of oxygen, high temperature and $\mathrm{pH}$ are required to obtain reasonable rates, but carbohydrates in the presence of alkali and oxygen undergo both oxidation and alkaline degradation to produce a complex mixture of products.

Two types of lime treatment that show high total sugar yields have been awarded a US Patent (Holtzapple and Davison, 1999) and are currently used in our laboratory, short term and long term. Short-term lime pretreatment involves boiling the biomass with a lime loading of $0.1 \mathrm{~g} \mathrm{Ca}(\mathrm{OH})_{2} / \mathrm{g}$ dry biomass at temperatures of $85-135^{\circ} \mathrm{C}$ for $1-3$ hours (Chang et al., 1997, 1998). This removes approximately a third of the lignin and all the acetyl groups from hemicellulose (Chang et al., 2000). Chang et al., (2000) showed that oxidative lime pretreatment could be used to pretreat high-lignin biomass. Long-term pretreatment involves using the same lime loading at lower temperatures $\left(40-55^{\circ} \mathrm{C}\right)$ for $4-6$ weeks in the presence of air. Kim (2004) showed that long-term pretreatment removes about half of the lignin and all the acetyl groups in corn stover. It is important to note that long-term pretreatment has the benefit of not requiring an expensive reactor (e.g., stainless steel tank that resists high pressure and corrosion). Also, pure oxygen may be replaced by air, thus reducing process costs. 
The performance and economics of the different pretreatment alternatives are hard to compare, due to differences in feedstocks tested, chemical analysis methods, and data reporting methodologies. A summary of some relevant results on pretreatment of biomass is presented in Table 1.

Improving the understanding of differences among several leading pretreatment technologies and the effect of each pretreatment on other operations can facilitate selection, reduce commercialization risk, and suggest opportunities for improvements. To achieve this goal, it is required to provide comparative performance data on different pretreatments using the same source of lignocellulosic biomass and identical analytical methods.

This project is part of a multi-institutional effort funded by the US Department of Energy. The participants and their contributions follow: Auburn University with liquid ammonia recycled percolation (ARP) pretreatment, Dartmouth College with acid catalyzed steam-explosion pretreatment, Michigan State University with Ammonia Fiber Explosion (AFEX) pretreatment, Purdue University with controlled-pH pretreatment, Texas A\&M University with lime pretreatment, University of British Columbia with $\mathrm{SO}_{2}$ steam explosion pretreatment, Genecor International Inc with enzyme supply, and NREL laboratory with feedstock supply and logistical support.

All of these institutions are members of the biomass refining Consortium for Applied Fundamentals and Innovation (CAFI) that has the mission of developing a basic understanding of biomass hydrolysis. The overall goal is to provide a single source of comparative information that will assist in understanding the unique features and performances of leading options for releasing sugars from cellulosic biomass.

On that basis, the CAFI group collected data using corn stover as a lignocellulosic source. Table 2 shows results from this work on sugar yields. It is important to notice the homogeneity and thus, comparability of the data summarized in Table 2, as opposed to the data shown in Table 1. Consequently, it was possible to draw conclusions with no precedent regarding the processes themselves and the economics of the diverse pretreatment technologies. Comparative results and economic analysis have been published (Wyman et al., 2005a,b; Eggeman and Elander., 2005). 
Table 1

Effect of several different pretreatment methods on digestibility

\begin{tabular}{|c|c|c|c|c|c|c|}
\hline Pretreatment & Biomass & $\begin{array}{l}\text { Pretreament } \\
\text { Agent loading }\end{array}$ & Time & Temperature & $\begin{array}{c}\text { Effect on } \\
\text { digestibility (\%) }\end{array}$ & References \\
\hline$\overline{\mathrm{NH}_{3}}$ & $\begin{array}{c}\text { Trembling } \\
\text { aspen }\end{array}$ & $\begin{array}{c}155 \text { psia at } \\
30^{\circ} \mathrm{C}\end{array}$ & $8.5 \mathrm{~h}$ & 30 & $33-51^{\mathrm{a}}$ & Millet et al., 1970 \\
\hline $\mathrm{SO}_{2}$ & aspen & $\begin{array}{c}30 \text { psia at room } \\
\text { temperature }\end{array}$ & $2 \mathrm{~h}$ & 120 & $9-63^{b}$ & Baker and Millett, 1975 \\
\hline $\mathrm{H}_{2} \mathrm{SO}_{4}$ & Poplar & 0 to $1.5 \%$ & $3.6-12.7 \mathrm{~s}$ & 162 to 222 & 21.4 to $74.9^{\mathrm{c}}$ & Knappert et al., 1972 \\
\hline $\mathrm{NaOH}$ & $\begin{array}{c}\text { Trembling } \\
\text { aspen }\end{array}$ & $\begin{array}{l}0.2 \mathrm{~g} / \mathrm{g} \text { dry bio } \\
\text { biomass }\end{array}$ & $1 \mathrm{~h}$ & 30 & 11 to $51^{d}$ & Moore et al., 1972 \\
\hline $\mathrm{NH}_{3}+\mathrm{H}_{2} \mathrm{O}_{2}$ & $\begin{array}{l}\text { Hybrid } \\
\text { poplar }\end{array}$ & $\begin{array}{l}\mathrm{NH}_{3}=20 \mathrm{wt} \% \mathrm{H}_{2} \mathrm{O}_{2}= \\
0.28 \mathrm{~g} / \mathrm{g} \text { dry biomass }\end{array}$ & $90 \mathrm{~min}$ & 170 & $90^{\mathrm{c}}$ & Kim and Lee, 1996 \\
\hline $\begin{array}{l}\text { Steam explosion } \\
\left(\mathrm{H}_{2} \mathrm{SO}_{4}, \mathrm{SO}_{2}, \mathrm{CO} 2\right)\end{array}$ & & & $10 \mathrm{~min}$ & $160-260$ & & Kuznetsov et al., 2002 \\
\hline AFEX & & 1-2 $\mathrm{g} \mathrm{NH}_{3} / \mathrm{g}$ dry biomass & $30 \mathrm{~min}$ & 90 & & Holtzapple et al., 1991 \\
\hline Lime & Corn Stalks & $\begin{array}{c}0.12 \mathrm{~g} \mathrm{Ca}(\mathrm{OH})_{2} / \mathrm{g} \text { dry } \\
\text { biomass }\end{array}$ & $24 \mathrm{~h}$ & $\mathrm{RT}^{\mathrm{e}}$ & 5.55 to $85.59^{f}$ & Abou-Raya et al., 1964 \\
\hline Lime & Wheat straw & $\begin{array}{c}0.09 \mathrm{~g} \mathrm{Ca}(\mathrm{OH})_{2} / \mathrm{g} \text { dry } \\
\text { biomass }\end{array}$ & $24 \mathrm{~h}$ & $\mathrm{RT}^{\mathrm{e}}$ & 54.1 to $61.9^{g}$ & Djajanegara et al., 1964 \\
\hline Lime & Corn stover & $\begin{array}{c}0.04 \mathrm{~g} \mathrm{Ca}(\mathrm{OH})_{2} / \mathrm{g} \text { dry } \\
\text { biomass }\end{array}$ & $336 \mathrm{~h}$ & 21 & 53.2 to $54.5^{\mathrm{g}}$ & Oliveros et al., 1993 \\
\hline Lime & Bagasse & $\begin{array}{c}0.30 \mathrm{~g} \mathrm{Ca}(\mathrm{OH})_{2} / \mathrm{g} \text { dry } \\
\text { biomass }\end{array}$ & $192 \mathrm{~h}$ & 20 & 19.7 to $72.4^{\mathrm{g}}$ & Playne, 1984 \\
\hline
\end{tabular}


Table 1

Continued

\begin{tabular}{|c|c|c|c|c|c|c|}
\hline Pretreatment & Biomass & $\begin{array}{l}\text { Pretreament } \\
\text { Agent loading }\end{array}$ & Time & Temperature & $\begin{array}{c}\text { Effect on } \\
\text { digestibility (\%) }\end{array}$ & References \\
\hline Lime & Poplar wood & $\begin{array}{c}0.10 \mathrm{~g} \mathrm{Ca}(\mathrm{OH}) 2 / \mathrm{g} \text { dry } \\
\text { biomass }\end{array}$ & $6 \mathrm{~h}$ & 160 & $77 \mathrm{c}$ & Chang, 1999 \\
\hline Lime & Corn stover & $\begin{array}{c}0.10 \mathrm{~g} \mathrm{Ca}(\mathrm{OH}) 2 / \mathrm{g} \text { dry } \\
\text { biomass } \\
\end{array}$ & 4 weeks & 55 & $91 \mathrm{c}$ & Kim, 2004 \\
\hline Lime & Barley straw & $\begin{array}{c}0.056 \mathrm{~g} \mathrm{Ca}(\mathrm{OH}) 2 / \mathrm{g} \text { dry } \\
\text { biomass } \\
\end{array}$ & $2160 \min$ & RTe & 54.8 to $56.9 \mathrm{~g}$ & $\begin{array}{l}\text { Owen and } \\
\text { Nwadukwe, } 1980\end{array}$ \\
\hline Lime & Barley straw & $\begin{array}{c}0.025 \mathrm{~g} \mathrm{Ca}(\mathrm{OH}) 2 / \mathrm{g} \text { dry } \\
\text { biomass } \\
\end{array}$ & $2160 \mathrm{~min}$ & $\mathrm{RTe}$ & 47.6 to $64.5 \mathrm{~g}$ & $\begin{array}{l}\text { Wilkinson and } \\
\text { Santillana, } 1978 \\
\end{array}$ \\
\hline Lime & Poplar bark & $\begin{array}{c}5.3 \text { to } 21.1 \mathrm{~g} \mathrm{Ca}(\mathrm{OH}) 2 / \mathrm{g} \\
\text { dry biomass } \\
\end{array}$ & $3600 \mathrm{~min}$ & $\mathrm{RTe}$ & 38.6 to $52.0 \mathrm{~h}$ & Gharib et al., 1975 \\
\hline Lime & Soya bean & $\begin{array}{c}0.04 \mathrm{~g} \mathrm{Ca}(\mathrm{OH}) 2 / \mathrm{g} \text { dry } \\
\text { biomass }\end{array}$ & $720 \mathrm{~min}$ & $\mathrm{RTe}$ & 35.8 to $41.3 \mathrm{i}$ & Felix et al., 1990 \\
\hline $\begin{array}{l}\text { a in vitro dry } \mathrm{m} \\
\mathrm{b} \text { in vitro diges } \\
\mathrm{c} \text { Glucose yield } \\
\mathrm{d} \text { Reducing sug } \\
\text { e RT=room tem } \\
\mathrm{f} \text { Crude fibre di } \\
\mathrm{g} \text { Organic matte } \\
\mathrm{h} \text { in vitro true } \\
\text { I in vitro organ }\end{array}$ & $\begin{array}{l}\text { igestibility (IV } \\
\text { (IVD) } \\
\text { d } \\
\text { re } \\
\text { l coefficient } \\
\text { stibility (OMD } \\
\text { sility (IVTD) } \\
\text { ter digestibility }\end{array}$ & (IVOMD) & & & & \\
\hline
\end{tabular}


Table 2

Yields of xylose and glucose for each pretreatment system studied by CAFI followed by 3-day enzymatic hydrolysis with a loading of $15 \mathrm{FPU}^{(1)} / \mathrm{g}$ glucan in the original corn stover (C Wyman et al., 2005).

\begin{tabular}{|c|c|c|c|c|c|c|c|c|c|}
\hline \multirow{2}{*}{$\begin{array}{c}\text { Pretreatment } \\
\text { System }\end{array}$} & \multicolumn{3}{|c|}{ Xylose yields } & \multicolumn{3}{|c|}{ Glucose yields } & \multicolumn{3}{|c|}{ Total sugars } \\
\hline & Stage 1 & Stage 2 & $\begin{array}{c}\text { Total } \\
\text { xylose }\end{array}$ & Stage 1 & Stage 2 & $\begin{array}{c}\text { Total } \\
\text { glucose }\end{array}$ & Stage 1 & Stage 2 & Combined \\
\hline Dilute acid & $32.1 / 31.2$ & 3.2 & 35.3 & 3.9 & 53.2 & 57.1 & $36.0 / 35.1$ & 56.4 & $92.4 / 91.5$ \\
\hline Flowthrough & $36.3 / 1.7$ & $0.6 / 0.5$ & $36.9 / 2.2$ & $4.5 / 4.4$ & 55.2 & $59.7 / 59.6$ & $40.8 / 6.1$ & $55.8 / 55.7$ & $96.6 / 61.8$ \\
\hline $\begin{array}{l}\text { Partial flow } \\
\text { pretreatment }\end{array}$ & $31.5 / 2.8$ & $2.6 / 2.4$ & $34.1 / 5.2$ & $4.3 / 4.2$ & 51.2 & $55.5 / 55.4$ & $35.8 / 7.0$ & $53.8 / 53.6$ & $89.6 / 60.6$ \\
\hline $\begin{array}{c}\text { Controlled } \\
\mathrm{pH}\end{array}$ & $21.8 / 0.9$ & 9.0 & 30.8 & $3.5 / 0.2$ & 52.9 & 56.4 & $25.3 / 1.1$ & 61.9 & 87.2 \\
\hline AFEX & & $34.6 / 29.3$ & $34.6 / 29.3$ & & 59.8 & 59.8 & & $94.4 / 89.1$ & $94.4 / 89.1$ \\
\hline ARP & $17.8 / 0$ & 15.5 & $33.3 / 15.5$ & 0 & 56.1 & 56.1 & $17.8 / 0$ & 71.6 & $89.4 / 71.6$ \\
\hline Lime & $9.2 / 0.3$ & 19.6 & $28.8 / 19.9$ & $1.0 / 0.3$ & 57.0 & $58.0 / 57.3$ & $10.2 / 0.6$ & 76.6 & $86.8 / 77.2$ \\
\hline \multicolumn{10}{|c|}{$\begin{array}{l}\text { Stage } 1 \text { refers to pretreatment and Stage } 2 \text { refers to the enzymatic digestion of the solids produced in pretreatment. The first value } \\
\text { reported in each column is for total sugars released into solution and the second is for just the monomers released. A single value } \\
\text { indicates release of only monomers. Yields are defined based on the maximum potential sugars released from the corn stover used of } \\
64.4 \mathrm{~g} \text { per } 100 \text { grams of dry solids with the maximum potential xylose being } 37.7 \% \text { and the maximum potential yield of glucose } \\
\text { being } 62.3 \% \text { on this basis. } \\
{ }^{(1)} \text { See definition of FPU on Appendix J. }\end{array}$} \\
\hline
\end{tabular}


However, the project is not complete because it lacks data about other lignocellulose sources. Expectations for similar performance are extrapolations that cannot be substantiated without information. In fact, it would be unrealistic to imply alike results with hardwoods such as poplar, because poplar wood is harder to pretreat.

\subsection{Objective}

The main purpose of this work is to explore the effect of different conditions of longterm lime pretreatment on the digestibility of poplar wood. Accurate analysis and measurements are quite simple in concept; however, they are challenging for biomass, and extensive time and care are essential to obtain meaningful information.

More specifically, this work includes:

- Preparation and long-term lime pretreatment of the poplar wood provided by NREL at 25 (or room temperature), $35,45,55$ and $65^{\circ} \mathrm{C}$, in both the oxidative and the non-oxidative conditions for 1,2, and 4 weeks.

- Determination of the composition of the poplar wood before and after pretreatment.

- Determination of the enzymatic digestibility of poplar wood before pretreatment and after pretreatment at an enzyme loading of $15 \mathrm{FPU} / \mathrm{g}$ glucan in raw biomass (See definition of FPU on Appendix J).

- Mass balances for untreated and pretreated poplar wood.

These data are going to be useful to determine the pretreatment condition that maximize enzymatic digestibility of cellulose using poplar wood. The data will also become part of the bank of data of the CAFI group to make economic analysis possible. Because poplar wood is harder to pretreat than most of other abundant agricultural residues (e.g., corn stover), the relative merits of each pretreatment will become evident allowing selection of the best, most robust pretreatment options. 


\section{CHAPTER II \\ FEEDSTOCK}

\subsection{Preparation, storage and handling}

Hybrid poplar wood (var NM6) is the feedstock for this study. NREL acquired and processed it in the following manner: approximately 30 trees of 4-8 inch diameter were harvested from private land in Alexandria, MN. The poplar logs were shipped to United Wood Products (Longmont, $\mathrm{CO}$ ) for debarking and chipping. Chips were then milled by Hazen Research Inc. (Golden, CO) using the NREL (National Renewable Energy Laboratory)-owned Mitts and Merrill Model 10×12 knife mill (Saginaw, MI) to pass a 1/4inch round screen. The milled feedstock was then thoroughly mixed by a cone-and-quarter method and was subdivided into 5-gallon pails that were shipped directly to each CAFI group member, when requested. After this process, the moisture content of the poplar wood was very high $(\sim 50 \%)$.

Upon arrival, the biomass was re-packaged into Zip-Loc bags (either completely filled or tightly wrapped to reduce evaporation into the headspace), and stored frozen at $-20^{\circ} \mathrm{C}$. When needed, the poplar wood was slowly thawed at room temperature. Then, it was air dried to a moisture content less than or equal to $10 \%$, and the particle size was reduced to pass 20 to 80 (ASTM) mesh using a knife mill. The biomass was ground and sieved to improve its uniformity and to assure reproducibility because the effect of particle size on enzymatic hydrolysis sugar yields after lime pretreatment is not important, as long as the particle size is lower than 4 mesh (Chang, 1999). There is no information for larger particle sizes.

After grinding and sieving, following the procedure explained in Appendix A, the particle size distribution was determined as the weight percentage of solids on each of six USA Standard Testing Sieves. The results are shown in Table 3 and Fig. 3. A discussion is presented at the end of the chapter. Not all the biomass obtained after grinding and sieving was used in pretreatment. Neither the particles retained on the 20 mesh, nor the ones passing the 80 mesh were used. 
Table 3

Particle size distribution of poplar wood

\begin{tabular}{|c|c|c|c|c|c|}
\hline \multicolumn{2}{|c|}{ Opening designation } & \multirow{2}{*}{$\begin{array}{c}\text { Total } \\
\text { Average } \\
\text { (\%wt) }\end{array}$} & \multirow[b]{2}{*}{$\begin{array}{l}\text { Std } \\
\text { Dev }\end{array}$} & \multirow{2}{*}{$\begin{array}{c}\text { Average for } \\
\text { Pretreatment } \\
\text { (\%wt) }\end{array}$} & \multirow[b]{2}{*}{$\begin{array}{l}\text { Std } \\
\text { Dev }\end{array}$} \\
\hline ISO & ASTM & & & & \\
\hline$<80$ & $<0.180 \mathrm{~mm}$ & 5.35 & 3.47 & & \\
\hline $50-80$ & $0.180-0.300 \mathrm{~mm}$ & 12.08 & 1.35 & 12.94 & 1.24 \\
\hline $40-50$ & $0.300-0.425 \mathrm{~mm}$ & 23.31 & 3.06 & 25.29 & 2.83 \\
\hline $30-40$ & $0.425-0.600 \mathrm{~mm}$ & 32.79 & 3.30 & 35.76 & 3.19 \\
\hline $20-30$ & $0.600-0.850 \mathrm{~mm}$ & 22.76 & 2.57 & 25.33 & 3.56 \\
\hline$>20$ & $>0.850 \mathrm{~mm}$ & 2.78 & 1.27 & & \\
\hline
\end{tabular}

a)

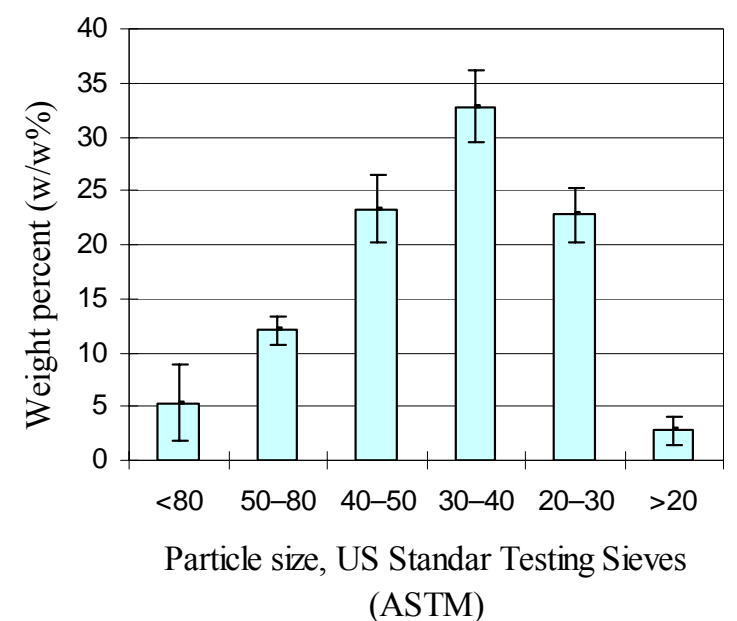

b)

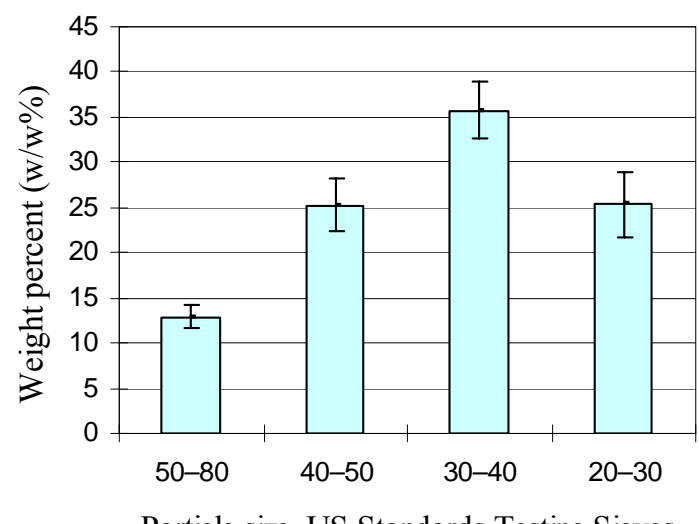

Particle size, US Standards Testing Sieves (ASTM)

Fig. 3. Average particle size distribution. a) After grinding and sieving. b) Used in pretreatment. 
The former were discharged to prevent the need of further grinding after pretreatment, and before compositional analysis where the particle size is required to be lower than 20 mesh.The later were not included because very fine particles can produce deviation in the compositional analysis due to excessive carbohydrate degradation.

\subsection{Composition of poplar wood feedstock}

The composition of poplar wood can vary greatly with the particular season and place where the crop arises, the part of the tree from which the sample is taken, and the variety of poplar, among other factors. Table 4 shows the composition of the poplar wood used in this study as measured in our laboratory, as well as the official data reported from NREL (National Renewable Energy Laboratory). It is important to compare with NREL, because they establish remarkable levels of accuracy due to their highly regarded knowledge and finely tuned experience on the analytical procedures involved in compositional analysis determination of biomass.

The methods used to determine each of the components are briefly explained below. A more detailed description of each of the experimental procedures is included in the corresponding appendixes.

\subsubsection{Extractives}

These were measured by exhaustive Soxhlet extraction of the biomass using 190-proof ethanol as solvent. Extractives include non-structural component of biomass samples that potentially could interfere with the analysis of the sample, and as such, must be removed prior to compositional analysis. NREL Standard Method "Determination of Extractives in Biomass" was used to quantify the extractives (Appendix B).

\subsubsection{Determination of structural carbohydrates and lignin}

The procedure uses a two-step acid hydrolysis to fractionate the biomass into forms that are more easily quantified. 
Table 4

Composition of poplar wood feedstock

\begin{tabular}{|c|c|c|c|c|c|c|c|c|c|c|c|}
\hline \multirow{2}{*}{$\begin{array}{c}\text { Components } \\
\text { (g/100 g biomass) }\end{array}$} & \multicolumn{8}{|c|}{ Sample } & \multirow[b]{2}{*}{ Average $^{(1)}$} & \multirow{2}{*}{$\begin{array}{l}\text { Std } \\
\text { Dev }\end{array}$} & \multirow[b]{2}{*}{ NREL $^{(2)}$} \\
\hline & 1 & 2 & 3 & 4 & 5 & 6 & 7 & 8 & & & \\
\hline Glucan & 41.67 & 42.18 & 42.42 & 43.14 & 43.29 & 43.10 & 44.45 & 41.46 & 42.71 & 0.98 & 43.80 \\
\hline Xylan & 15.94 & 15.76 & 17.61 & 15.91 & 16.78 & 15.68 & 16.12 & 15.12 & 16.12 & 0.76 & 14.85 \\
\hline Mannan & 2.79 & 2.66 & 2.89 & 3.81 & 3.90 & 3.55 & 3.75 & 3.59 & 3.37 & 0.50 & 3.94 \\
\hline $\operatorname{Lignin}^{(3)}$ & 24.68 & 28.00 & 26.57 & 29.45 & 24.40 & 27.35 & 27.07 & 27.50 & 26.88 & 1.67 & 29.12 \\
\hline Galactan & $\mathrm{NF}$ & $\mathrm{NF}$ & $\mathrm{NF}$ & $\mathrm{NF}$ & $\mathrm{NF}$ & $\mathrm{NF}$ & $\mathrm{NF}$ & $\mathrm{NF}$ & $\mathrm{NF}$ & ND & 1.27 \\
\hline Arabinan & $\mathrm{NF}$ & $\mathrm{NF}$ & $\mathrm{NF}$ & NF & $\mathrm{NF}$ & $\mathrm{NF}$ & $\mathrm{NF}$ & $\mathrm{NF}$ & $\mathrm{NF}$ & ND & 0.69 \\
\hline Extractives & 3.31 & 3.31 & 3.31 & 3.31 & 3.31 & 3.31 & 3.31 & 3.31 & 3.31 & ND & 3.56 \\
\hline Ash & 1.45 & 1.28 & 1.33 & 1.44 & 1.45 & 1.47 & 1.25 & 1.36 & 1.45 & 0.09 & 1.07 \\
\hline Acetyl & 3.39 & 3.18 & 3.34 & 3.37 & 3.14 & 3.27 & 3.26 & 3.27 & 3.35 & 0.09 & 3.62 \\
\hline TOTAL & 93.22 & 96.38 & 97.47 & 100.43 & 96.28 & 97.74 & 99.23 & 95.61 & 97.19 & & 101.92 \\
\hline
\end{tabular}

NF: (Not found) The component concentration in the sample was too small to be detected by our HPLC system.

ND: No data was taken

(1) Average of eight samples analyzed in this study.

(2) Average of five samples analyzed by NREL

(3) Klason lignin plus acid-soluble lignin 
The lignin fractionates into acid-soluble material and acid-insoluble material (Klason lignin). The acid soluble lignin is quantified by UV-visible spectroscopy and the insoluble lignin is determined by gravimetric analysis. During hydrolysis the polymeric carbohydrates are hydrolyzed into monomeric forms, which are soluble in the hydrolysis liquid. They are then measured by HPLC. The method is based on NREL Standard Procedure "Determination of Structural Carbohydrates and Lignin in Biomass" (Appendix C).

\subsubsection{Acetyl content}

The hydrolysis liquid obtained during the procedure to determine structural carbohydrates and lignin, contains acetate. This is quantified by HPLC (Appendix C).

\subsubsection{Ash}

It is the organic residue left after dry oxidation at $575^{\circ} \mathrm{C}$. The procedure used to measure ash is based on NREL Standard Procedure "Determination of Ash in Biomass" (Appendix D).

\subsection{Results and discussion}

The relatively small standard deviation shows that the particle size after grinding and sieving was consistently maintained as reported. The greatest particle size fraction is $30-40$ mesh, but there are significant fractions in the 20-30 and in the 40-50 mesh as well. The sizes not used in pretreatment (i.e., $>20$ mesh and $<80$ mesh) are very small fractions in the ground material.

The compositional analysis obtained falls into the expected values within an error of $3 \%$ for the summative mass closure. Due to the relatively high variability between different samples inherent to biomass (illustrated by presenting the data of each single experiment in addition to the standard deviation), this is an acceptable margin. Consequently, the average 
values attained in our laboratory were used when needed in all the subsequent calculations presented in this work.

Among carbohydrates, the most deviated value (as compared to NREL data) was that obtained for xylan. A plausible explanation for this result is that due to the relative close retention times of xylan and galactan in the Biorad Aminex HPX-87P column (i.e., 13.583 and 14.350 min respectively), they both may have appeared together in a single peak. This is further substantiated running the standards in which the peaks display very close together in the base (Fig. 4). Adding xylan and galactan NREL averages, one ends up with the exact same value obtained in our laboratory for xylan (i.e., $16.12 \mathrm{~g} / 100 \mathrm{~g}$ biomass).

Lignin, on the other hand, is the component that shows the highest standard deviation and the greatest difference with NREL data. The measurements of this component greatly depend on several details such as balance calibration (within $\pm 0.1 \mathrm{mg}$ ), exact times of cooling, if the vessel where the sample is stored had direct contact with skin, etc. Extreme care on each single step and permanent monitoring of the balance calibration are required to obtain an accurate value. A calibration curve to calculate soluble lignin is suggested.

The extractives measurement was carefully obtained only once for a relatively large sample $(8 \mathrm{~g})$. This extractives-free biomass was used as the source for the analysis of the eight samples reported in Table 4. This value is very close to NREL data, so no duplicated measurements were made.

\subsection{Conclusion}

The particle size of the poplar wood used in pretreatment was consistently maintained between 20 and 80 mesh (ASTM). The greatest weight percentage was 30 to 40 mesh. The composition of the feedstock was obtained within 3\% error in the summative mass closure and the obtained values were used when needed in the subsequent calculations of this work. 
a)

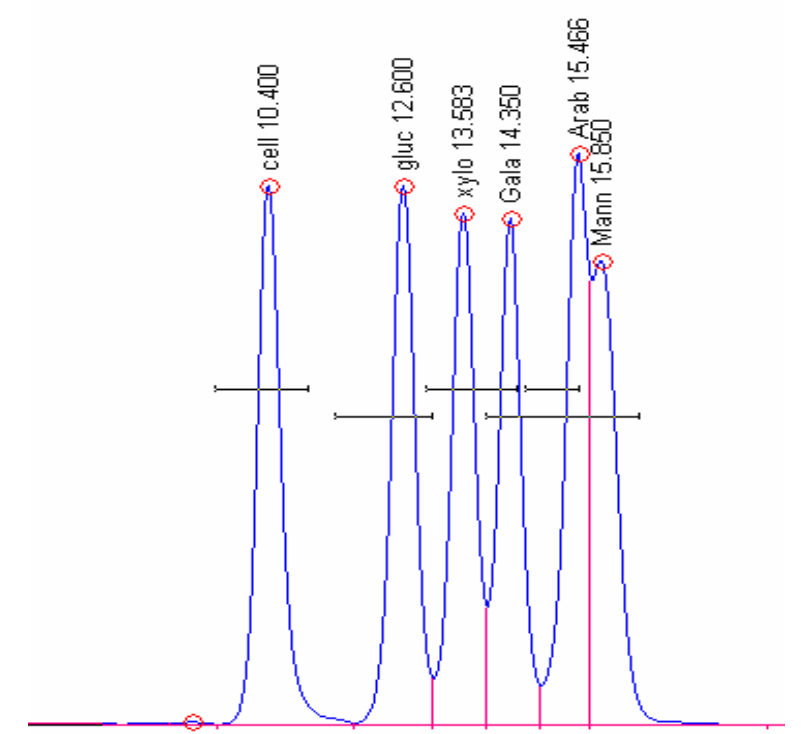

b)

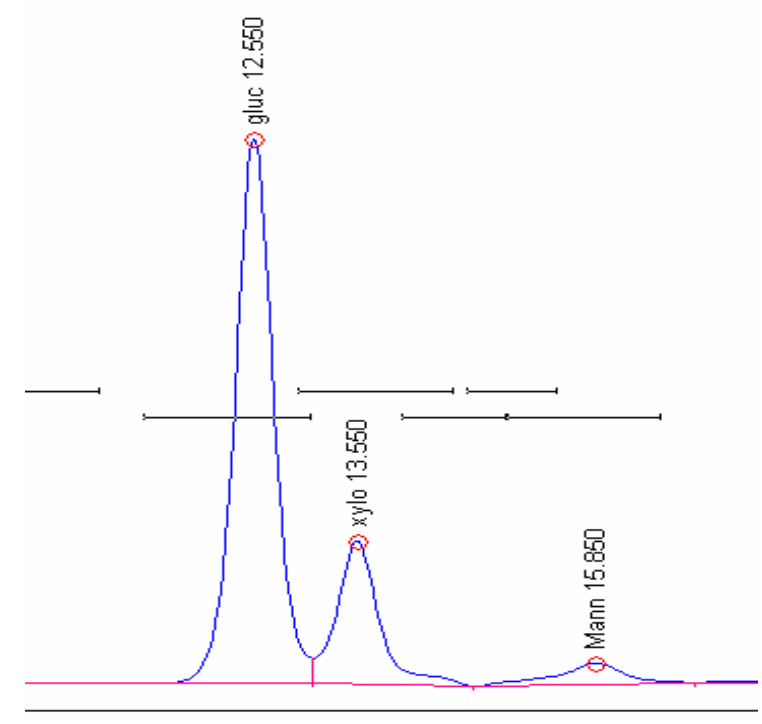

Fig 4. Chromatograms to interpreter results on xylan and arabinan concentration. a) All carbohydrate components in a single standard. b) Xylan and arabinan appear as a single peak. 


\section{CHAPTER III \\ PRETREATMENT}

\subsection{Experimental design}

It has been shown that strategic variables in lime pretreatment of biomass are temperature, time, oxidation, lime concentration, and water loading (Kim, 2004; Chang, 1999; Granda, 2004). On that basis, the experimental conditions for this study were selected as follows:

\subsubsection{Oxidizing agent}

Air and compressed oxygen are abundant worldwide. Granda (2004) compared them as oxidizing agents in long-term lime pretreatment. He reported that both air and pure oxygen have an important effect on lime pretreatment, enhancing significantly the delignification of lime pretreated bagasse at $57^{\circ} \mathrm{C}$ for 2 months, with a minor difference between the two.

However, this difference could be more important if the temperature is increased because the partial pressure of oxygen in the air (thus its concentration) inversely depends on temperature. The percentage of diminution of the oxygen concentration in the air at temperatures greater than $50^{\circ} \mathrm{C}$ with respect to the concentration of oxygen in the air at $25^{\circ} \mathrm{C}$ was calculated and is presented in Table 5. (The equations used to obtain these results are summarized in Appendix E.)

The concentration of oxygen in the air is only about $15 \%$ lower at $57^{\circ} \mathrm{C}$ than it would be if the air were $25^{\circ} \mathrm{C}$. The decrease of oxygen concentration could be considered small for temperatures up to $65^{\circ} \mathrm{C}$ (Table 5). Additionally, the economics of the process obviously favor oxidation with air. Accordingly, air was selected as the oxidizing agent in this study. Its effect was controlled as present or absent. 
Table 5

Percentage of decrease of oxygen concentration in the air at temperature $T\left({ }^{\circ} \mathrm{C}\right)$ compared to what it would be if it were $25^{\circ} \mathrm{C}^{(*)}$.

\begin{tabular}{ccccc}
\hline $\begin{array}{c}\text { Temperature } \\
\left({ }^{\circ} \mathrm{C}\right)\end{array}$ & $\begin{array}{c}\text { Saturation } \\
\text { Pressure } \\
(\mathrm{kPa})\end{array}$ & $\begin{array}{c}\text { Vapor } \\
\text { Pressure } \\
(\mathrm{kPa})\end{array}$ & $\begin{array}{c}\text { Oxygen } \\
\text { molar } \\
\text { fraction }\end{array}$ & $\begin{array}{c}\text { Decrease of } \\
\text { oxygen } \\
\text { concentration } \\
(\%)\end{array}$ \\
\hline 25 & 3.17 & 1.901 & 0.203 & 0.000 \\
\hline 50 & 12.35 & 7.409 & 0.184 & 9.352 \\
\hline 55 & 15.76 & 9.454 & 0.177 & 12.826 \\
\hline 57 & 17.85 & 10.709 & 0.173 & 14.956 \\
\hline 60 & 19.94 & 11.964 & 0.169 & 17.086 \\
\hline 65 & 25.03 & 15.018 & 0.158 & 22.272 \\
\hline 70 & 31.19 & 18.714 & 0.145 & 28.547 \\
\hline 75 & 38.58 & 23.148 & 0.130 & 36.076 \\
\hline 80 & 47.39 & 28.434 & 0.112 & 45.052 \\
\hline 85 & 57.83 & 34.698 & 0.090 & 55.688 \\
\hline 90 & 70.14 & 42.084 & 0.065 & 68.229 \\
\hline
\end{tabular}

${ }^{(*)}$ Saturated air (100\% humidity) and standard atmospheric pressure 101,325 Pa. 


\subsubsection{Temperature}

Corn stover (Kim, 2004) and bagasse (Granda, 2004) have been pretreated with lime for periods of several weeks at temperatures ranging from room temperature (RT) to $57^{\circ} \mathrm{C}$. Woody biomass is more recalcitrant to pretreatment than other types of biomass, consequently, it necessary to attack the lignin more severely, trying to avoid the degradation of carbohydrates as much as possible.

Increasing the temperature, could be the key to accomplish this purpose. Accordingly, the equipment and materials that set out the reactor system, (explained in the next section) were carefully tested at $65^{\circ} \mathrm{C}$ and this temperature was found experimentally attainable.

The diminution of the oxygen concentration in the air at $65^{\circ} \mathrm{C}$, calculated as $23 \%$ with respect to what it would be if the air were at $25^{\circ} \mathrm{C}$ (Table 5), was initially presumed negligible. The results of experimentation would support or undermine this assumption. Therefore, the temperatures studied are the following: 25 (room temperature), 35, 45, 55 and $65^{\circ} \mathrm{C}$.

\subsubsection{Time}

Corn stover and bagasse submitted to one week of lime pretreatment showed important delignification (Kim, 2004; Granda, 2004). After this time, the delignification significantly slowed. Also, the optimum sugar yields were found at about 4 weeks of oxidative pretreatment at $55^{\circ} \mathrm{C}$. Based on this information, four time periods were chosen for this study: 0 (or raw biomass), 1, 2 and 4 weeks.

\subsubsection{Lime loading and water loading}

Lime consumption was found to be less or equal to $0.1 \mathrm{~g}$ lime/g dry biomass for 4 weeks of lime pretreatment in the oxidative condition at $55^{\circ} \mathrm{C}$ (Kim, 2004). However, to determine accurately the lime consumption, and maintain high $\mathrm{pH}$, a great excess of lime was used (i.e., $0.5 \mathrm{~g}$ lime/g dry biomass). After pretreatment, the remaining lime was titrated with $5-\mathrm{N} \mathrm{HCl}$ and the actual lime consumption was calculated. 
Water loading, on the other hand, has no important effect on lime pretreatment as long as it is maintained at least at 9 to $10 \mathrm{~g}$ water/g dry biomass. Therefore, this water loading was used. The experimental conditions for pretreatment are summarized in Table 6.

\subsection{Reactor system}

The long-term lime pretreatment of poplar wood was performed in packed-bed reactors, made using PVC pipe (diameter 1 in, length 17 in, Fig. 5). To maintain the desired operation temperature (i.e., $25,35,45,55$, and $65^{\circ} \mathrm{C}$ ) the reactors were jacketed with a larger diameter (diameter 2 in, length 15 in) PVC pipe and water was pumped (centrifugal pump, $3 / 4$ hp, TEEL, USA) from a temperature controlled tank (8-gallon, Nagalene Co, USA).

The temperature control system included the following main parts: a temperature controller (PXV3 series Fuji Electric), a thermocouple (KTSS-18G-18, Omega), a heating element (1.5 kW, $120 \mathrm{~V})$, and a solid-state relay (RSSDN-25A, Idec Co.).

Forty of these reactors were attached to a metal frame using clamps. They were separated into five groups of eight reactors each, allowing the pretreatment at all temperatures, oxidative and non-oxidative run simultaneously (Fig. 6). Compressed air, previously scrubbed of carbon dioxide was preheated to the reaction temperature and saturated with air. It was continuously bubbled into four of the eight reactors corresponding to each temperature, at a flow rate of about $3.5 \mathrm{~mL} / \mathrm{min}$. Compressed nitrogen gas (Praxair Co, College Station, TX), previously preheated to the operation temperature and saturated with water, was continuously bubbled into the four remaining reactors at a flow rate of about $3.5 \mathrm{~mL} / \mathrm{min}$.

To scrub carbon dioxide, the compressed air was passed through a lime-water slurry. To preheat and saturate the air and nitrogen, they were passed through a water column immersed in the temperature-controlled tank.

The gasses entered the reactors through an inlet located at the bottom and exited at the top. The gas flow was measured using a Fisherbrand $50-\mathrm{mL}$ plastic centrifuge tube, half full of water, at the top end. The flow rate was controlled by clamps in the inlet and was measured as number of bubbles in the centrifuge tube per second. 
Table 6

Experimental conditions for pretreatment

\begin{tabular}{cc}
\hline Varible & Conditions tested \\
\hline Oxidation & Air present - Air absent \\
Temperature & $25,35,45,55$ and $65^{\circ} \mathrm{C}$ \\
Pretreatment time & 0 (raw biomass), 1,2 and 4 weeks \\
Lime loading & $0.5 \mathrm{~g} \mathrm{Ca}(\mathrm{OH})_{2} / \mathrm{g}$ dry biomass (excess) \\
Water loading & $10 \mathrm{~g} \mathrm{water} / \mathrm{g}$ dry biomass \\
\hline
\end{tabular}




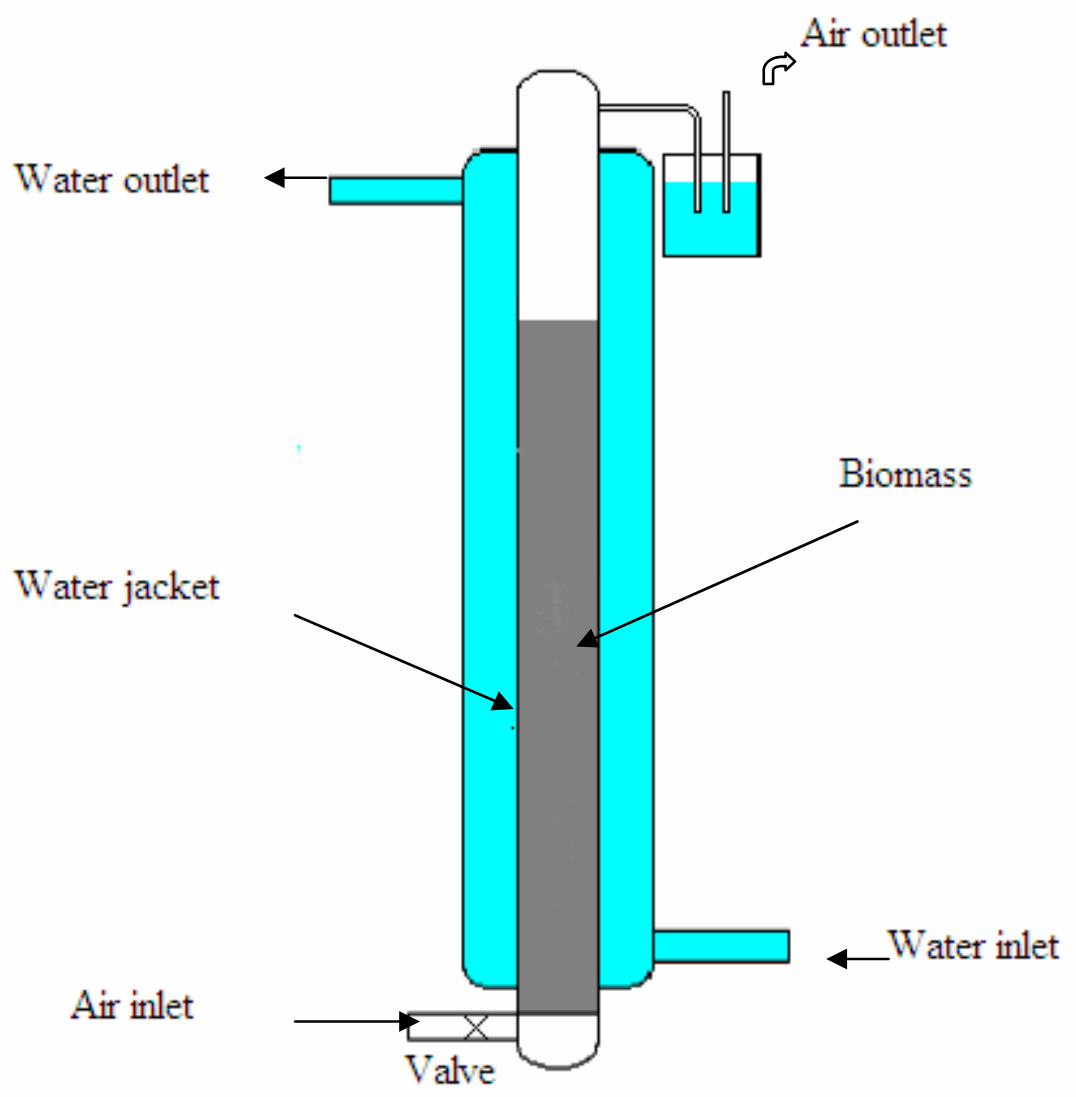

Fig. 5. Schematic diagram of the lime pretreatment reactor. 


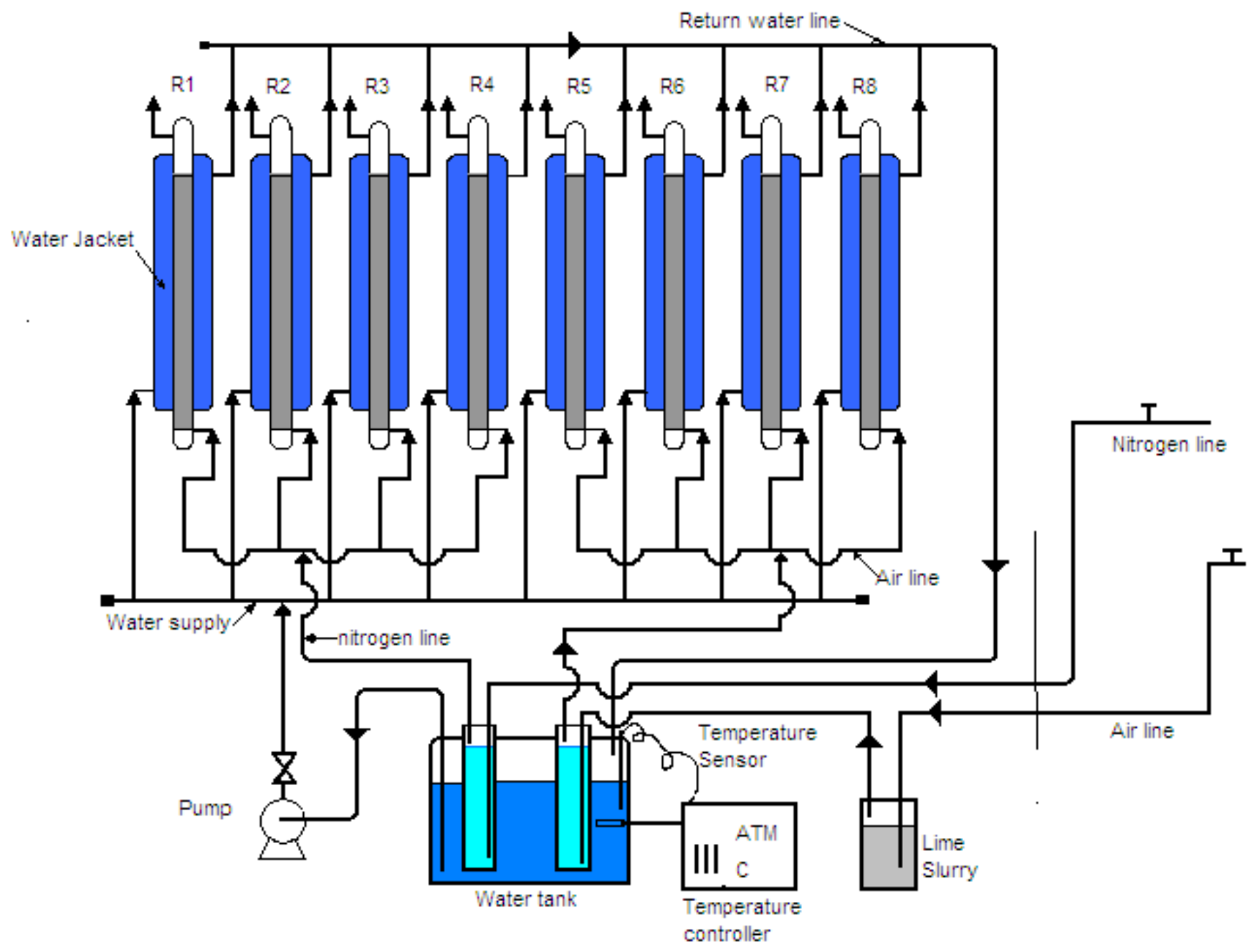

Fig. 6. Schematic diagram of a set of eight reactors in the reactor system for lime pretreatment 
The diameter of the bubbles was $3.5 \mathrm{~mm}$, thus two to three bubbles per second would be about 2.7 to $4.0 \mathrm{~mL} / \mathrm{min}$.

Because there were eight reactors for each temperature, it was possible to run two different pretreatment times simultaneously at all temperatures using both oxidative and non-oxidative conditions, in two separate reactors (duplicates). Pictures and details of the whole reactor system are shown in Fig. 7.

\subsection{Pretreatment method}

When the reactor system was operating properly (see Appendix F for starting up procedure), and the reactor temperature was steady at the desired value, a mixture of $15 \mathrm{~g}$ of biomass (dry weight), with $7.5 \mathrm{~g}$ of lime (calcium hydroxide, certified) and $150 \mathrm{~g}$ of distilled water was charged into each reactor and the gasses flow rate was adjusted to about 2.7 to $4.0 \mathrm{~mL} / \mathrm{min}$. (i.e., two to three bubbles per second). Regular and consistent monitoring of the reactor system was performed during the pretreatment time.

Once the pretreatment time was completed, the mixture in the reactors was transferred to a 1-L centrifuge bottle (Fisherbrand, polyethylene). Distilled water (about $500 \mathrm{~mL}$ ) was used to carefully rinse and move all the solids from the reactor to the centrifuge bottle. Future sections will describe how the contents of the centrifuge bottle were treated. 
a)

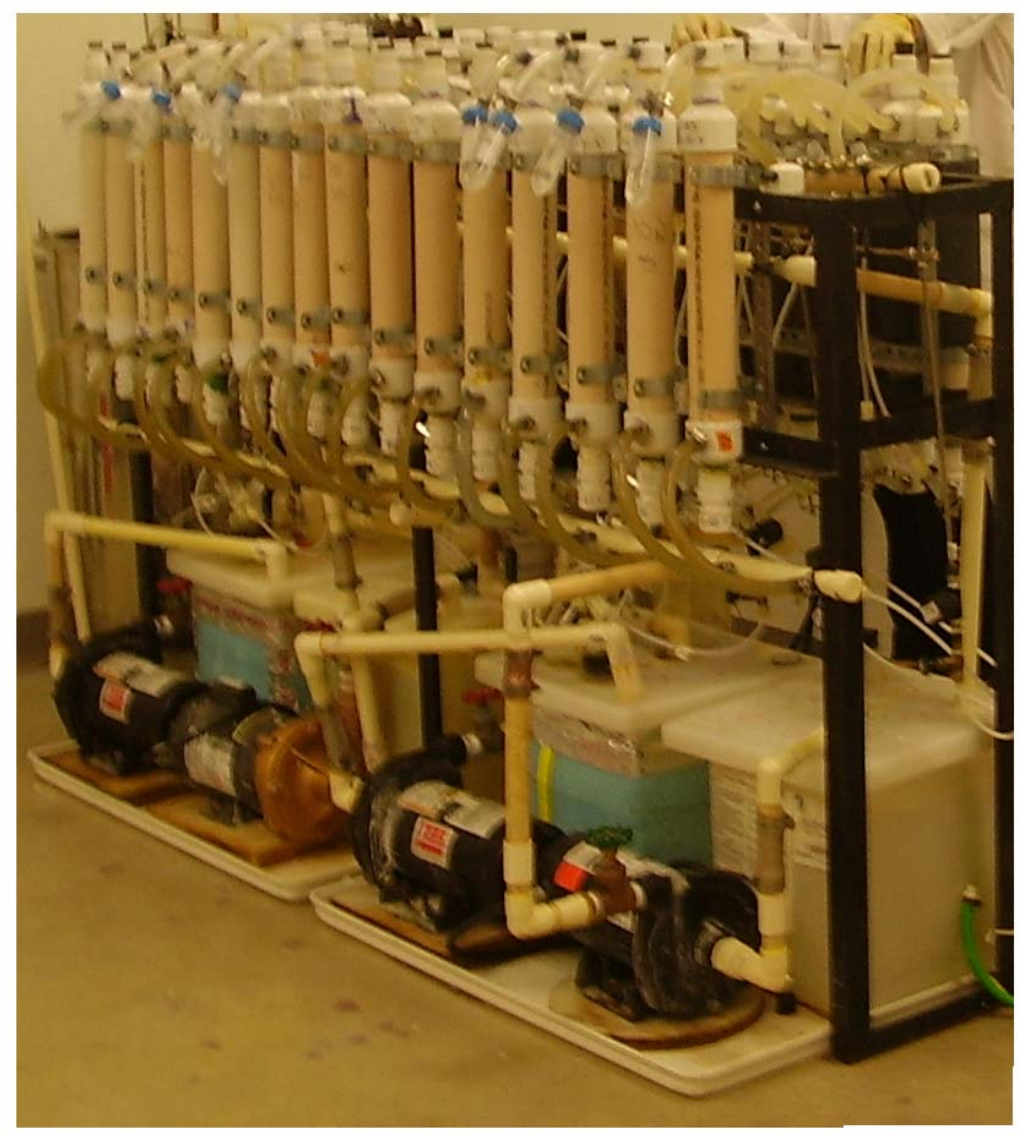

b)

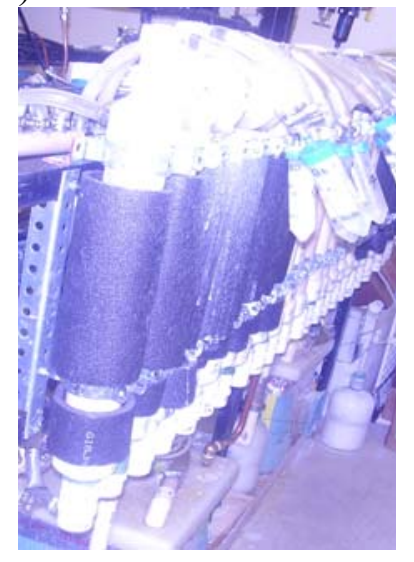

c)
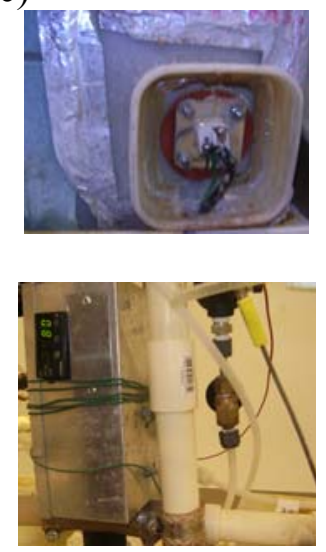

d)

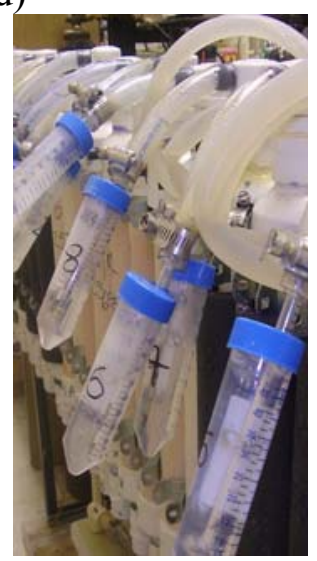

e)

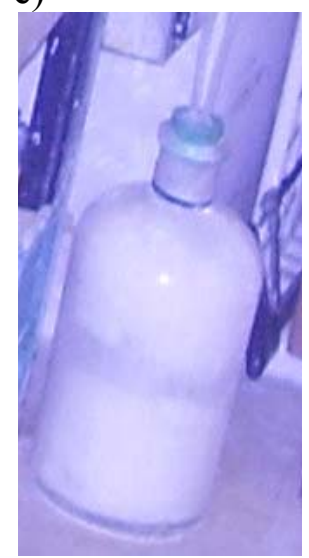

Fig. 7. Reactor system. a) Complete system. b) Reactors at 55 and $65^{\circ} \mathrm{C}$ were coated with insulating material. c) Temperature controller. d) Flow rate of gasses measured as bubbles per second. e) Bottle with lime slurry to scrub $\mathrm{CO}_{2}$ in the air. 


\section{CHAPTER IV \\ PRETREATMENT, HYDROLYSIS, AND OVERALL YIELDS}

Pretreatment yields, hydrolysis yields, and overall yields will be discussed in the following chapters. An illustration of the general definitions of these yields is presented in Fig. 8. In general, pretreatment yields specify how much of the component (i.e., lignin, glucan or xylan) in the raw biomass was found in the pretreated biomass, thus they assess pretreatment. Hydrolysis yields specify how much glucan or xylan present in the pretreated biomass was found after saccharification (i.e., enzymatic hydrolysis), thus they assess saccharification. Overall yields indicate how much glucan or xylan present in the untreated biomass were found after pretreatment and enzymatic hydrolysis, thus they assess the combined effect of the two operations.

More specifically, lignin, glucan, and xylan fractionate during pretreatment generating two parts each as illustrated in Fig. 9. In the case of lignin these parts are $\mathrm{Al}$ and $\mathrm{Cl}$. In the case of glucan one part is $\mathrm{Ag}+\mathrm{Bg}$ and the other part is $\mathrm{Cg}$. In the case of xylan one part is $A x+B x$ and the other part is $C x$. Other components of biomass are also fractionated into two parts (Ao and Co).

Changes that may occur (if any) in lignin or other components of biomass during enzymatic hydrolysis are not assessed, but it is important to account for the two parts in which glucan and xylan fractionate during this operation. These are $\mathrm{Ag}$ and $\mathrm{Bg}$ for glucan and $A x$ and $B x$ for xylan. Thus, using the nomenclature established in Fig. 9, and the general definitions specified above, several yields can be defined as follows:

Pretreatment yield (also named recovery yield of total mass or yield of total solids):

$$
Y_{p} \equiv \frac{\text { g pretrated biomass }}{100 \mathrm{~g} \text { raw biomass }}=\frac{A g+A x+A l+A o+B g+B x}{D}
$$

Pretreatment yield of lignin:

$$
Y_{L} \equiv \frac{\mathrm{g} \text { lignin remaining after pretreatment }}{100 \mathrm{~g} \text { lingin in raw biomass }}=\frac{\mathrm{Al}}{\mathrm{Al}+\mathrm{Cl}}
$$




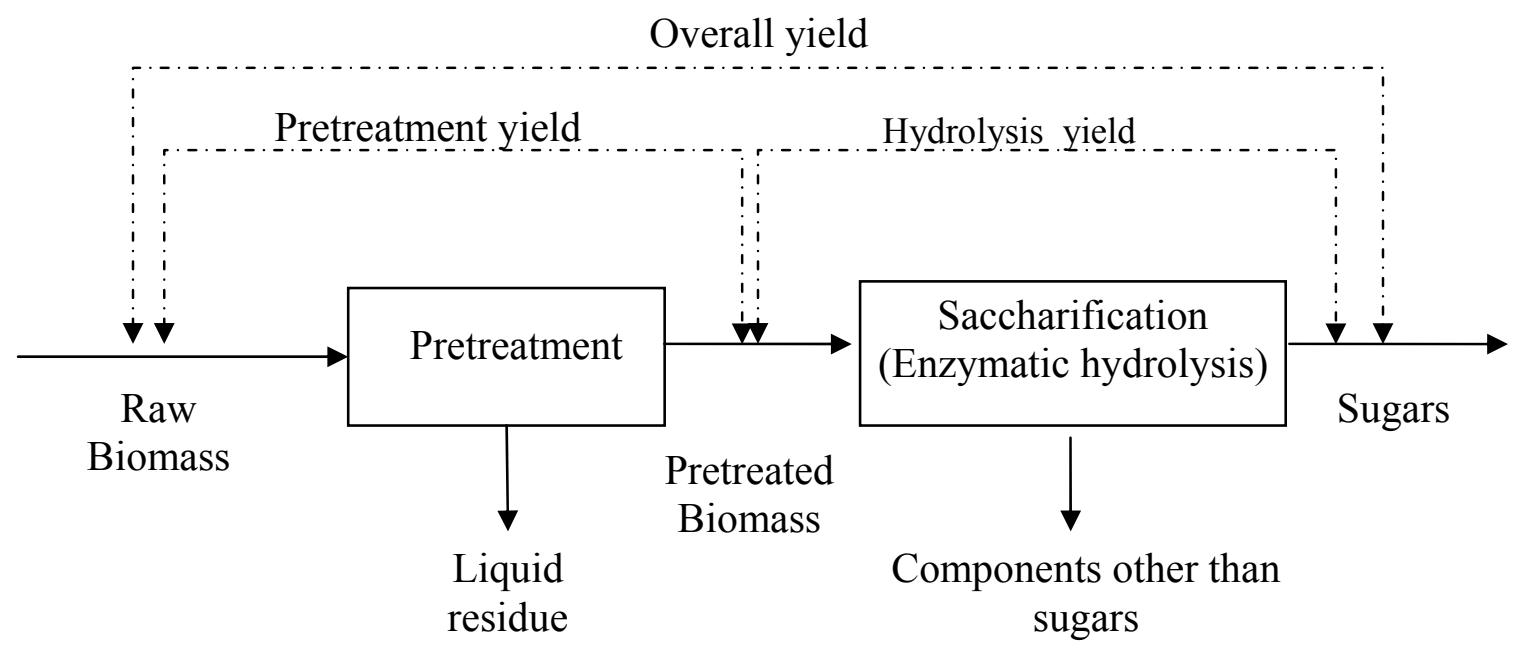

Fig. 8. Schematic definitions of pretreatment yield, hydrolysis yield and overall yield 


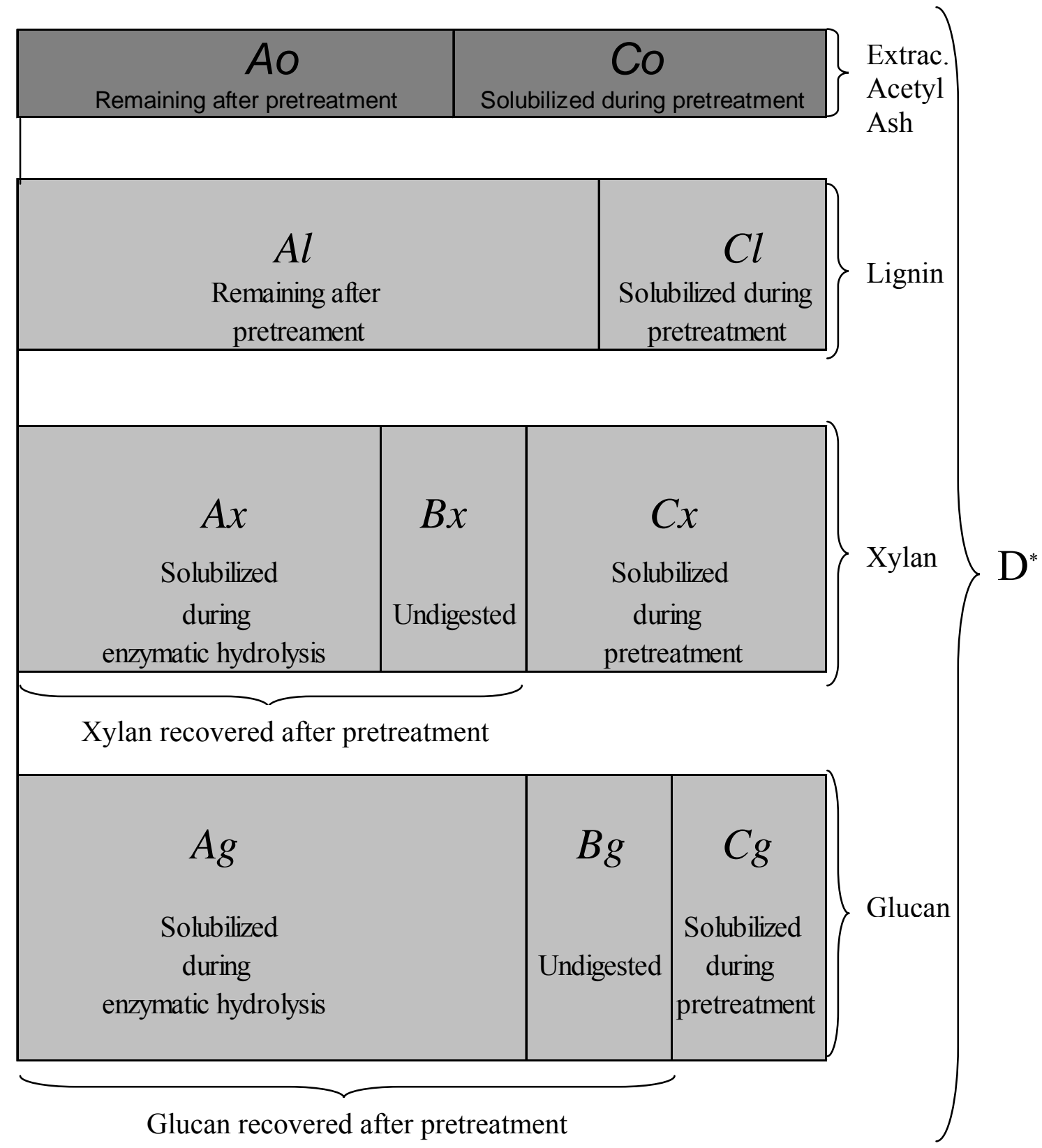

*D: Total dry weight of biomass

Fig. 9. Nomenclature and definition of fractions used to calculate pretreatment yield, hydrolysis yield, and overall yield. 
Accordingly, the fraction of lignin removed during pretreatment is:

$$
1-Y_{L}=\frac{C l}{A l+C l}
$$

Pretreatment yield of glucan (cellulose):

$$
Y_{G} \equiv \frac{\text { g glucan recovered after pretreatment }}{100 \text { g glucan in raw biomass }}=\frac{A g+B g}{A g+B g+C g}
$$

Pretreatment yield of xylan (hemicellulose):

$$
Y_{X} \equiv \frac{\text { g xylan recovered after pretreatment }}{100 \mathrm{~g} \text { xylan in raw biomass }}=\frac{A x+B x}{A x+B x+C x}
$$

Hydrolysis yield of glucan (cellulose):

$$
Y_{g} \equiv \frac{\text { g glucan hydrolyzed }}{100 \text { g glucan in treated biomass }}=\frac{A g}{A g+B g}
$$

Hydrolysis yield of xylan (hemicellulose):

$$
Y_{x} \equiv \frac{\text { g xylan hydrolyzed }}{100 \text { g xylan in treated biomass }}=\frac{A x}{A x+B x}
$$

Overall yield of glucan (cellulose):

$$
Y_{g}^{T} \equiv \frac{\text { g glucan obtained after pretreatment and saccharification }}{100 \text { g glucan in raw biomass }}=\frac{A g}{A g+B g+C g}
$$

Overall yield of xylan (hemicellulose):

$$
Y_{x}^{T} \equiv \frac{\mathrm{g} \text { xylan obtained after pretreatment and saccharification }}{100 \mathrm{~g} \text { xylan in raw biomass }}=\frac{A x}{A x+B x+C x}
$$

Two important notes follow:

1. Pretreatment yields, hydrolysis yields, and overall yields are related as follows: 


$$
\begin{aligned}
& Y_{g}^{T}=Y_{G} \times Y_{g} \\
& Y_{x}^{T}=Y_{X} \times Y_{x}
\end{aligned}
$$

2. The hydrolysis reactions are

$$
\begin{aligned}
& {\left[\mathrm{C}_{6} \mathrm{H}_{10} \mathrm{O}_{5}\right]_{n}+n \cdot \mathrm{H}_{2} \mathrm{O} \rightarrow n \cdot \mathrm{C}_{6} \mathrm{H}_{12} \mathrm{O}_{6}} \\
& \text { Cellulose (glucan) Glucose } \\
& \mathrm{Mw}=162.2 \quad \mathrm{Mw}=180.2 \\
& {\left[\mathrm{C}_{5} \mathrm{H}_{8} \mathrm{O}_{4}\right]_{n}+n \cdot \mathrm{H}_{2} \mathrm{O} \rightarrow n \cdot \mathrm{C}_{5} \mathrm{H}_{10} \mathrm{O}_{5}} \\
& \text { Xylan Xylose } \\
& \mathrm{Mw}=132.1 \quad \mathrm{Mw}=150.1
\end{aligned}
$$

Thus, monomeric sugars (i.e., xylose and glucose) can be expressed as polymeric sugars (i.e., glucan and xylan) using a conversion factor obtained from the hydrolysis reactions:

$$
\begin{gathered}
\text { glucan }=\text { glucose } \times \frac{162.2}{180.2} \\
\text { xylan }=\text { xylose } \times \frac{132.1}{150.1}
\end{gathered}
$$

These conversion factors are used to express $A g$ and $A x$ as polymeric carbohydrates and maintain consistency in the definitions of yields, even though they are actually soluble (monomeric) sugars. 


\section{CHAPTER V \\ LIME CONSUMPTION}

\subsection{Lime mode of action}

The structure of lignin is modified by the presence of an alkali making it more soluble. This modification occurs as follows: first, the lignin is degraded into smaller units by cleaving interunit linkages, and then, hydrophilic groups (e.g., $\left.\mathrm{OH}^{-}\right)$are introduced into the polymer and cleaved fragments.

Alkaline delignification is accompanied to varying extents by degradation of the carbohydrate constituents (i.e., cellulose and hemicellulose). One type of reaction that is responsible for this degradation (peeling reaction) may lead to considerable losses in sugars yield. The peeling reaction continues in carbohydrates until the introduction of a carboxyl group at the reducing end. This stopping reaction stabilizes the carbohydrate against further peeling.

The function of oxygen in delignification operations is to target lignin removal (Fig. 10). Unfortunately, oxygen delignification reactions are not sufficiently selective to preserve the carbohydrate fraction of the biomass.

The cations $\mathrm{Ca}^{+}$are deposited in the cellulose matrix in the form of calcium carbonate. This statement was confirmed by López (2000) using scanning electron microscopy, X-ray microanalysis, Fourier-transform infrared spectroscopy, and thermogravimetric analysis. The $\mathrm{CO}_{2}$ for this reaction may come from complete oxidation of cellulose and hemicellulose.

\subsection{Materials and methods}

Lime consumption was determined by neutralization with $5-\mathrm{N}$ certified $\mathrm{HCl}$ (Appendix G). This procedure is usually very slow, therefore it was necessary to verify that there were no further changes in $\mathrm{pH}$ for a minimum period of $1 \mathrm{~h}$. The salts obtained due to neutralization of the pretreated biomass slurry did not affect subsequent analysis because 


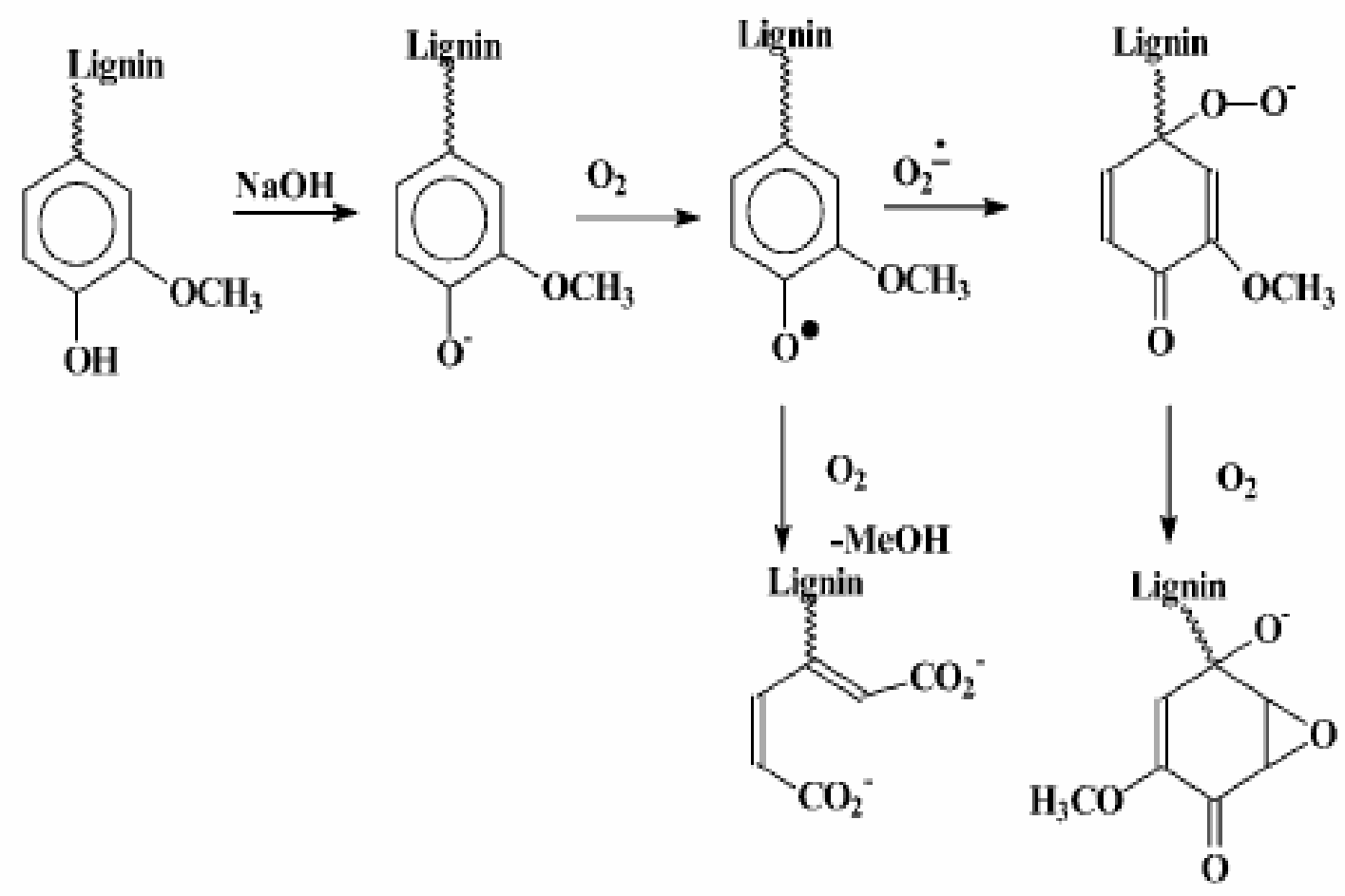

Fig. 10. The salient chemical structural units associated with lignin in woody tissue. (C) 2001 IUPAC, Pure and Applied Chemistry 73, 2059-2065) 
after neutralization the biomass was washed (Appendix G). During the washing procedure, all liquid-phase components were removed. Accordingly, any neutralizing agent whose calcium salts are completely soluble in water (e.g., $\mathrm{CaCl}_{2}$ ) would have been suitable for this procedure. Because the lime was loaded in great excess, and the $\mathrm{pH}$ after pretreatment is very high $(\geq 12)$, a moderately concentrated strong acid (i.e., 5 -N HCl) was preferred. It is important to monitor the $\mathrm{pH}$ during the washing procedure that follows neutralization, because it is possible to observe changes in the $\mathrm{pH}$ and further neutralization may be required.

\subsection{Results and discussion}

The results presented here show lime consumption after neutralization and washing without checking for $\mathrm{pH}$ changes during the washing procedure. It was later found, that the $\mathrm{pH}$ of the washed biomass may have increased again when washing and more neutralization and washing may have been required. Consequently, it appears that in these results, the lime consumption was overestimated.

Lime consumption shows a strong dependence on the pretreatment time, temperature, and oxidative condition. In general, more lime was consumed at higher temperatures, in the oxidative condition, and for longer periods of pretreatment (Figs. 11 and 12). The highest lime consumption was about $0.2 \mathrm{~g}$ lime/g dry biomass and was obtained for poplar wood pretreated with air at $65^{\circ} \mathrm{C}$ and $55^{\circ} \mathrm{C}$ for 4 weeks. The rate of lime consumption decreased with time. The fastest lime consumption was recorded during the first week of pretreatment; after that, the lime consumption slowed.

The highest lime consumption in the non-oxidative pretreatment was obtained for 4 weeks of lime pretreatment at $65^{\circ} \mathrm{C}$, and was about $0.1 \mathrm{~g}$ lime $/ \mathrm{g}$ dry biomass. This value is half what is obtained for the analogous pretreatment at the oxidative condition, which shows the important effect of oxygen in pretreatment.

Because lime acts as a reactant in the delignification reactions, lime consumption should be a rough indication of how much deliginification was achieved (Fig. 13). (The variable used to measure delignification is the fraction of lignin removed defined on page $35)$. 

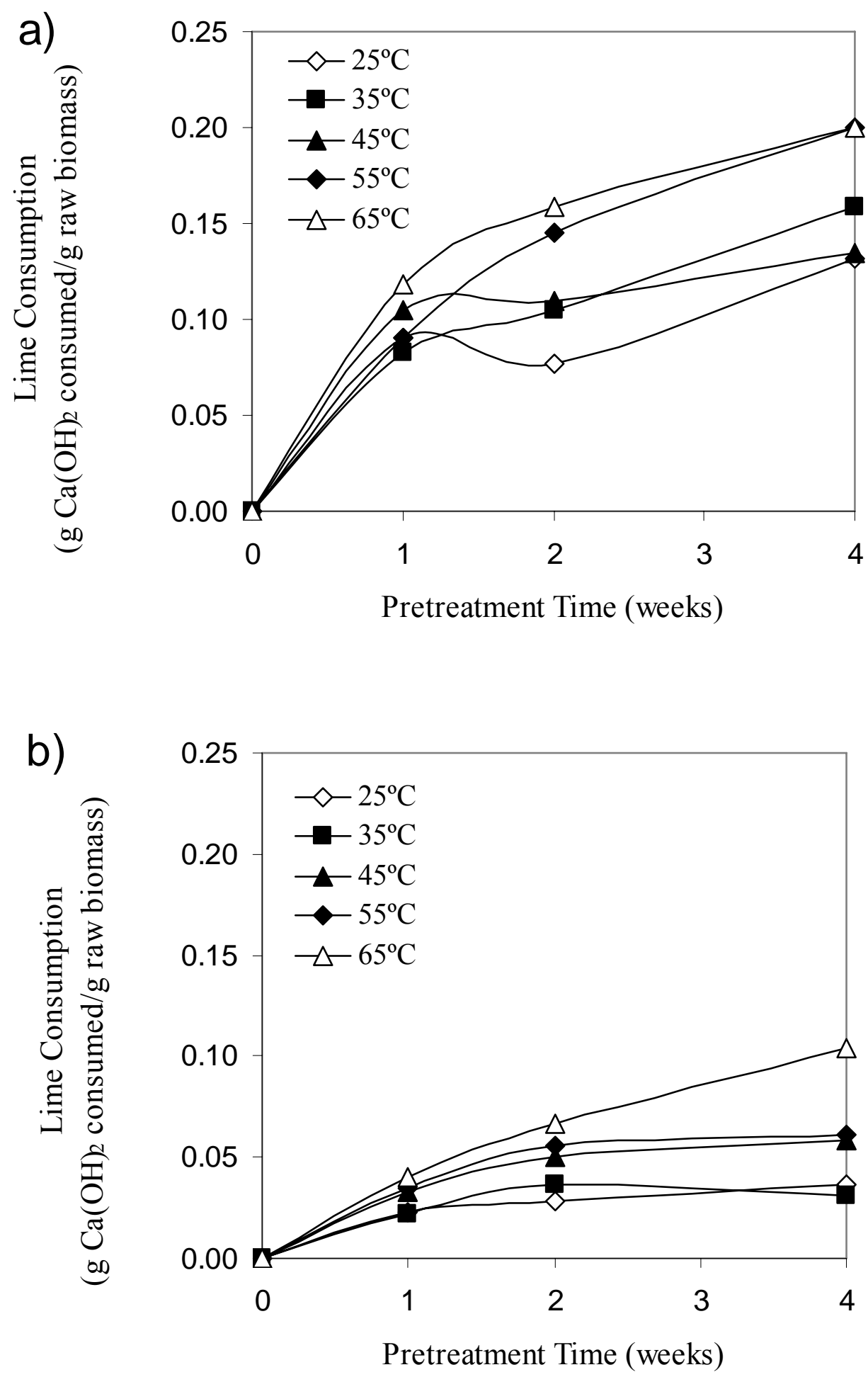

Fig. 11. Lime consumption as a function of pretreatment time and temperature. a) Oxidative. b) Non-oxidative. 

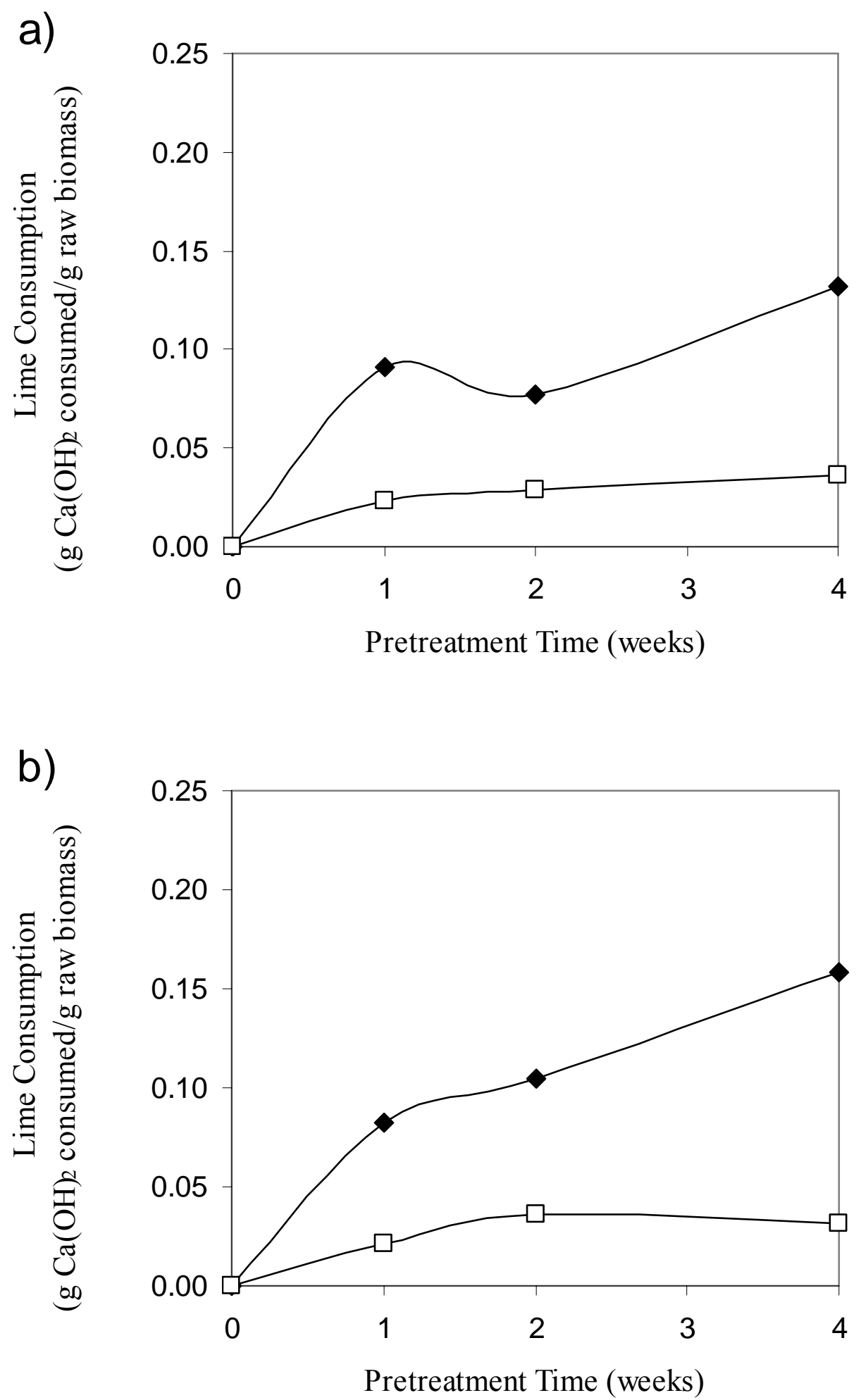

Fig. 12. Lime consumption along pretreatment time at a) 25, b) 35, c) 45, d)55, and e) $65^{\circ} \mathrm{C}$ in the oxidative and non-oxidative conditions. 

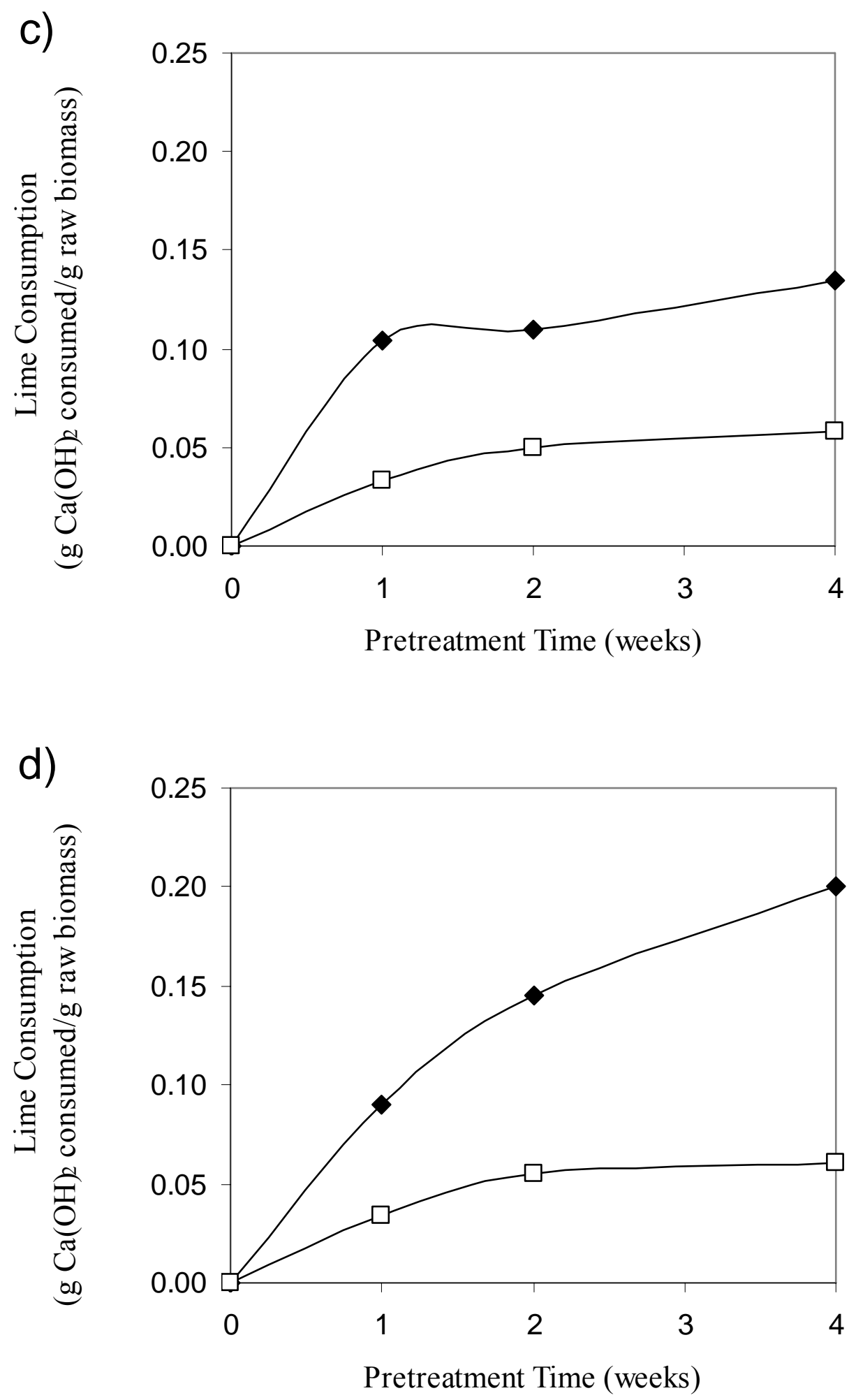

Fig. 12. Continued. 


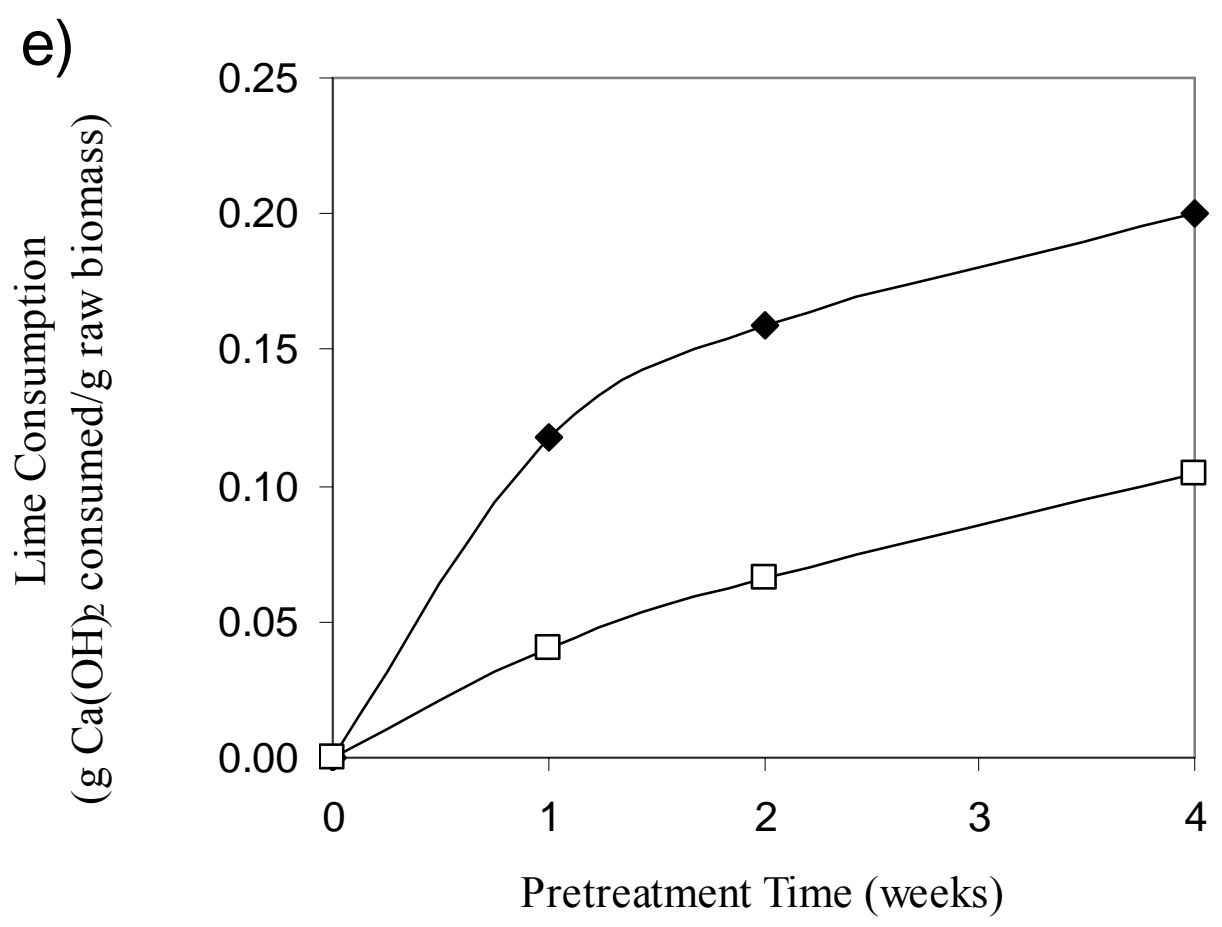

Fig. 12. Continued

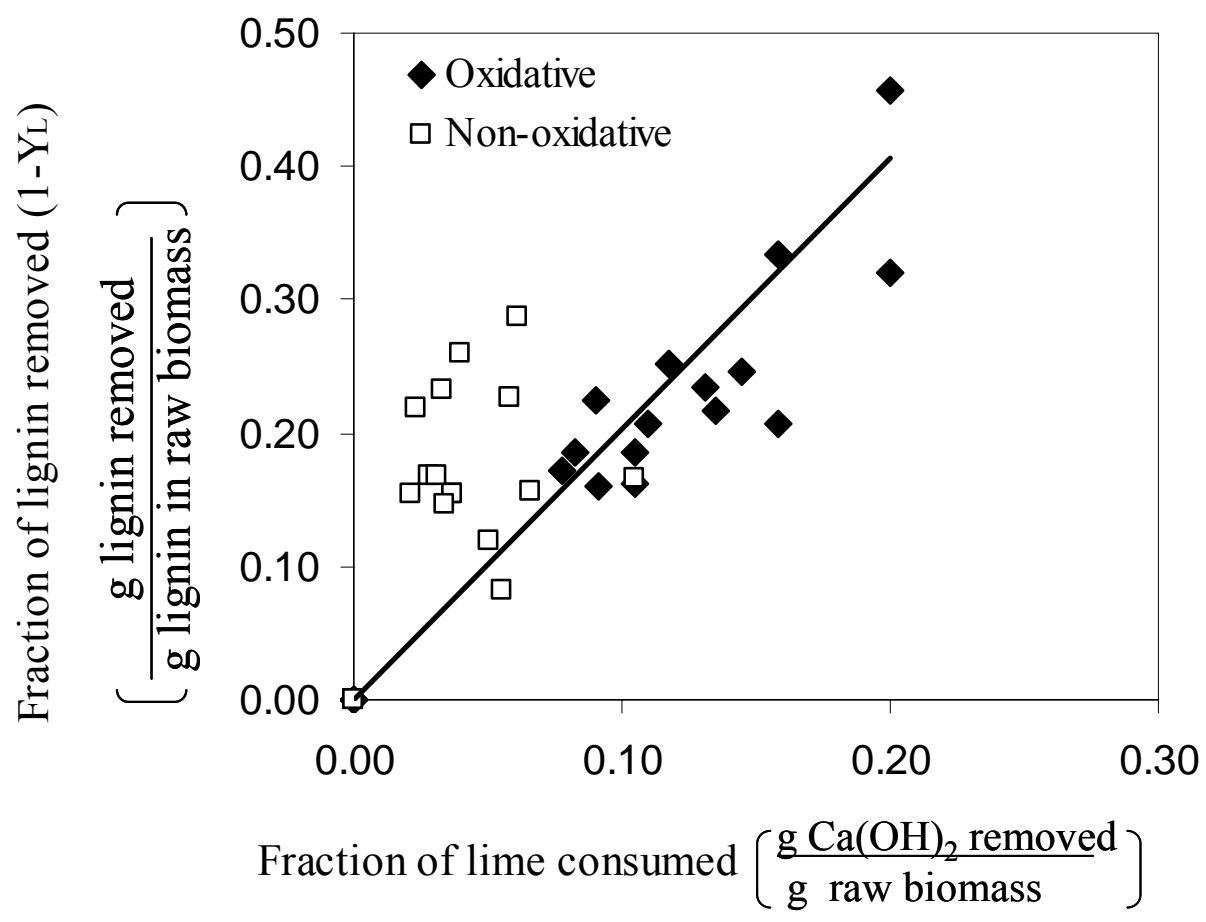

Fig. 13. Delignification as a function of lime consumption in the oxidative and non-oxidative conditions. 
However, the relationship between these 2 variables was not very strong and in the nonoxidative condition, the fraction of lime consumed varied very poorly with fraction of lignin removed. For the oxidative condition, the relationship is better but the R-squared is low $\left(\mathrm{R}^{2}=0.51\right)$.

\subsection{Conclusions}

Lime consumption presented a strong, directly proportional dependency on pretreatment time and temperature. However, the rate of lime consumption (i.e., the slope of the lime consumption vs pretreatment time) decreased with time for all temperatures and for oxidative and non-oxidative conditions. Lime consumption is higher in the oxidative conditions for all temperatures. The relationship between lime consumption and extent of delignification was not clearly observed. 


\section{CHAPTER VI \\ CHANGES IN COMPOSITION OF POPLAR WOOD CAUSED BY LIME \\ PRETREATMENT}

\subsection{Introduction}

A complex mixture of products are produced during the oxidative lime pretreatment of biomass (Montgomery 1953; Klinke et al., 2002). Degradation reactions of cellulose and hemicellulose may be limited by the formation of D-glucometasaccharinate and Dxylometasaccharinate, respectively, which terminate or 'cap' the reactions. However, there is evidence of degradation to carbon dioxide (Klinke et al., 2002). In fact, calcium carbonate salts have been found in deposits that modify the surface of bagasse submitted to oxidative lime treatment (López et al., 2000).

Experiments show that although the degradation reactions are known to occur, sugars are acceptably preserved during oxidative lime treatment. Therefore, it has been hypothesized that carbonate salts protect cellulose by forming insoluble carbonate deposits in the places where there has already been degradation, thus forming a protective layer that prevents further attack of carbohydrates (Robert et al., 1968).

All these reactions and events promote compositional changes in the biomass submitted to oxidative lime pretreatment in an extent that is subjected to the type of biomass under pretreatment. Indeed, there are data on the difficulty of penetrating oxygen into wood chips as compared to other lignocellulosic sources, such as bagasse (Nagieb et al., 2000; Trivedi and Murthy, 1982).

Consequently, a conscious and complete analysis of the compositional changes during long-term lime pretreatment is needed to clarify the effectiveness of this type of pretreatment in more recalcitrant biomass, such as poplar wood. This is task is assessed in this section. 


\subsection{Materials and methods}

After pretreatment (see pages 23 to 31 ), the contents of the reactors were transferred to a 1-L centrifuge bottle (Fisherbrand, polyethylene). The biomass slurry in the centrifuge bottle was neutralized (Appendix G), washed and filtered (Appendix H), and slowly air dried for a period of 4 days. The moisture content obtained this way was $12 \%$ or less. Poplar wood was then submitted to the following analysis:

1. Determination of recovery yield of total mass (definition on page 32, experimental procedure on Appendix $\mathrm{H}$ ).

2. Determination of extractives performed by exhaustive Soxhlet extraction (Appendix B).

3. Determination of structural carbohydrates, lignin, and acetyl content realized after a two-step acid hydrolysis of biomass followed by UV/vis spectroscopy, gravimetric analysis, and HPLC analysis (Appendix C).

4. Determination of ash (Appendix D).

A brief explanation of most of these procedures can be found on $24 \mathrm{~s} 24$ to 26 . A detailed explanation is found in the corresponding appendixes.

\subsection{Recovery yield of total mass}

The equation to calculate the recovery yield of total mass, also known as pretreatment yield $\left(\mathrm{Y}_{\mathrm{p}}\right)$ or yield of total solids, was established on page 32. It indicates how much biomass was solubilized due to pretreatment. Some of the results are surprisingly low or high, which is due to the great variability inherent in biomass (Table 7), however, the general tendency is for high temperatures, long pretreatment times, and the presence of an oxidative agent to favor solubilization. Overall, the rate of solubilization decreased along time at all temperatures and particularly in the oxidative condition. 
Table 7

Variation of the recovery yield of total mass with pretreatment time for all temperatures, oxidative and non-oxidative condition

\begin{tabular}{|c|c|c|c|c|}
\hline \multicolumn{2}{|c|}{$\begin{array}{c}\text { Pretreatment } \\
\text { Condition }\end{array}$} & \multicolumn{3}{|c|}{$\begin{array}{c}\text { Pretreatment time } \\
\text { (weeks) }\end{array}$} \\
\hline $\begin{array}{c}\text { Temperature } \\
\left({ }^{\circ} \mathbf{C}\right)\end{array}$ & Oxidative & 1 & 2 & 4 \\
\hline $\mathbf{2 5}$ & Yes & 87.29 & 83.16 & 74.69 \\
\hline $\mathbf{3 5}$ & Yes & 84.71 & 84.58 & 76.84 \\
\hline $\mathbf{4 5}$ & Yes & 76.40 & 84.92 & 80.63 \\
\hline $\mathbf{5 5}$ & Yes & 84.13 & 82.66 & 71.92 \\
\hline $\mathbf{6 5}$ & Yes & 80.72 & 66.61 & 70.56 \\
\hline $\mathbf{2 5}$ & No & 81.59 & 86.44 & 86.59 \\
\hline $\mathbf{3 5}$ & No & 85.22 & 87.71 & 84.85 \\
\hline $\mathbf{4 5}$ & No & 81.50 & 87.72 & 79.70 \\
\hline $\mathbf{5 5}$ & No & 81.33 & 86.79 & 75.13 \\
\hline & No & 79.19 & 82.79 & 83.34 \\
\hline
\end{tabular}




\subsection{Mass balances}

The composition of the biomass after pretreatment was determined, as explained previously, and summative mass closures were performed for each pretreatment condition. The results are summarized in Figs. 14 to 18. The presentation of the results in this format has the advantage that all results are easily read at a glance and also that the rate of component removal can be drawn as the slope of the lines.

All components (but ash) solubilized during pretreatment. The extent of solubilization depended strongly on the component and the pretreatment conditions. Almost all acetate was removed within the first week regardless of the pretreatment condition (the acetyl content after 1 or more weeks or pretreatment was $<0.1 \mathrm{~g}$ acetyl $100 \mathrm{~g}$ raw biomass). Other components such as lignin, extractives, glucan, xylan, and mannose were removed slower showing the fastest rate of solubilization during the first week (first and second week for $65^{\circ} \mathrm{C}$ oxidative pretreatment) and solubilizing at slower rates after that.

Analogous pictures are found in previous studies of long-term lime pretreatment (Kim, 2004; Granda, 2004) of other types of biomass (i.e., corn stover and bagasse), but apparently, the rate of component removal, particularly lignin during the first week was greater. A more in-depth discussion of the results obtained in previous studies compared to what was obtained in this study, is found through the remainder of this chapter.

Delignification models for woody biomass are widely available, however, a comparison very meaningful in the context of this study follows: when comparing the delignification models of woody biomass (western hemlock wood) treated with sodium hydroxide under non-oxidative conditions (Dolk et al., 1989), with those obtained for corn stover (Kim, 2004), the activation energy and the Arrhenius constant were higher by a factor of about 4 and 3 respectively. This suggests that alkaline delignification of corn stover is easier to achieve than that of poplar wood. A delignification model for poplar wood pretreated with biomass would further substantiate or discharge this conclusion. 

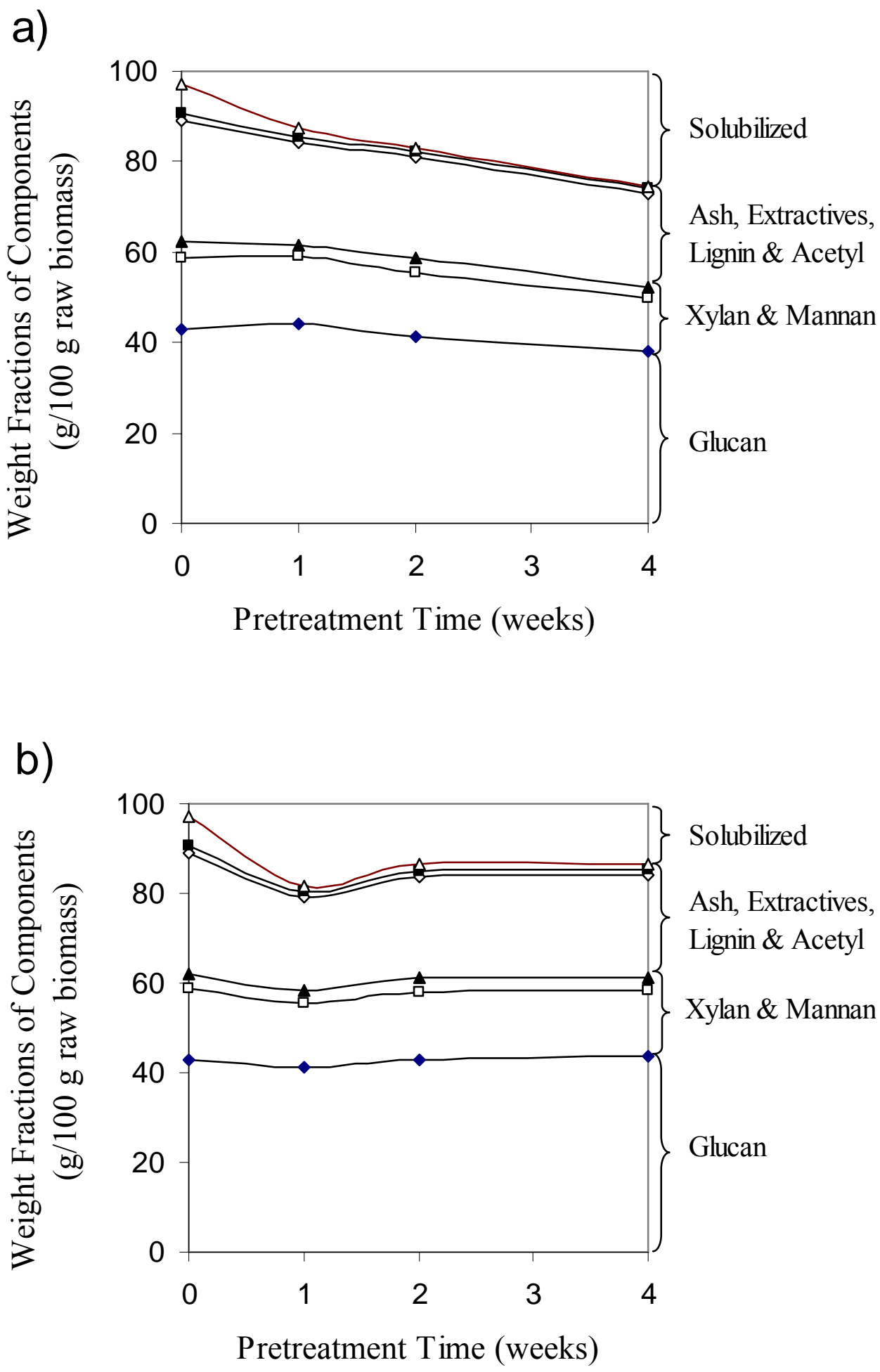

Fig. 14. Summative mass closure for poplar wood pretreated at $25^{\circ} \mathrm{C}$, a) oxidative, b) non-oxidative. 
a)

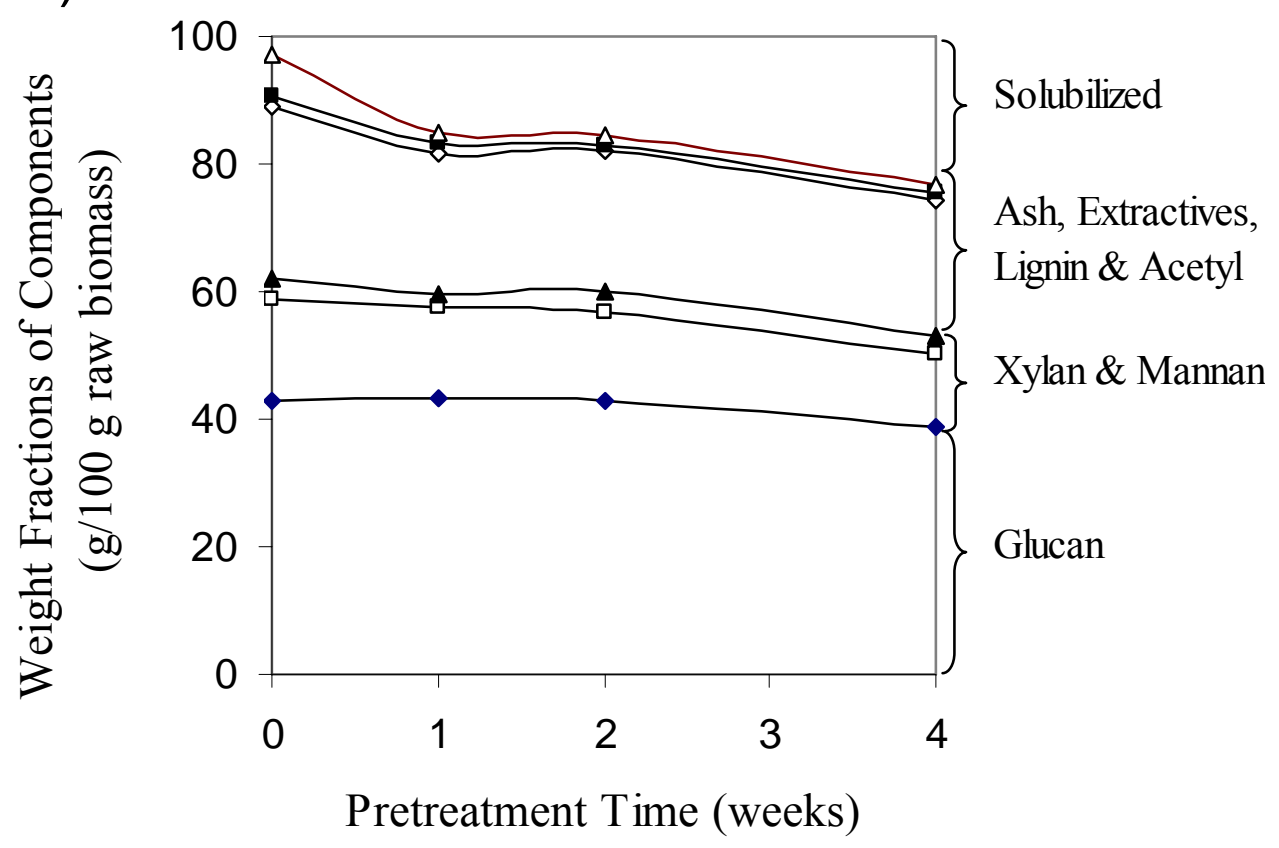

b)

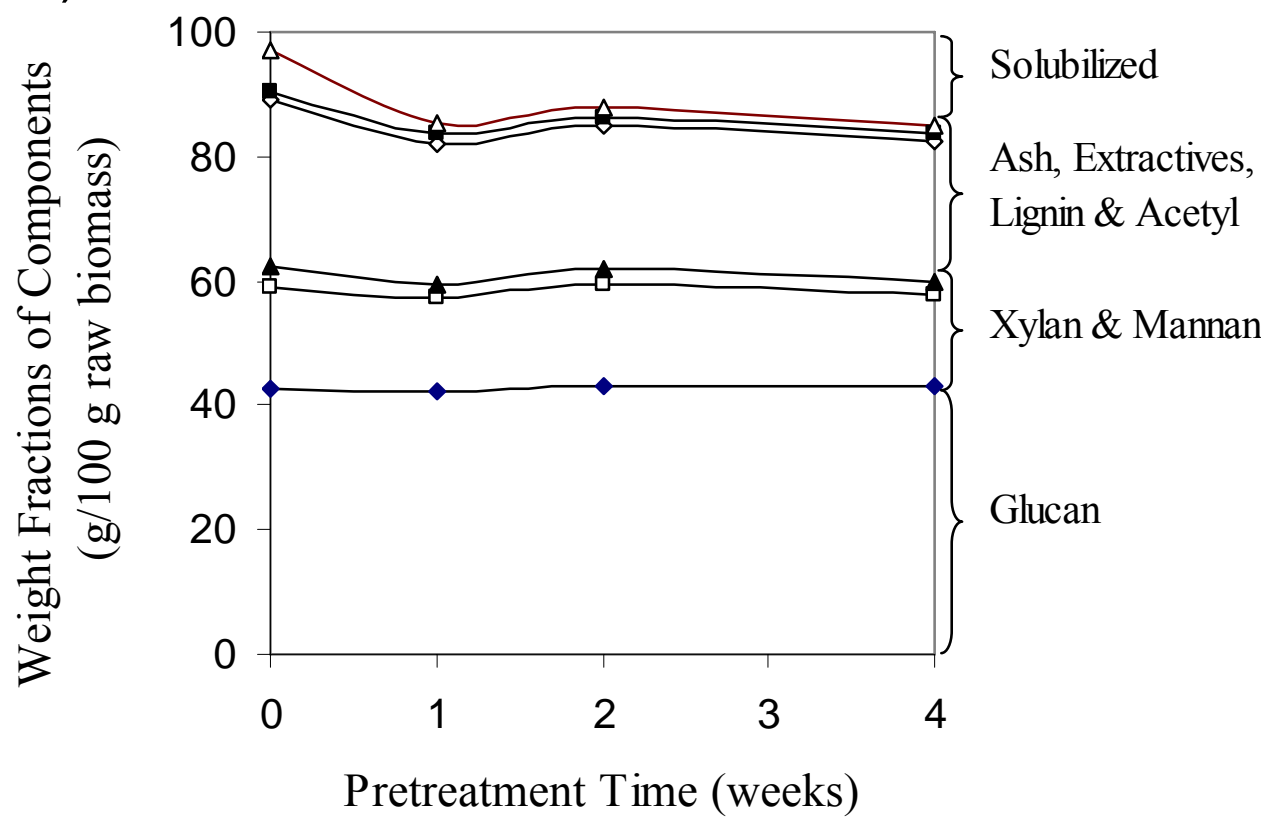

Fig. 15. Summative mass closure for poplar wood pretreated at $35^{\circ} \mathrm{C}$, a) oxidative, b) non-oxidative. 
a)

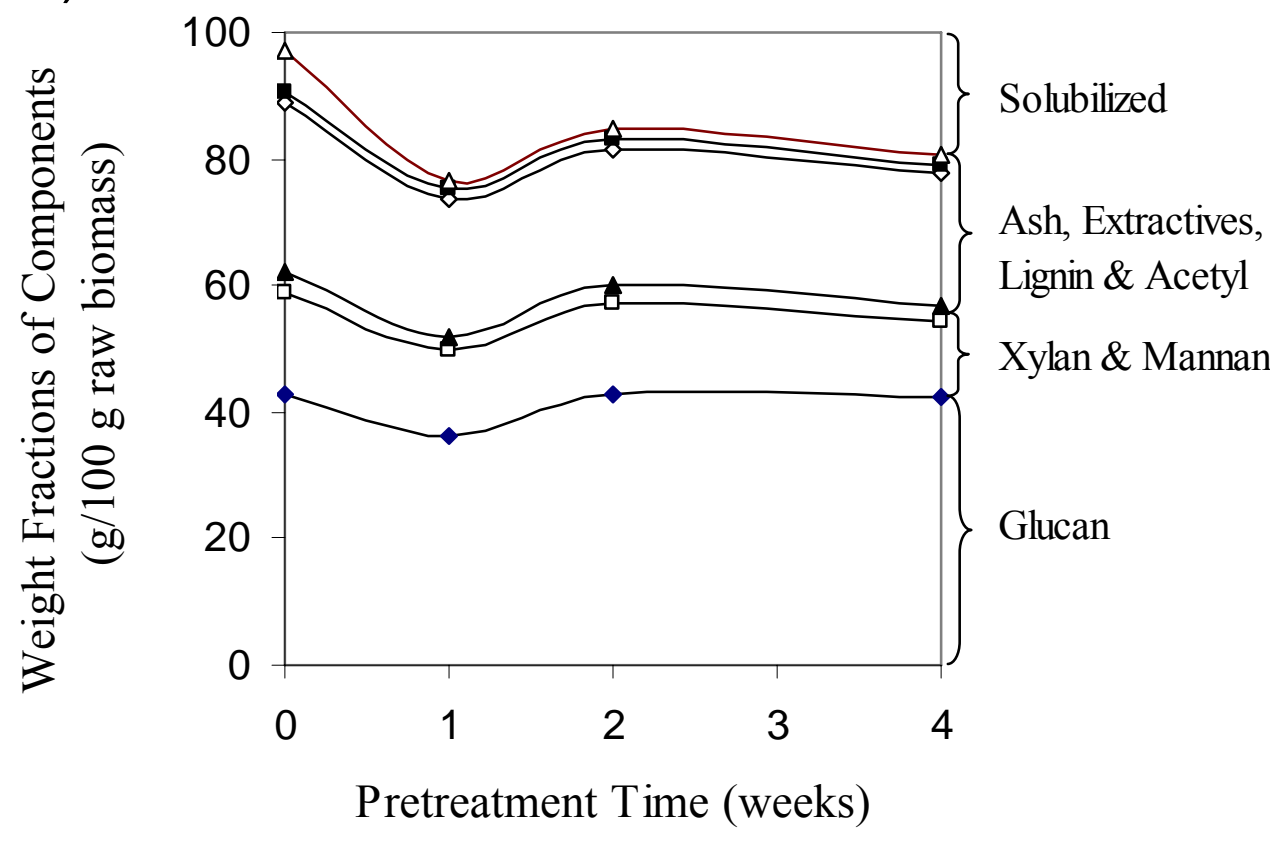

b)

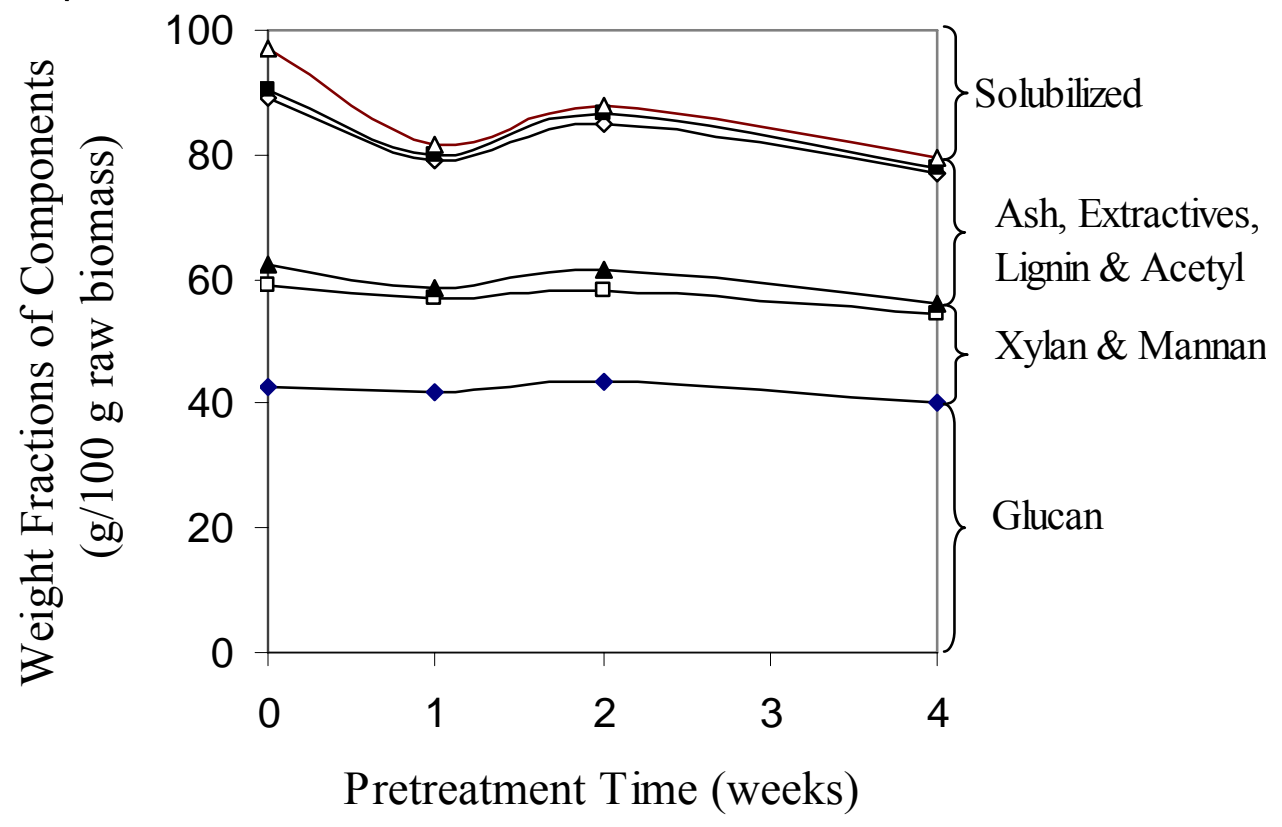

Fig. 16. Summative mass closure for poplar wood pretreated at $45^{\circ} \mathrm{C}$, a) oxidative, b) non-oxidative. 


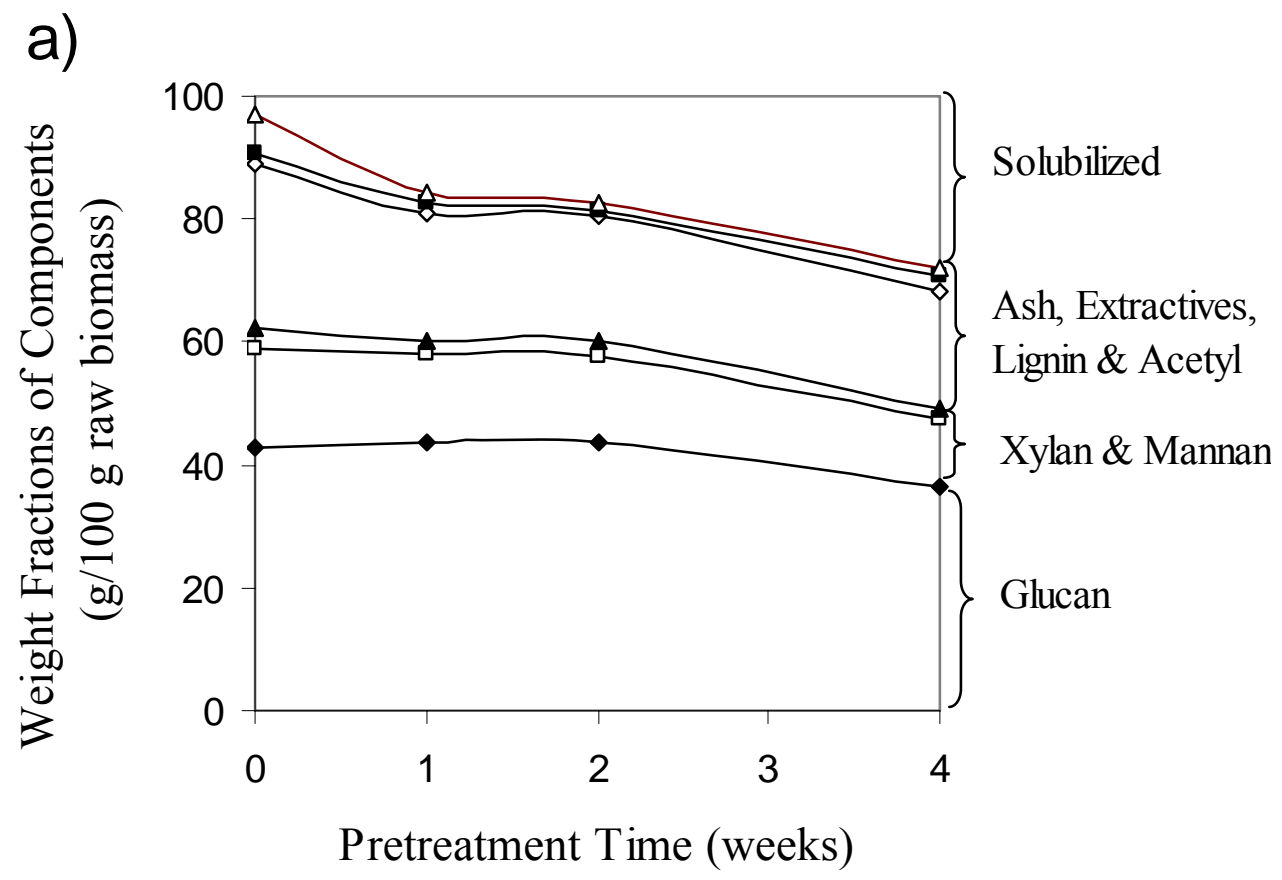

b)

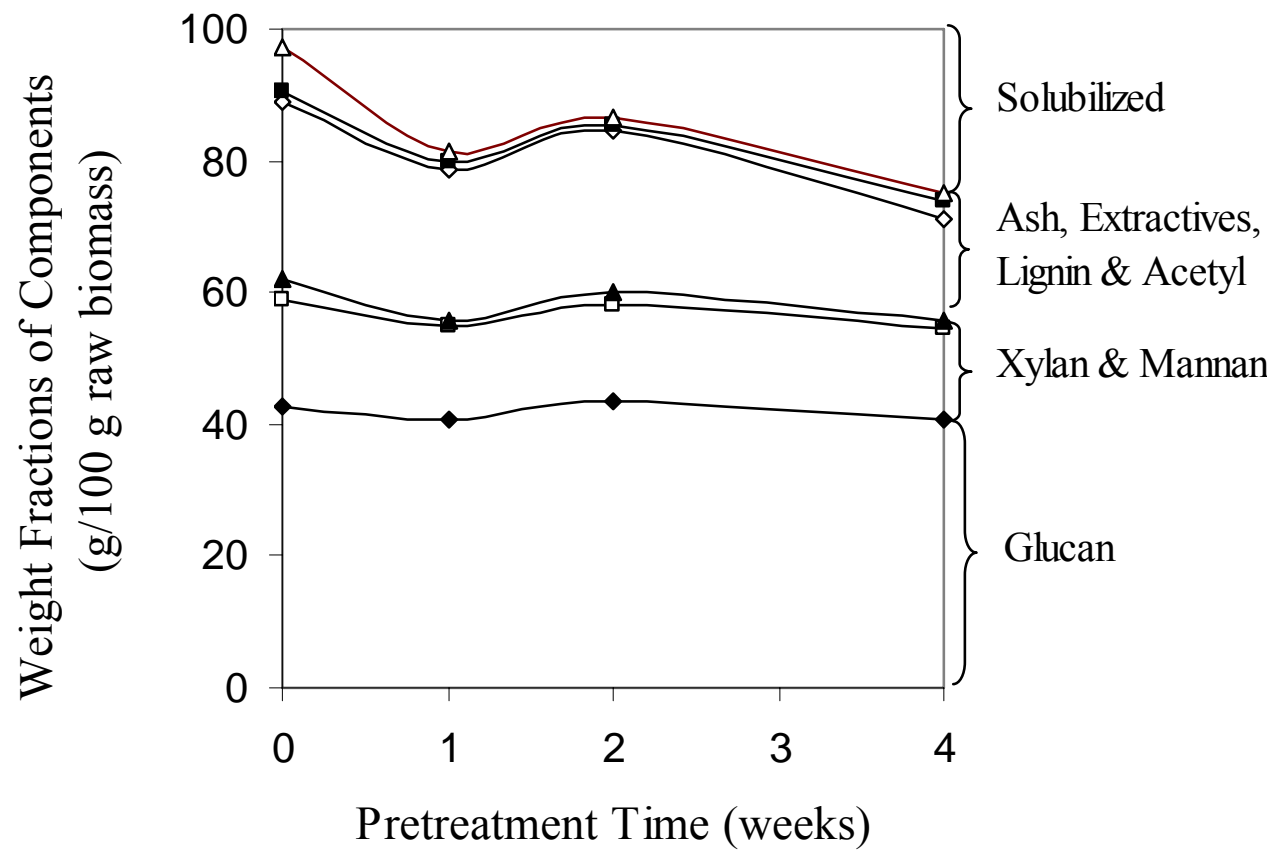

Fig. 17. Summative mass closure for poplar wood pretreated at $55^{\circ} \mathrm{C}$, a) oxidative, b) non-oxidative. 

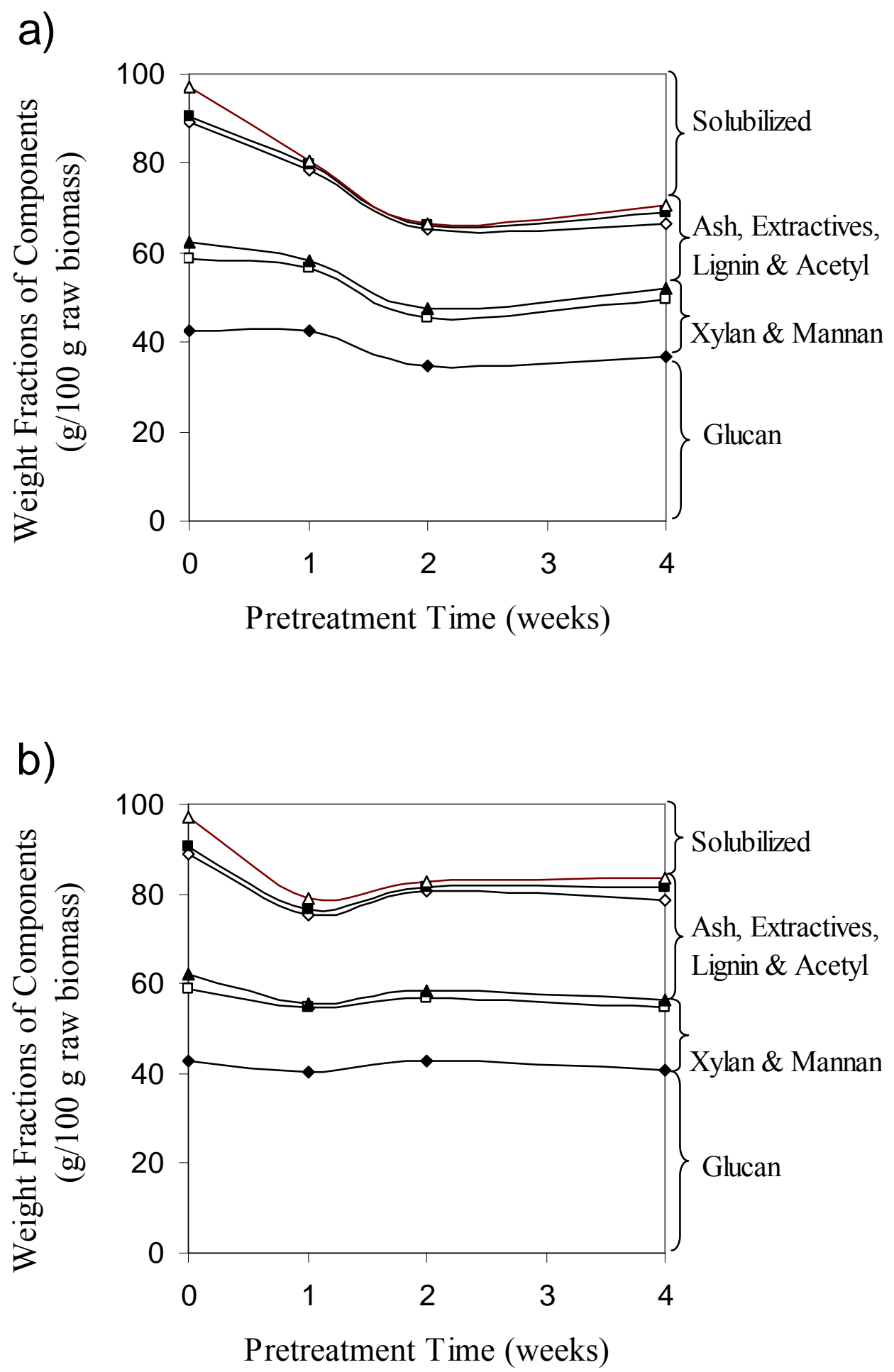

Fig. 18. Summative mass closure for poplar wood pretreated at $65^{\circ} \mathrm{C}$, a) oxidative, b) non-oxidative. 


\subsection{Pretreatment yields of cellulose $\left(Y_{G}\right)$ and hemicellulose $\left(Y_{X}\right)$}

The defining equations and nomenclature for these two yields are explained on pages 32 to 37. glucan and xylan were fully preserved up to the second week of pretreatment (first week for $65^{\circ} \mathrm{C}$ ) in both the oxidative and non-oxidative conditions. After that, carbohydrate yields $\left(\mathrm{Y}_{\mathrm{G}}\right.$ and $\left.\mathrm{Y}_{\mathrm{X}}\right)$ decreased depending on the oxidative condition as well as on temperature. The highest carbohydrates degradation was observed for 4 weeks of pretreatment at 55 and $65^{\circ} \mathrm{C}$ and in the oxidative condition. In general, cellulose (glucan) was more preserved than hemicellulose (xylan).

The lowest pretreatment yield of glucan $\left(\mathrm{Y}_{\mathrm{G}}\right)$ was reported as $86 \mathrm{~g}$ glucan recovered/100 g glucan in raw biomass and was obtained for poplar wood pretreated for 4 weeks at 55 and $65^{\circ} \mathrm{C}$ in oxidative condition. Kim (2004) reported $93 \mathrm{~g}$ glucan recovered $/ 100 \mathrm{~g}$ glucan in raw biomass for lime pretreated corn stover at $55^{\circ} \mathrm{C}$ and in oxidative condition. The lowest pretreatment yield of xylan $\left(\mathrm{Y}_{\mathrm{X}}\right)$ was reported as $67 \mathrm{~g}$ xylan recovered/100 g xylan in raw biomass and was obtained for poplar wood pretreated for 4 weeks at $55^{\circ} \mathrm{C}$ and oxidative condition. Comparing this result with that obtained for corn stover lime pretreated at $55^{\circ} \mathrm{C}$ and oxidative conditions (Kim, 2004), where the yield was $72 \mathrm{~g}$ xylan recovered/100 $\mathrm{g}$ xylan in raw biomass, no appreciable differences are observed. The cellulose and hemicellulose yields of each of the conditions tested in this study, are summarized in Figs. 19 to 23. 


\subsection{Delignification}

Because the independent variable is time, the slope of the function Pretreatment yield of lignin vs pretreatment time is the lignin degradation rate. In all pretreatment cases, the fastest lignin degradation rate (i.e., higher slope) was observed during the first week of pretreatment, after that, lignin degradation continued at slower rates and more in oxidative than in non-oxidative conditions. The effect of temperature on delignification was important, and more lignin was removed at higher temperatures. The lignin yields $\mathrm{Y}_{\mathrm{L}}$ obtained for all pretreatment conditions are summarized in Fig. 24.

The greatest pretreatment yield of lignin was observed for the $65^{\circ} \mathrm{C}$ oxidative pretreatment. It was $54 \mathrm{~g}$ lignin remaining/100 g lignin in raw biomass. Kim (2004) reported pretreatment yield of lignin in corn stover submitted to 4 weeks of lime pretreatment at $55^{\circ} \mathrm{C}$ and oxidative condition of about $30 \mathrm{~g}$ lignin remaining/100 $\mathrm{g}$ lignin in raw biomass. This value is a little more than half of the value found in this study. Therefore, through these measurements, it is clear that woody biomass is significantly harder to delignify than herbaceous biomass. However, lignin removal accounted for most of the solubilization in long-term lime pretreatment of poplar wood. Furthermore, the recovery yield of total mass $\left(\mathrm{Y}_{\mathrm{p}}\right)$ was linearly related with residual lignin, as shown in Figs. 25 to 29 . 


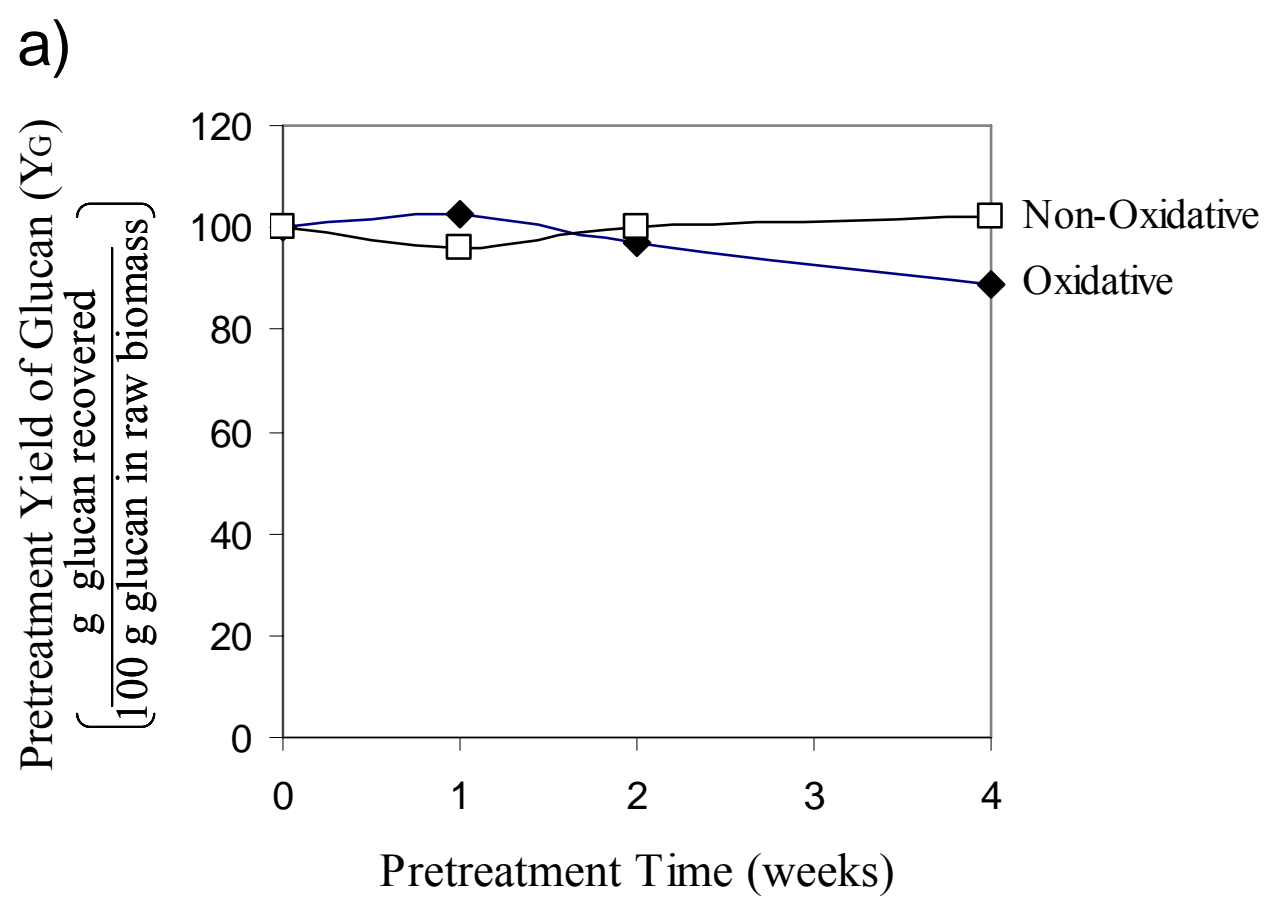

b)

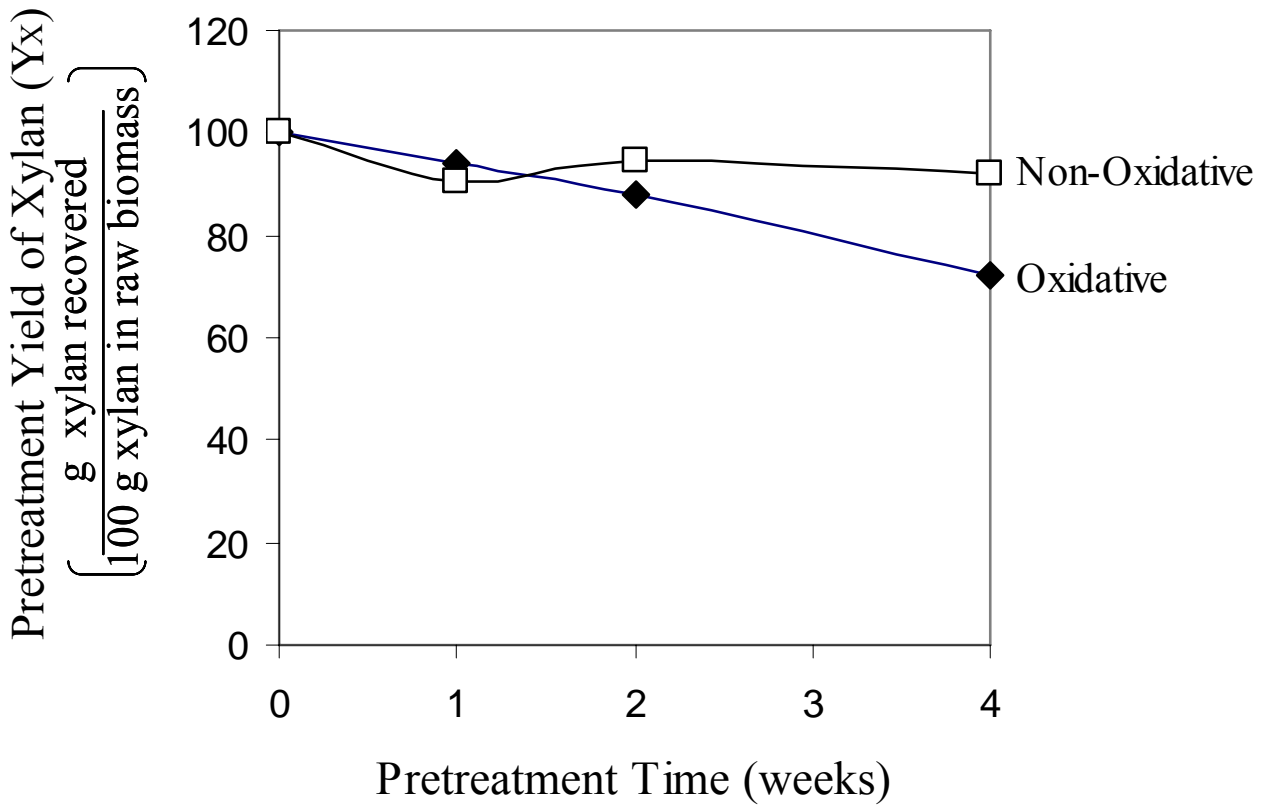

Fig. 19. a) Cellulose and b) hemicellulose yields of poplar wood pretreated at $25^{\circ} \mathrm{C}$. 


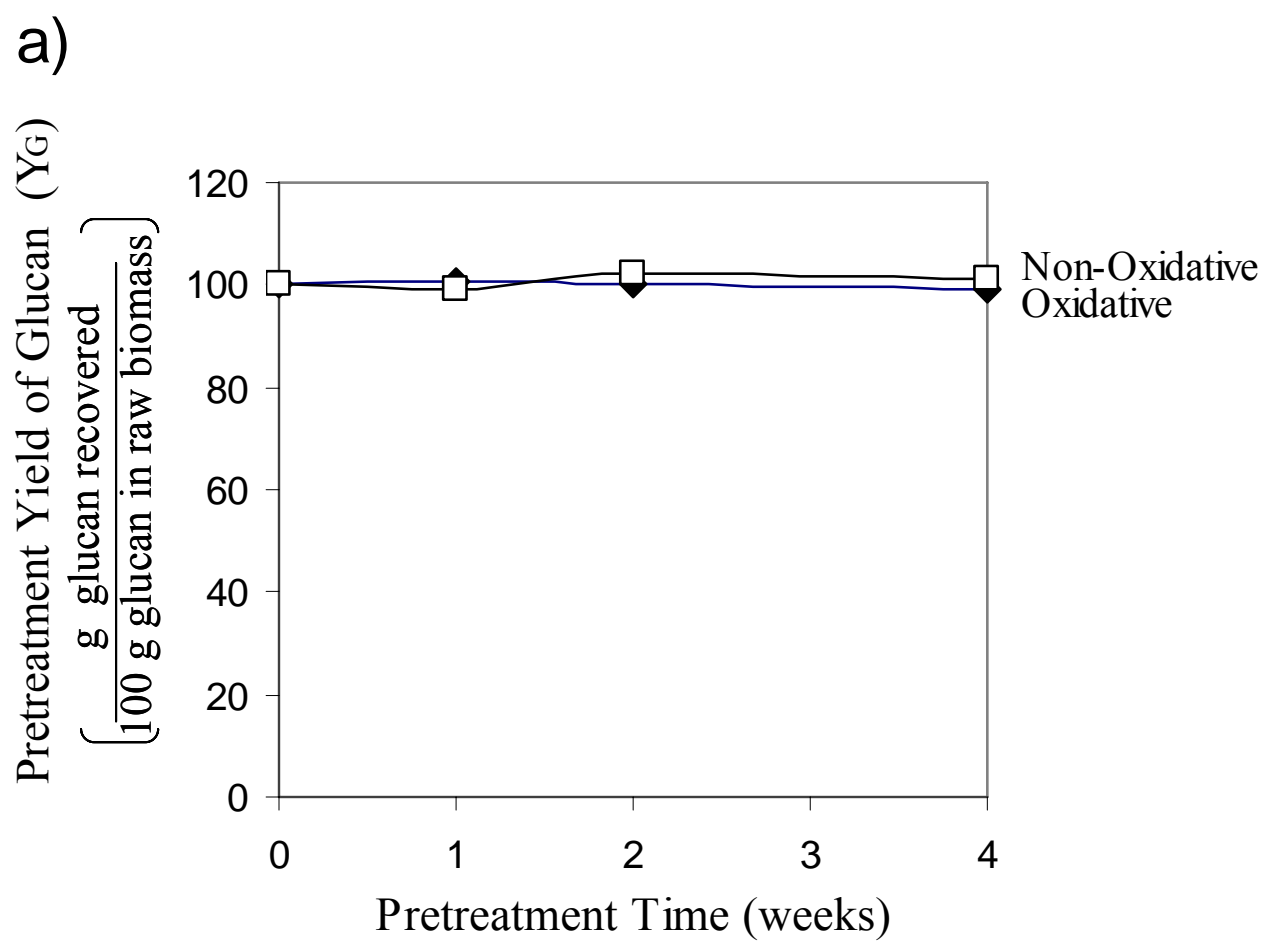

b)

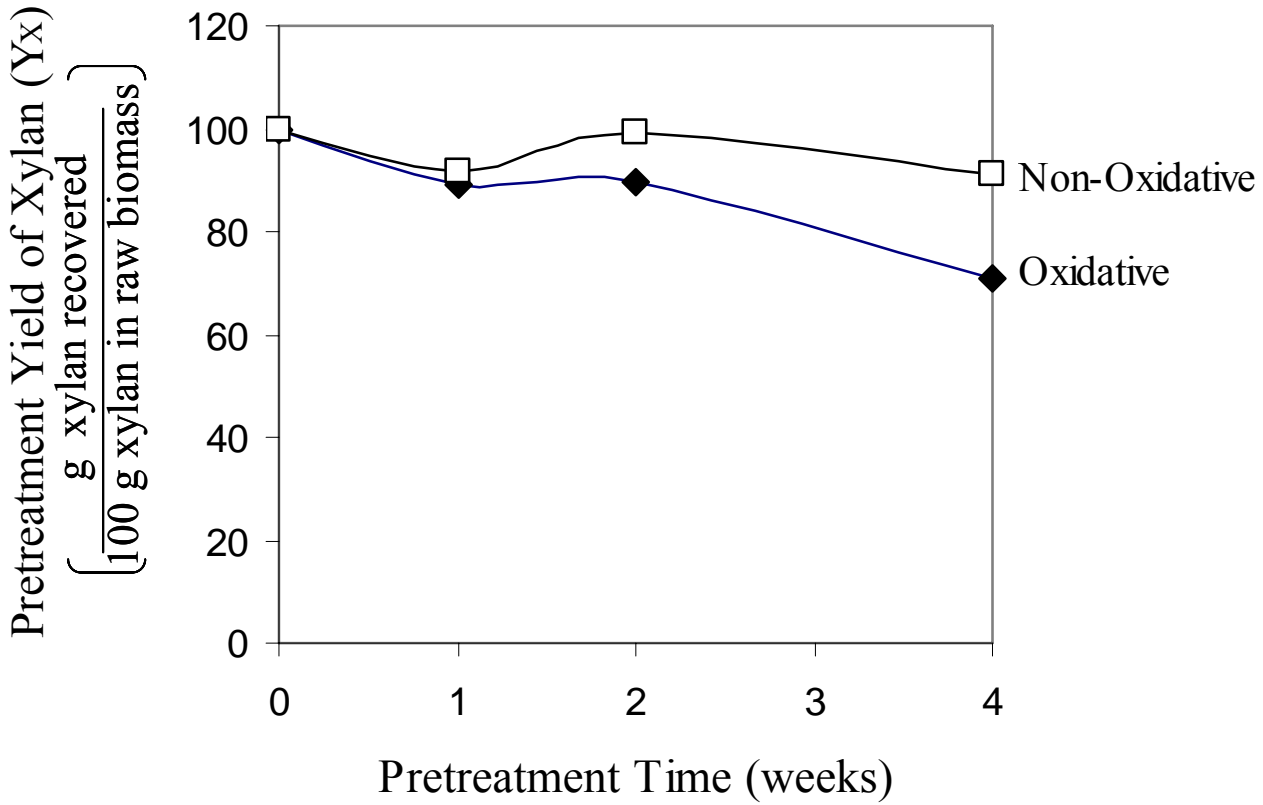

Fig. 20. a) Cellulose and b) hemicellulose yields of poplar wood pretreated at $35^{\circ} \mathrm{C}$. 
a)

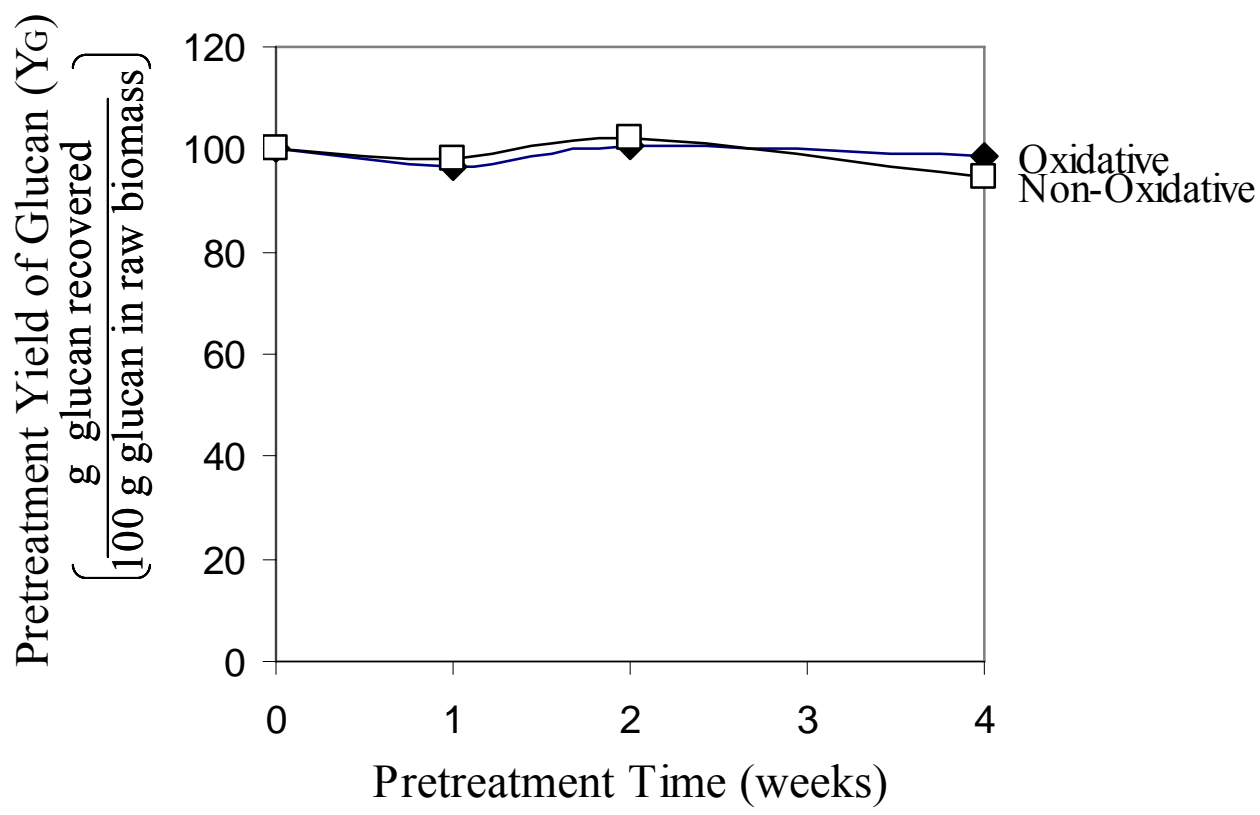

b)

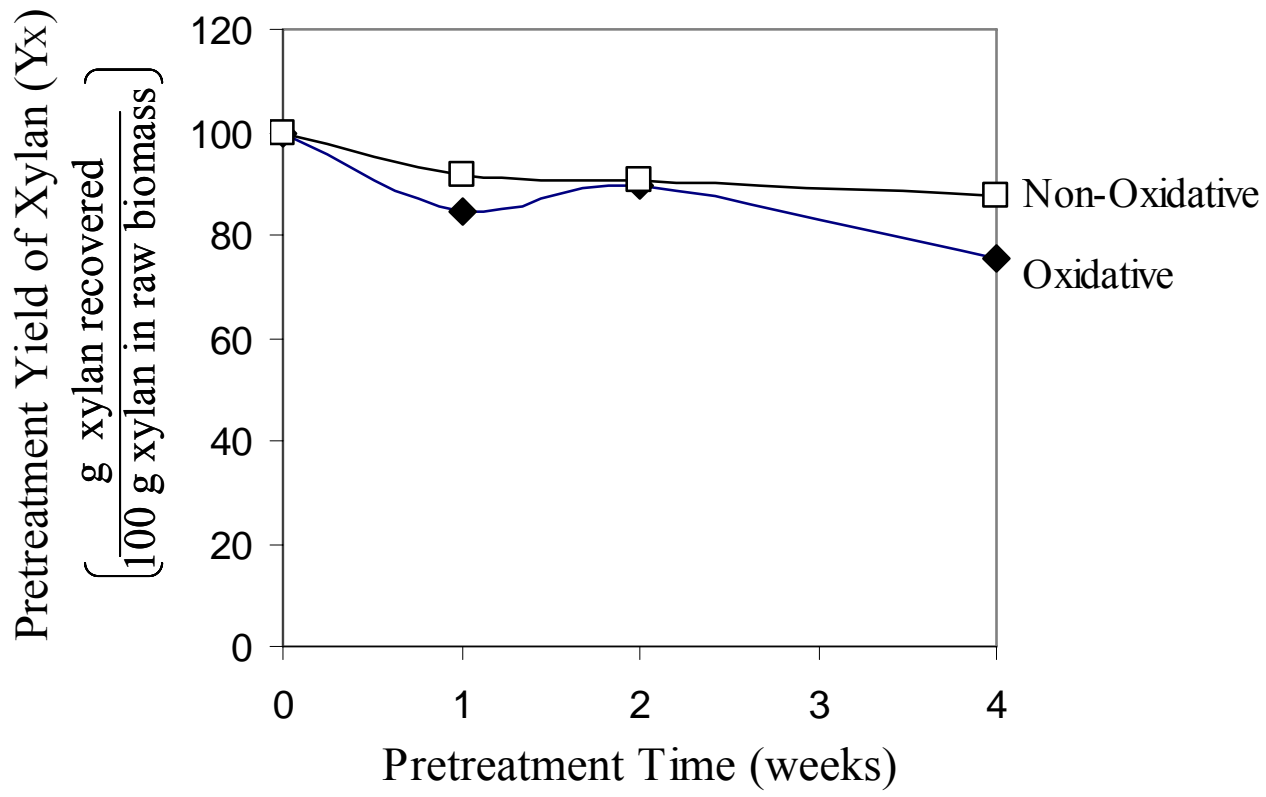

Fig. 21. a) Cellulose and b) hemicellulose yields of poplar wood pretreated at $45^{\circ} \mathrm{C}$. 


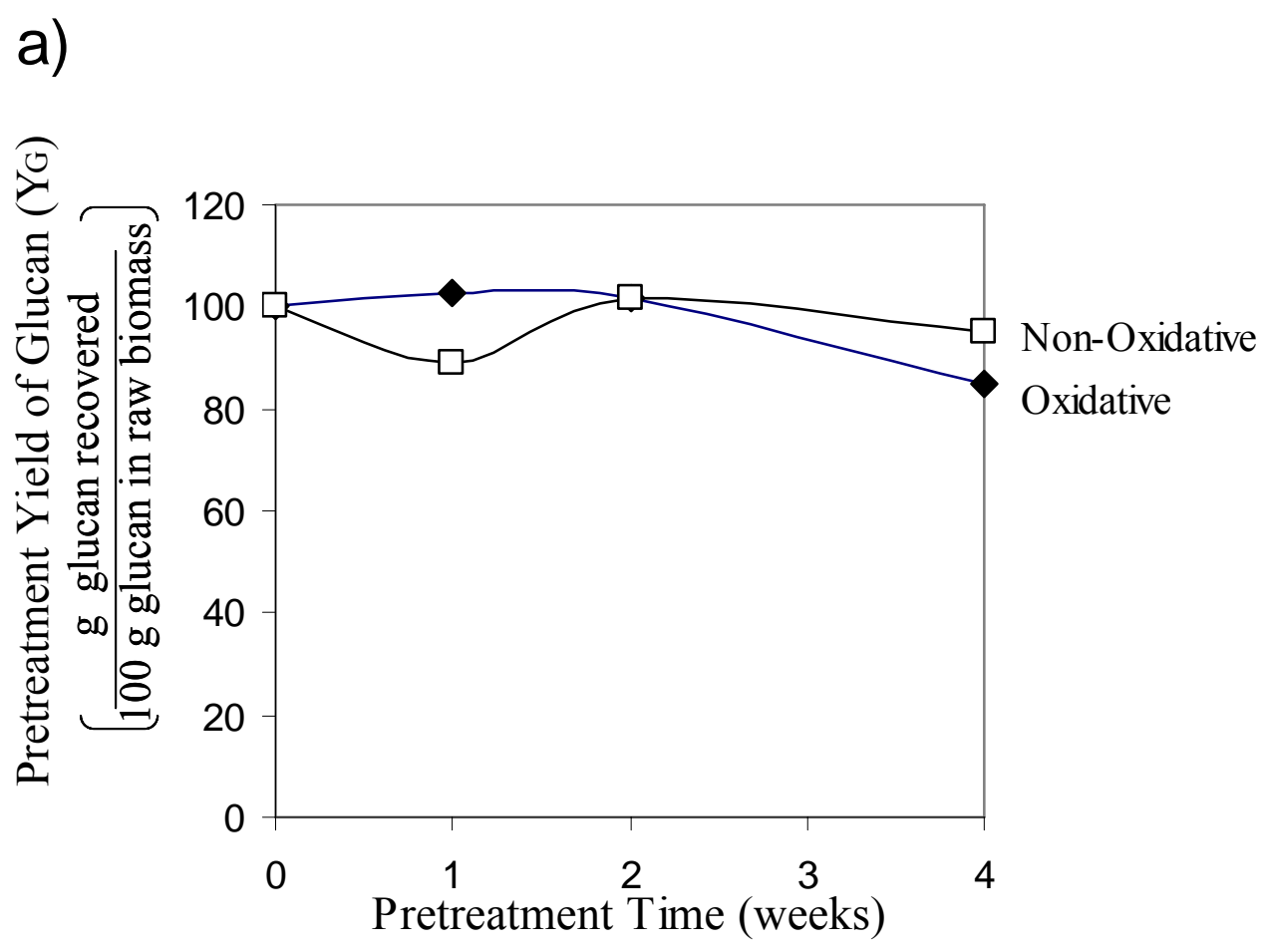

b)

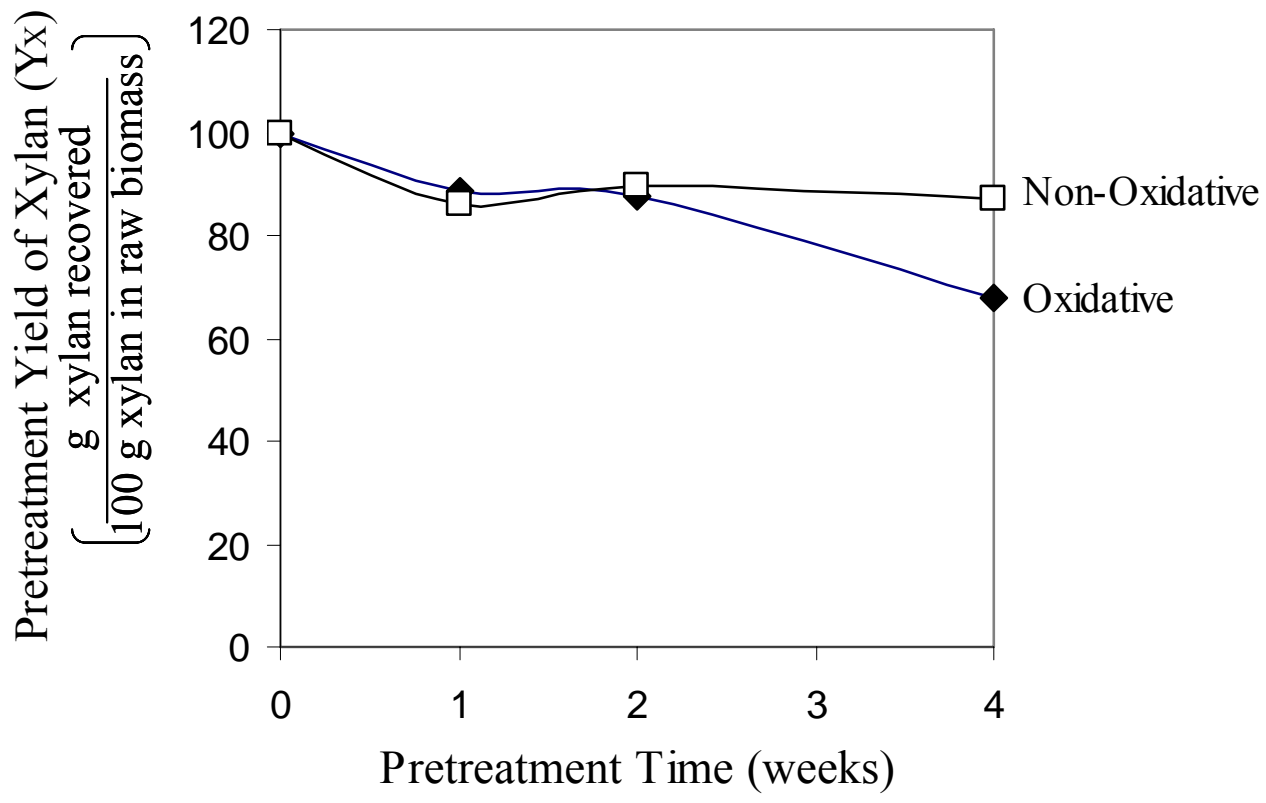

Fig. 22. a) Cellulose and b) hemicellulose yields of poplar wood pretreated at $55^{\circ} \mathrm{C}$. 
a)

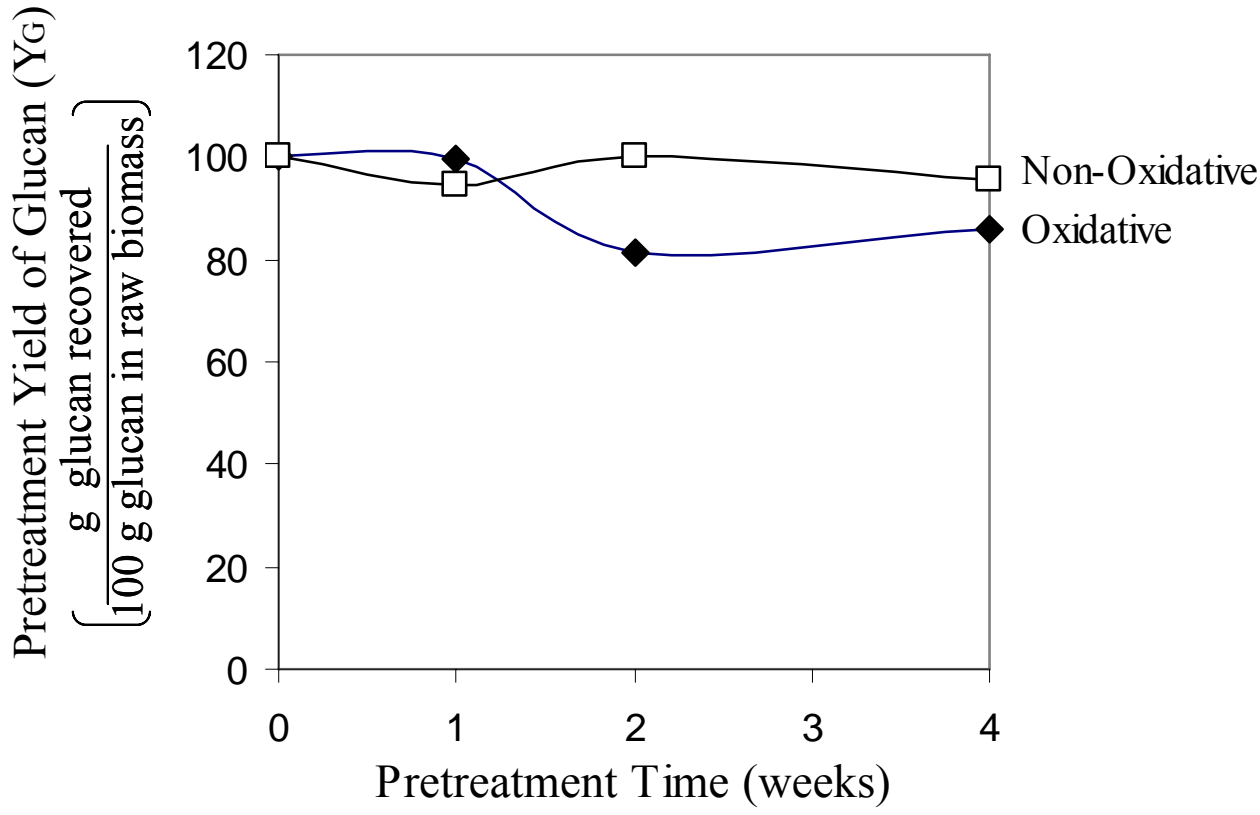

b)

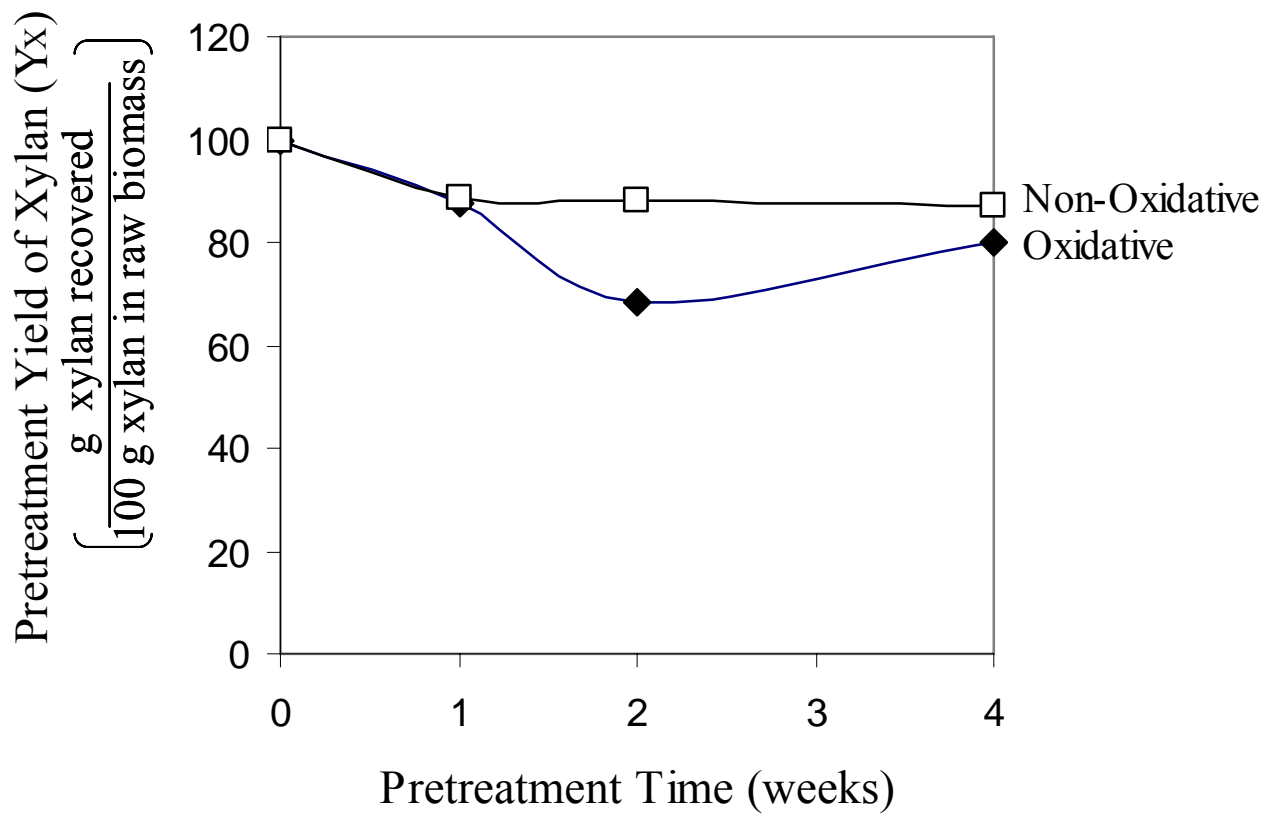

Fig. 23. a) Cellulose and b) hemicellulose yields of poplar wood pretreated at $65^{\circ} \mathrm{C}$. 


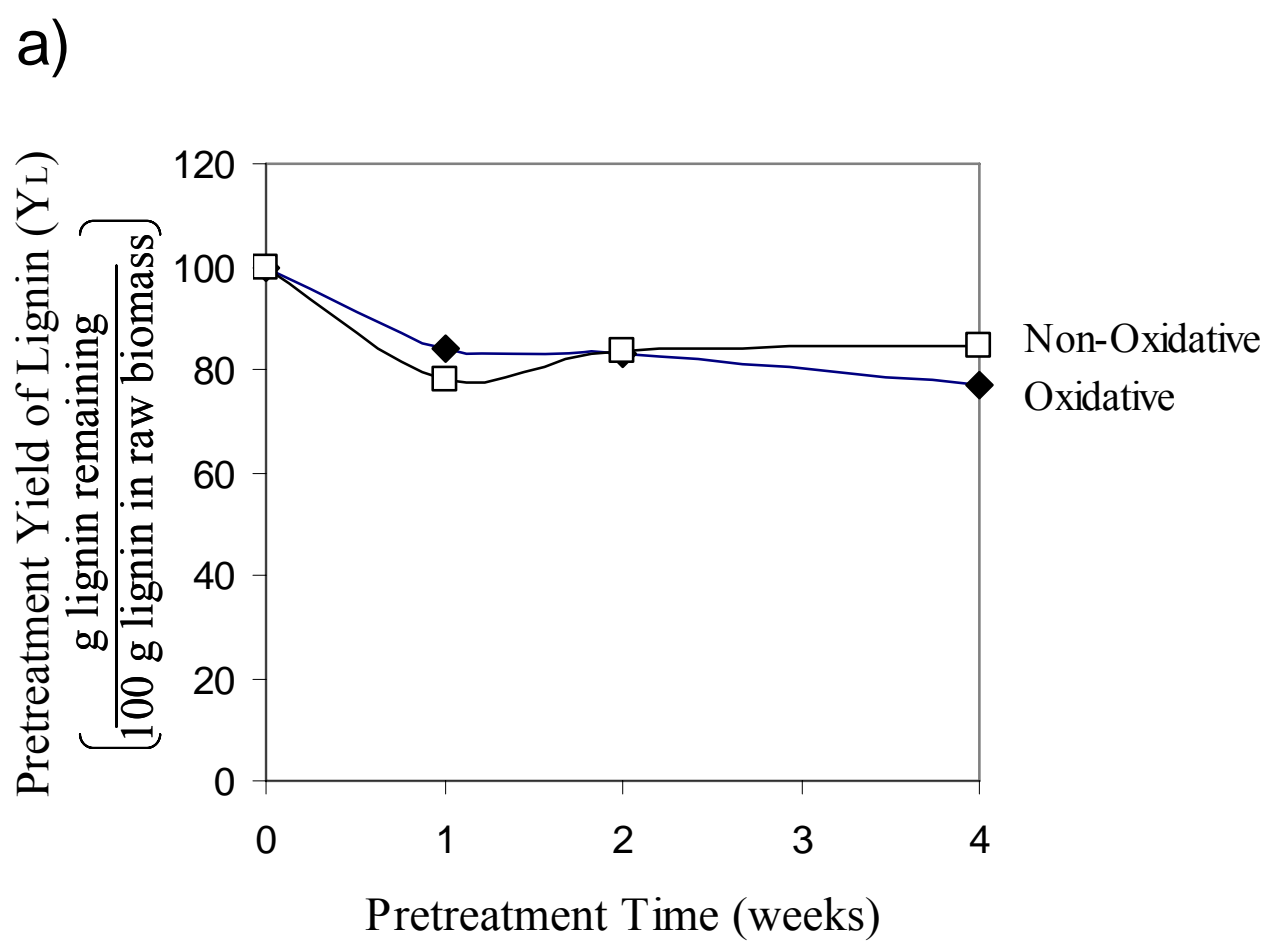

b)

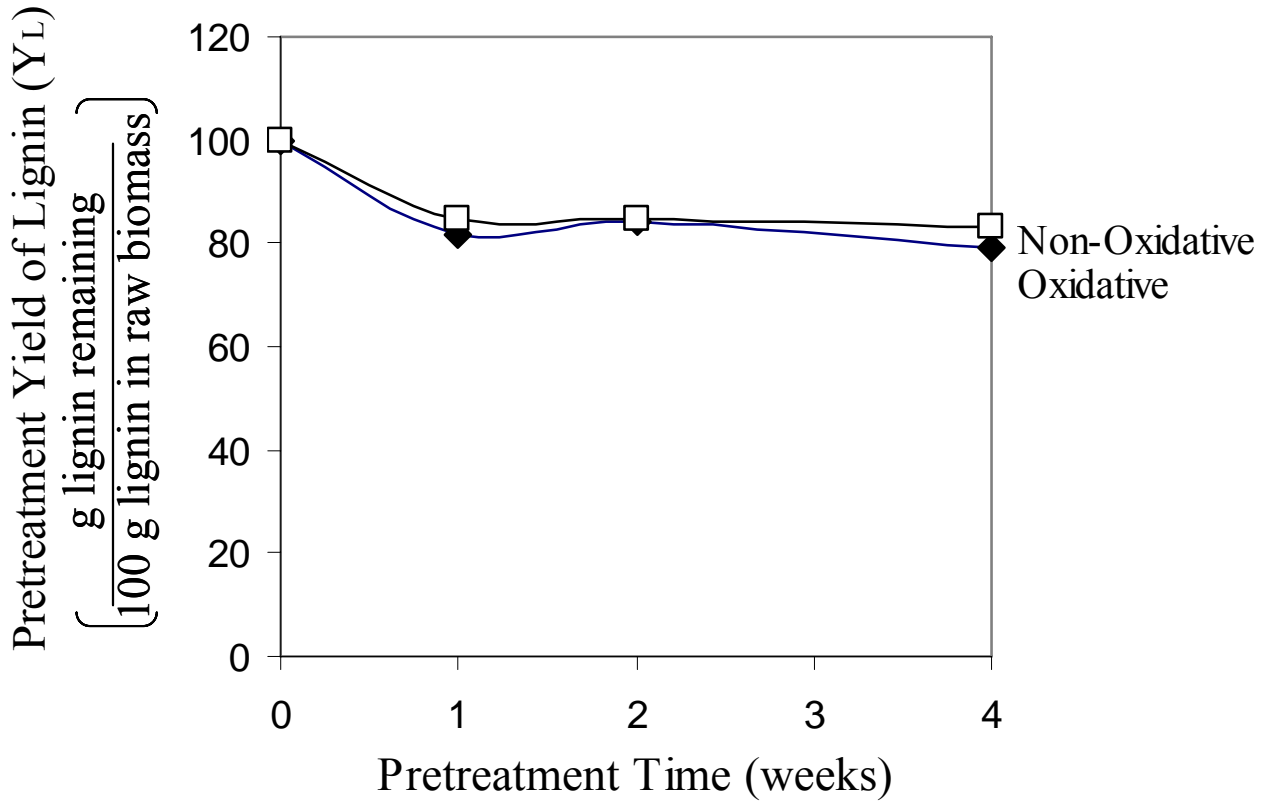

Fig. 24. Fraction of lignin remaining after pretreatement a) 25 , b) 35 , c) 45 , d) 55 , e) $65^{\circ} \mathrm{C}$. 
c)

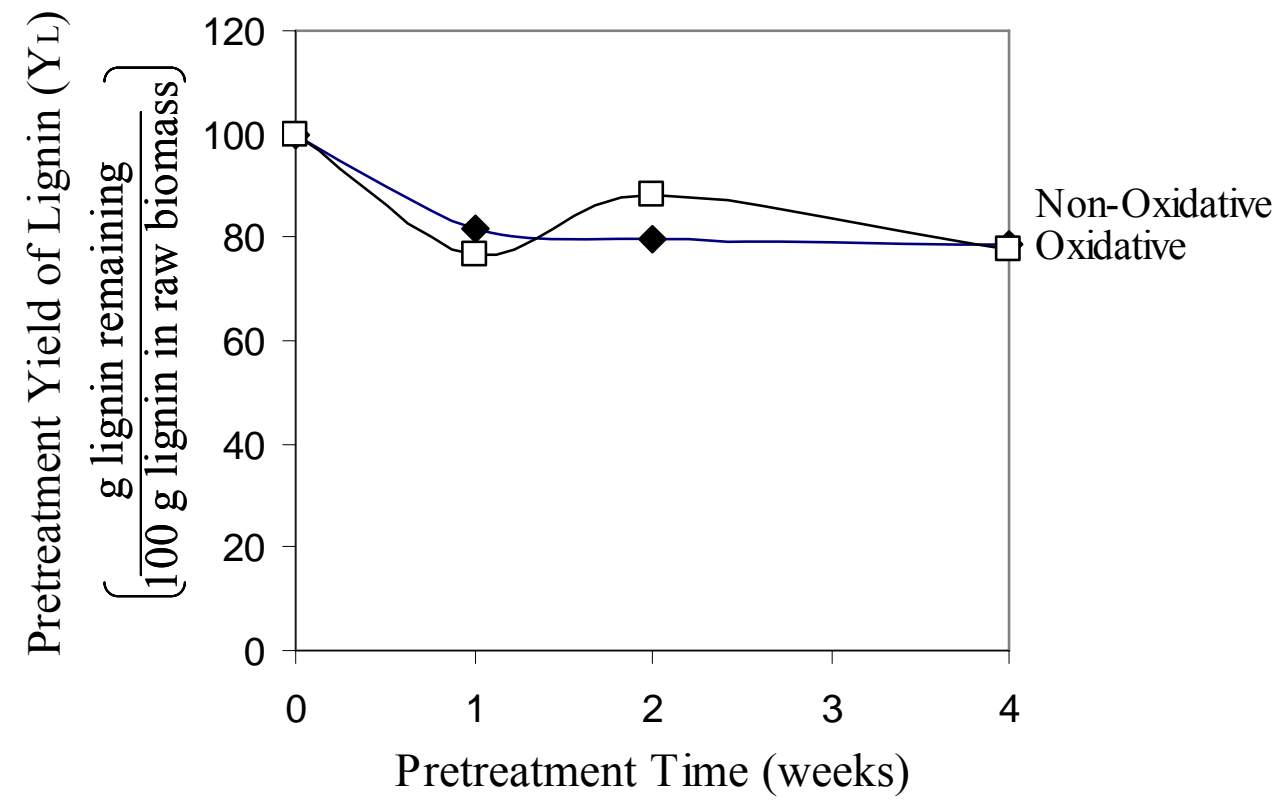

d)

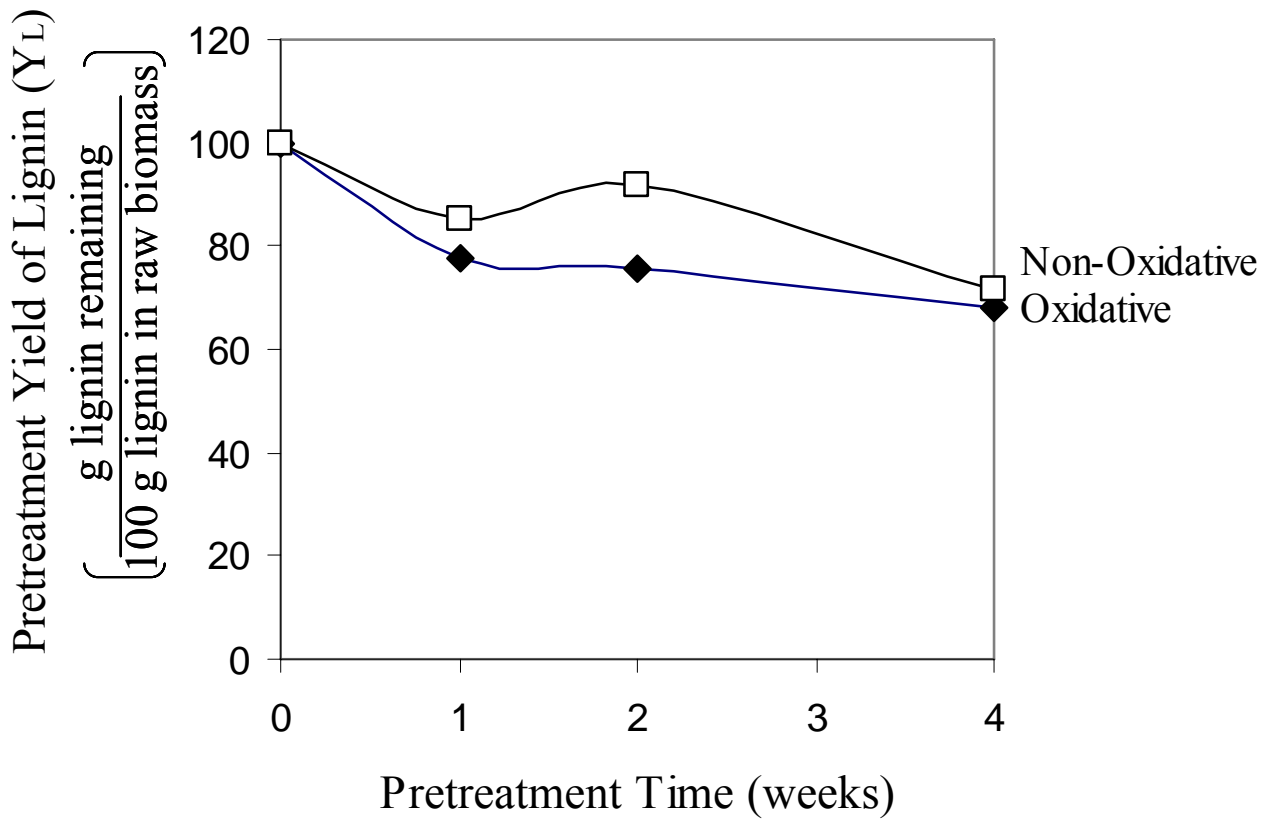

Fig. 24. Continued 
e)

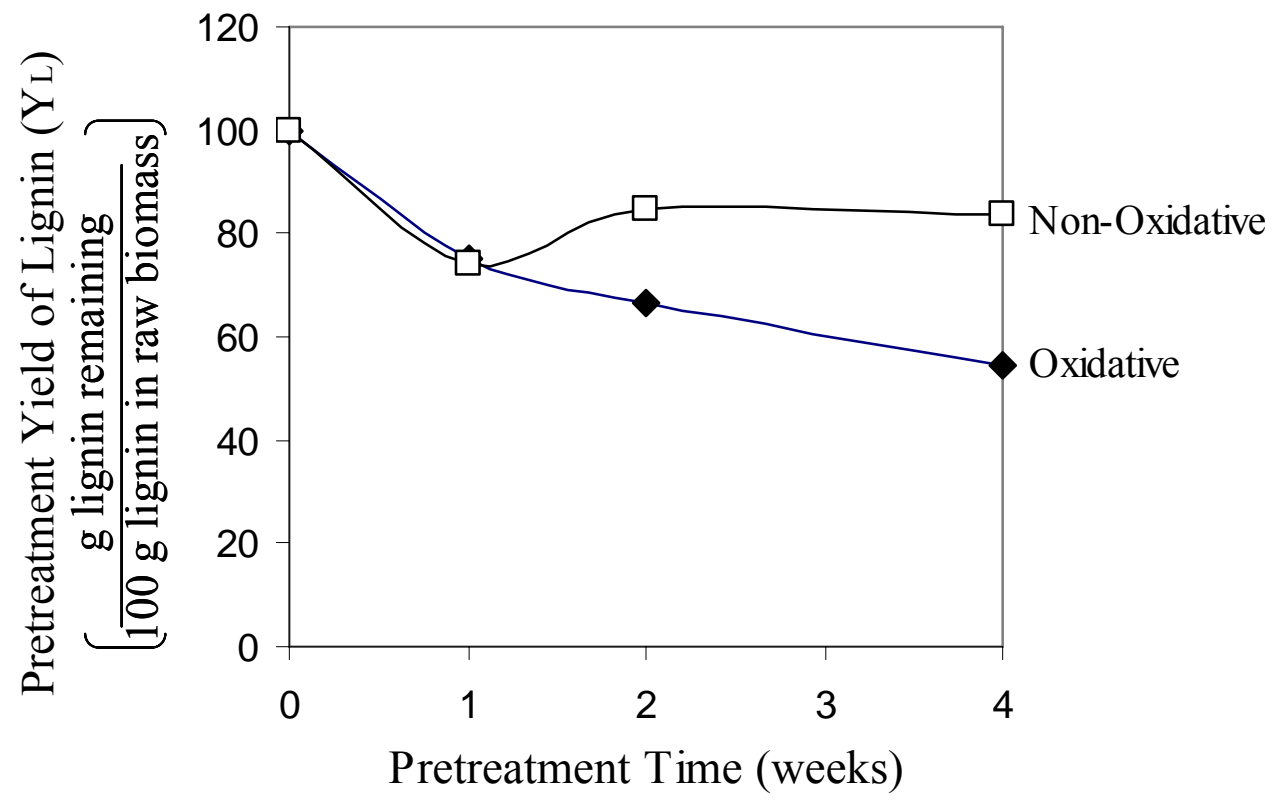

Fig. 24. Continued 

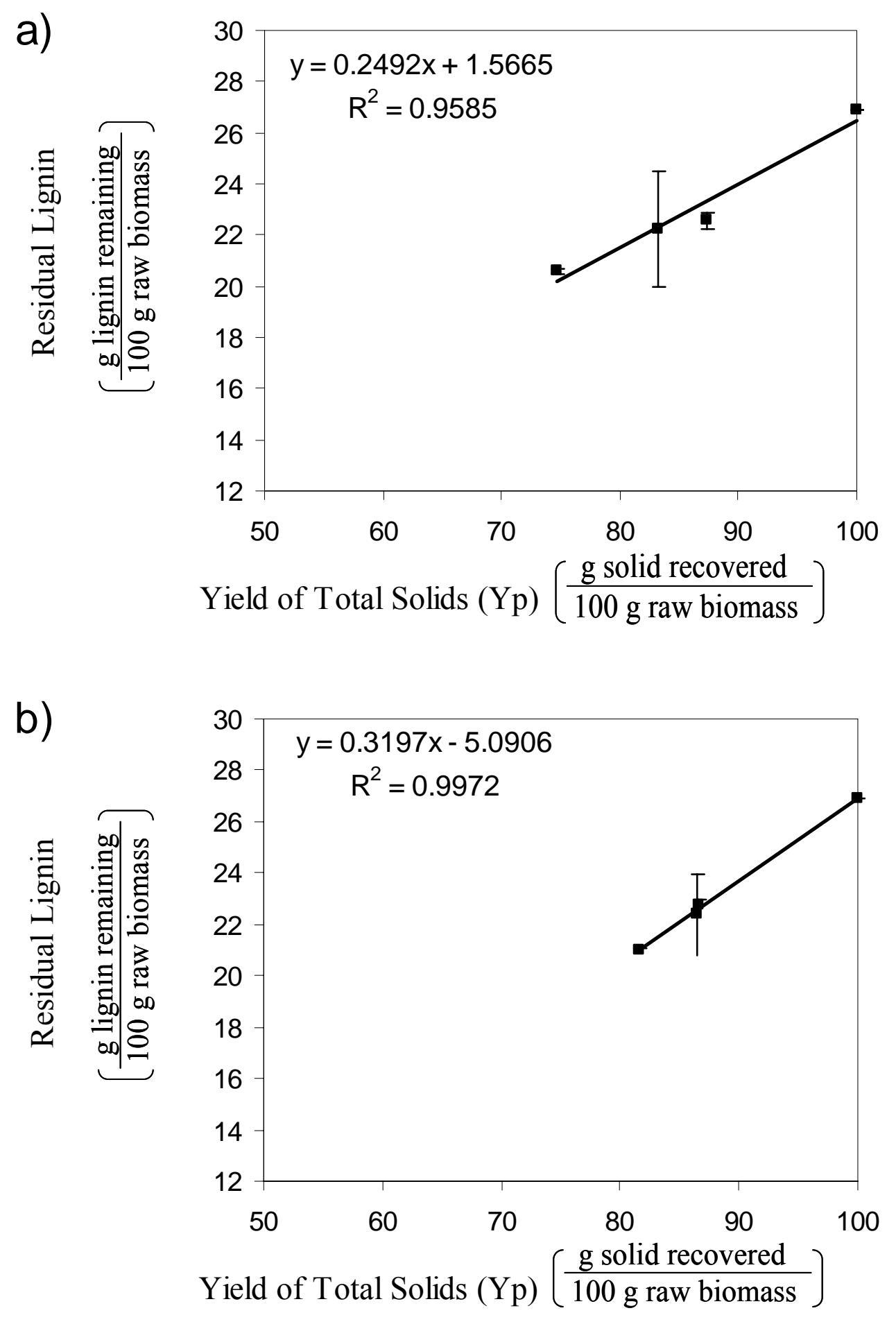

Fig. 25. Calculation of delignification selectivity at $25^{\circ} \mathrm{C}$. a) Oxidative. b) Non-oxidative. 

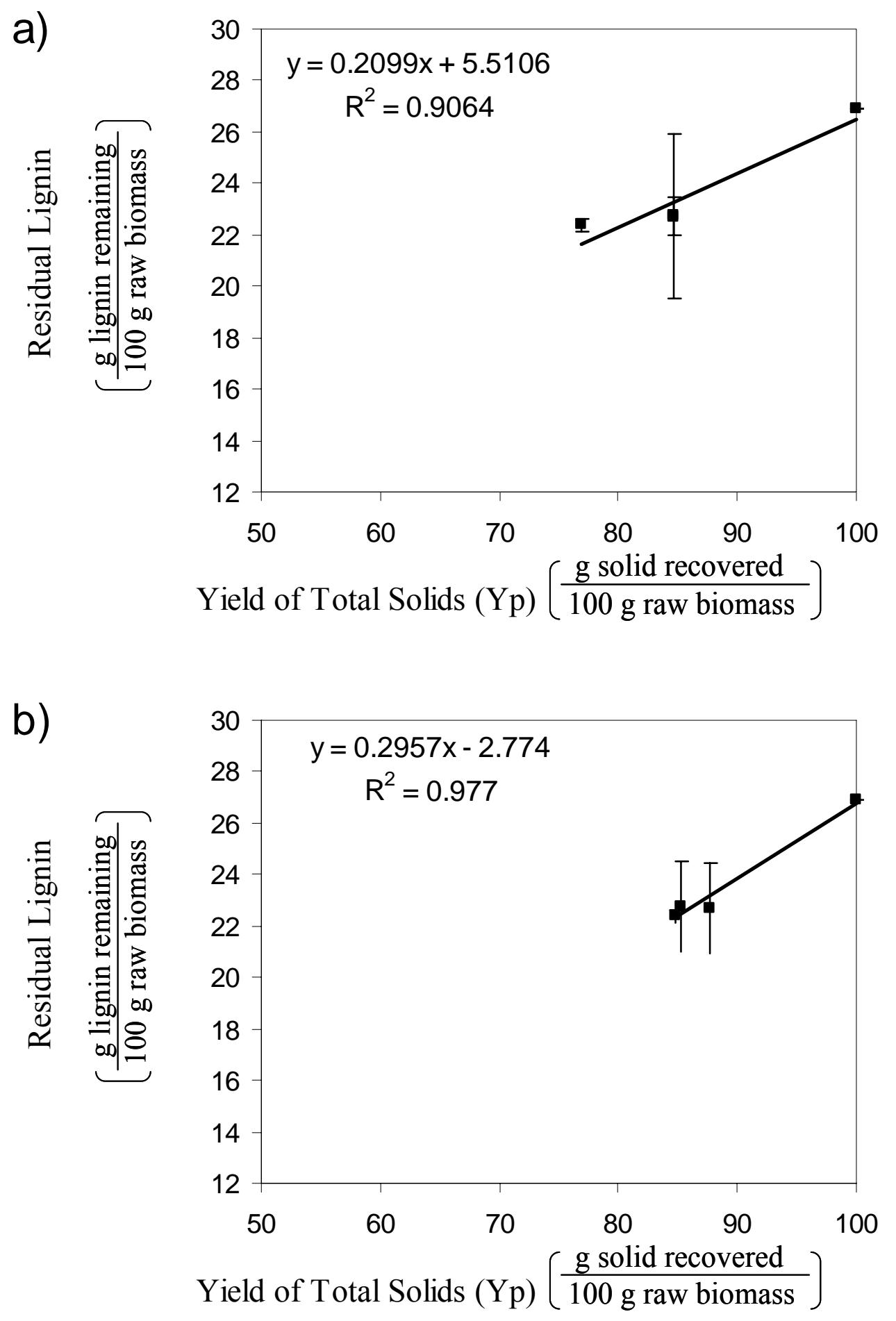

Fig. 26. Calculation of delignification selectivity at $35^{\circ} \mathrm{C}$. a) Oxidative. b) Non-oxidative. 

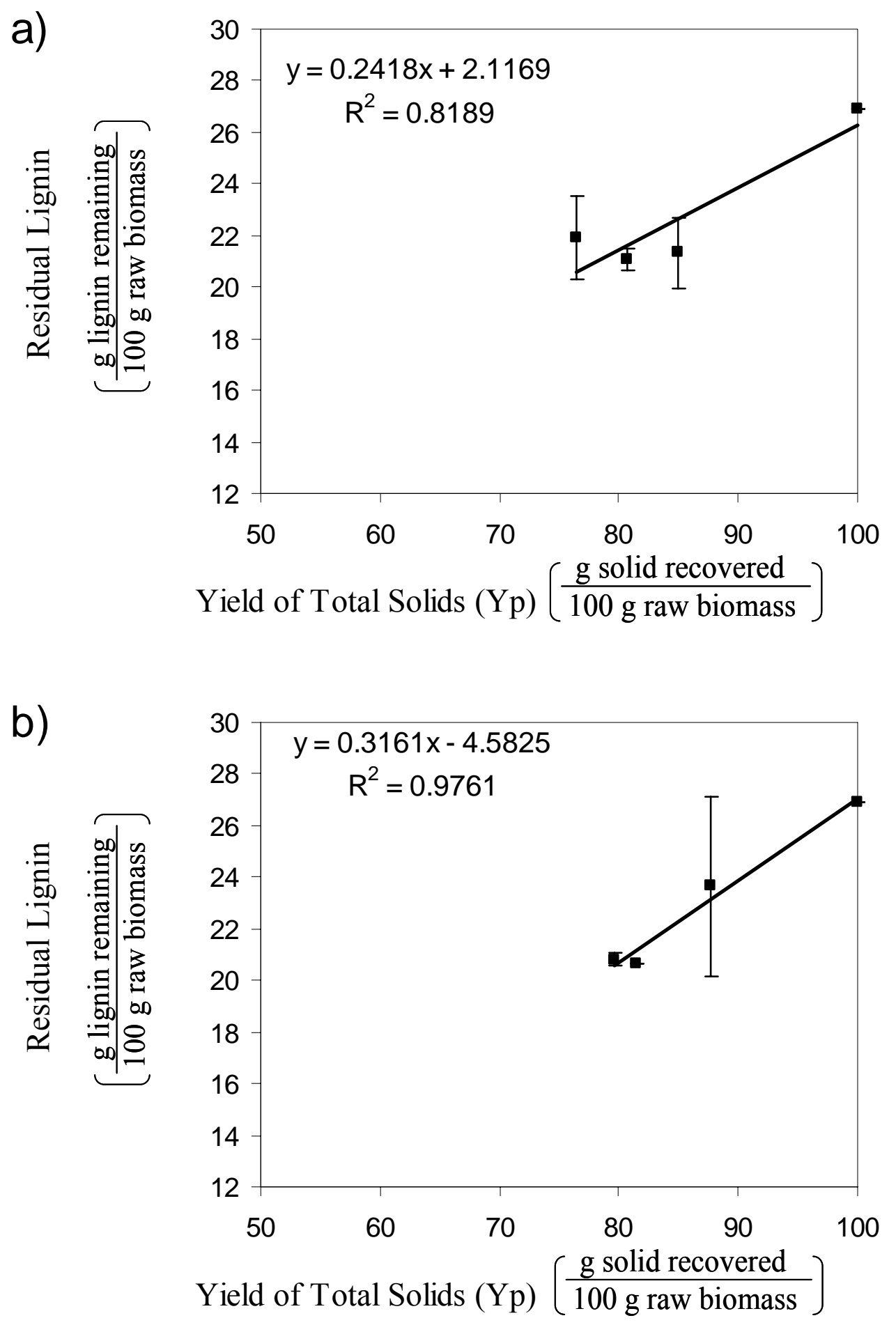

Fig. 27. Calculation of delignification selectivity at $45^{\circ} \mathrm{C}$. a) Oxidative. b) Non-oxidative. 

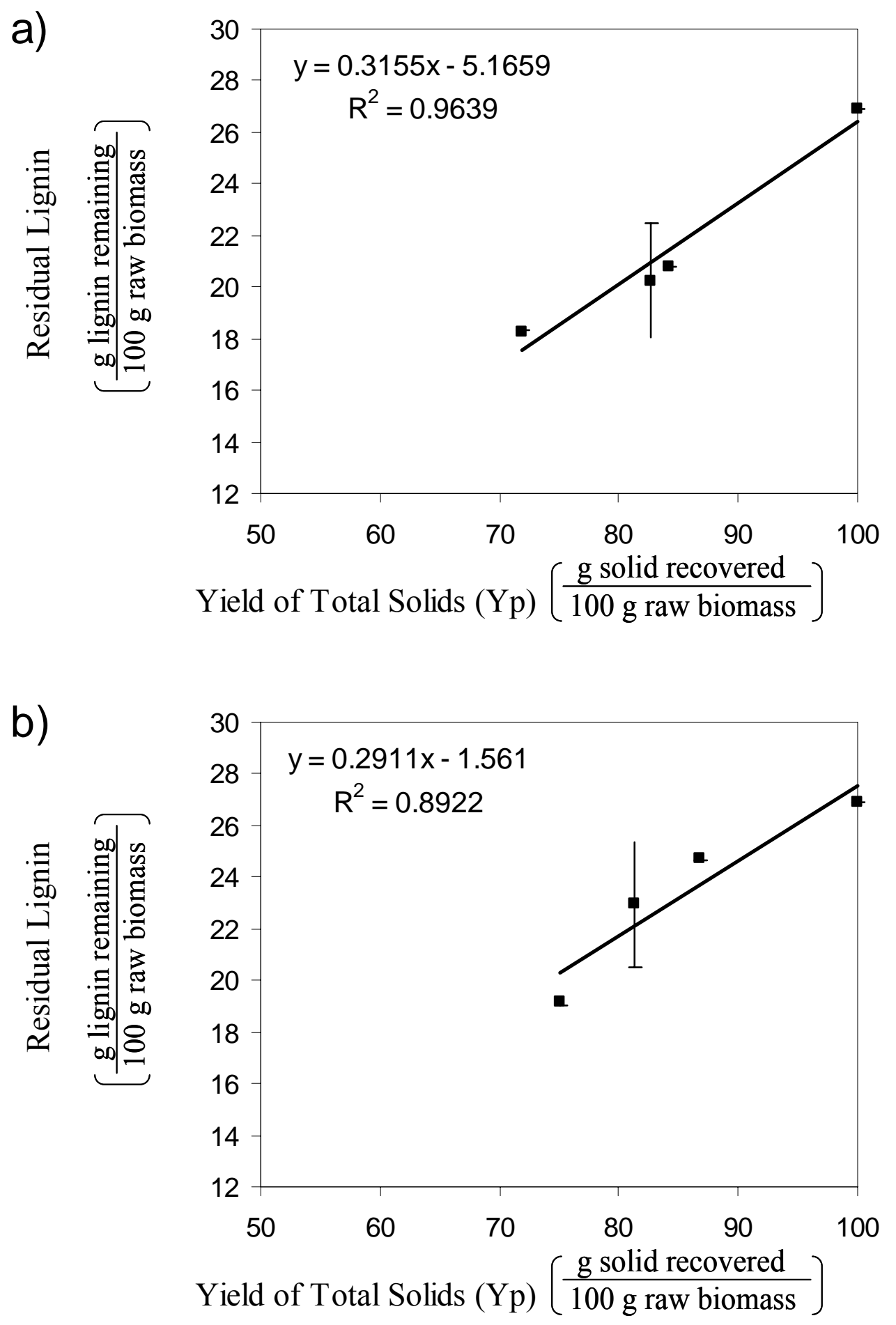

Fig. 28. Calculation of delignification selectivity at $55^{\circ} \mathrm{C}$. a) Oxidative. b) Non-oxidative. 

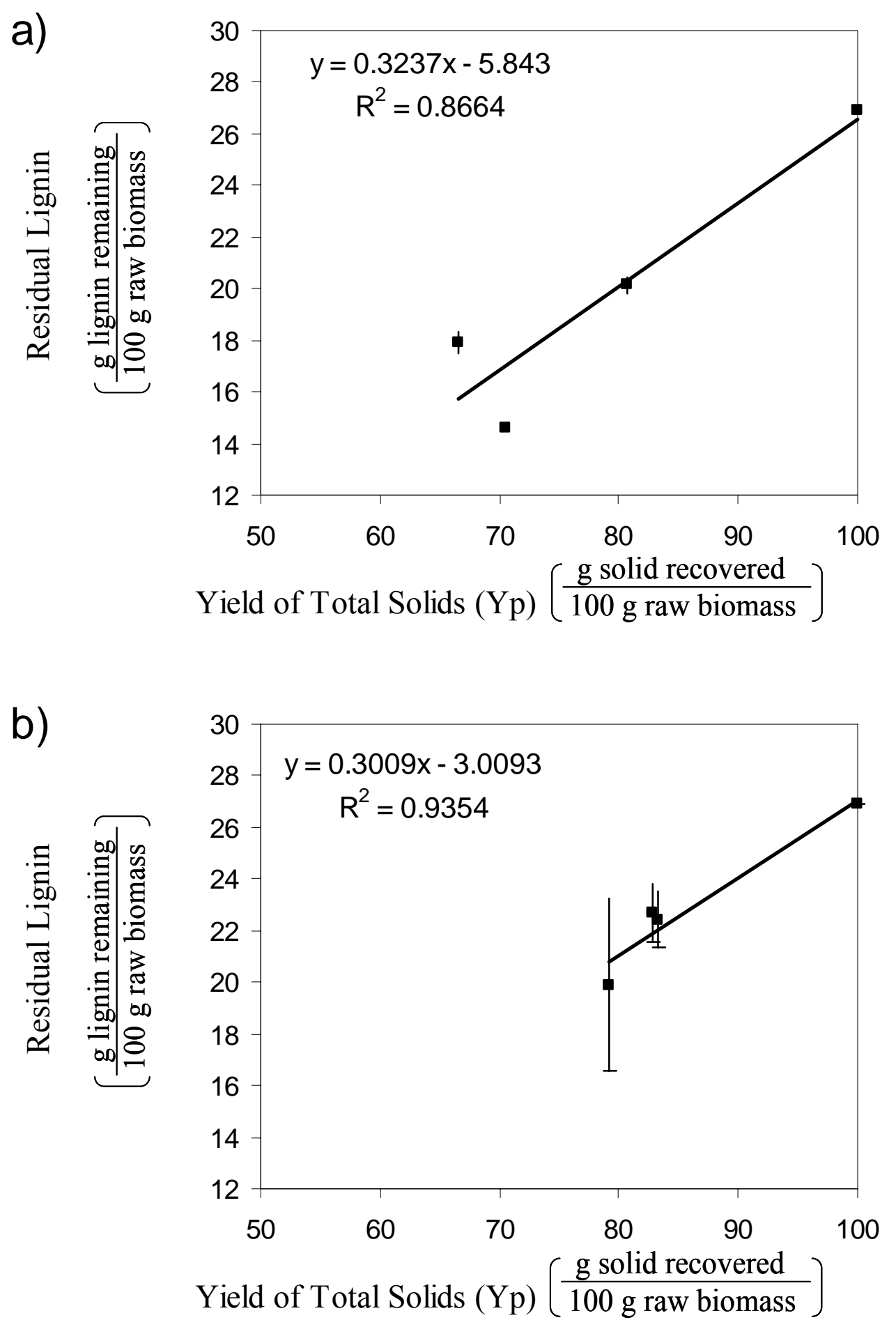

Fig. 29. Calculation of delignification selectivity at $65^{\circ} \mathrm{C}$. a) Oxidative. b) Non-oxidative. 
The slope of the lines in Figs. 25 to 29 represents the delignification selectivity. More specifically, delignification selectivity (S) is defined as:

$$
\mathrm{S} \equiv \frac{\Delta \mathrm{L}}{\Delta \mathrm{Y}}
$$

where $\Delta \mathrm{L}$ is the decrease in lignin corresponding to $\Delta \mathrm{Y}$ decrease in yield.

This slope was calculated in Microsoft Excel ${ }^{\circledR}$ using the linear regression trendline option (all equations are presented in the plots). The R-squared values were greater than $80 \%$ in most of the cases, showing good fit with the linear models.

The delignification selectivity for the oxidative condition increased with temperature and showed the greatest value for $65^{\circ} \mathrm{C}$, thus, the delignification selectivity in the oxidative contidition may be enhanced by higher temperatures. However, in the non-oxidative condition, the selectivity did not show any improvement with increasing temperature (Fig. 30).

In Fig. 31, the pretreatment yield of lignin is related to the pretreatment yield of glucose and the pretreatment yield of xylose. Data show high variability, however, because the Rsquared value is higher in the case of the pretreatment yield of xylose, a linear model appear to be more appropriate than in the case of pretreatment yield of glucose. No conclusive statements can be made, because the R-squared values are very small, however, a more strong relationship between the pretreatment yield of lignin and the pretreatment yield of xylan was expected due to the chemical bonding between lignin and hemicellulose in the biomass matrix. Nevertheless, it is clear that the oxidative condition influences more both the pretreatment yield of lignin and pretreatment yield of xylan than the non-oxidative condition does.

\subsection{Repeatability}

All the results reported in this chapter were obtained as an average of several measurements. At least duplicates taken from the same batch of pretreated material were analyzed in different days to assure repeatability. 


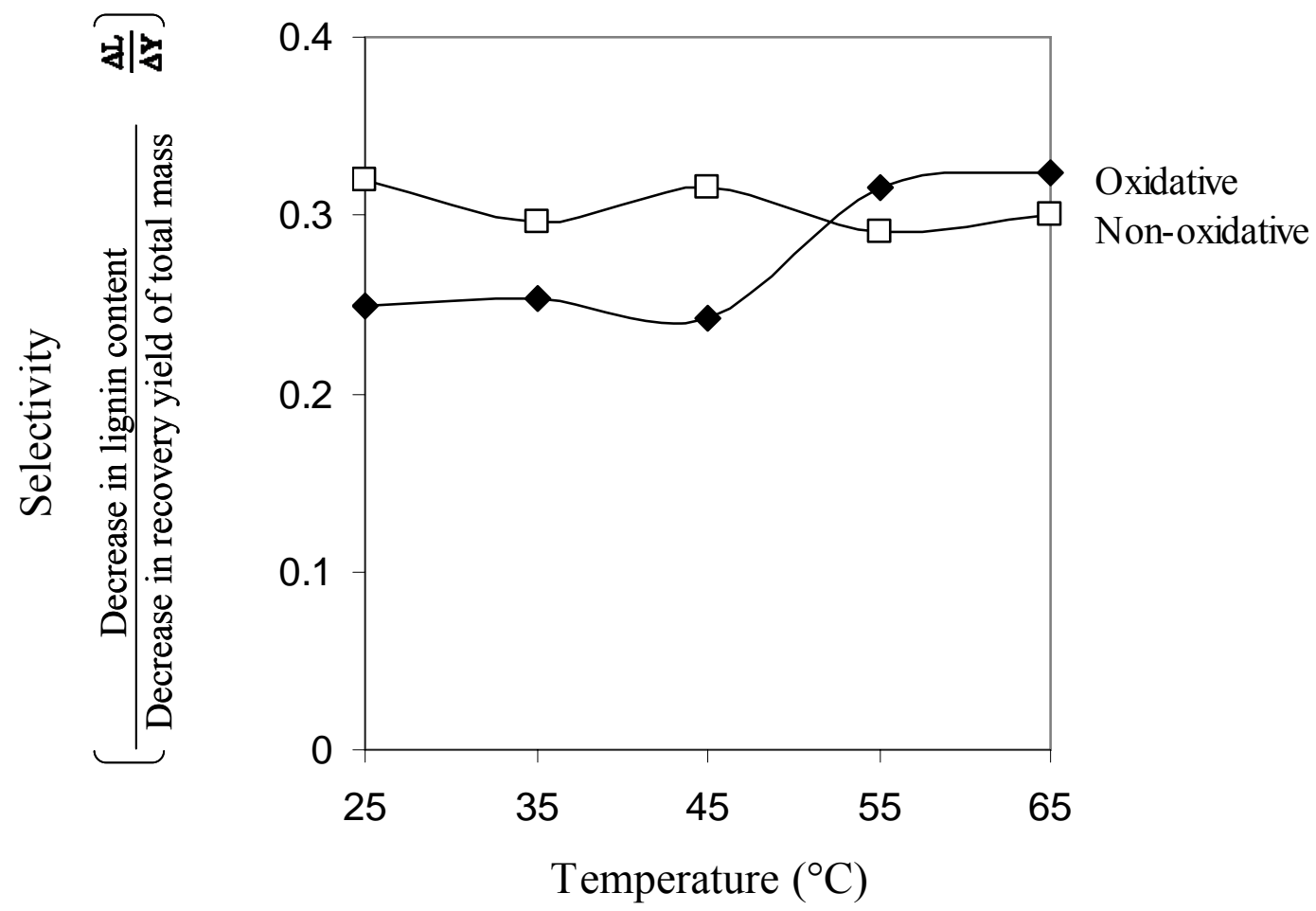

Fig. 30. Selectivity as a function of temperature and oxidative condition. 
a)
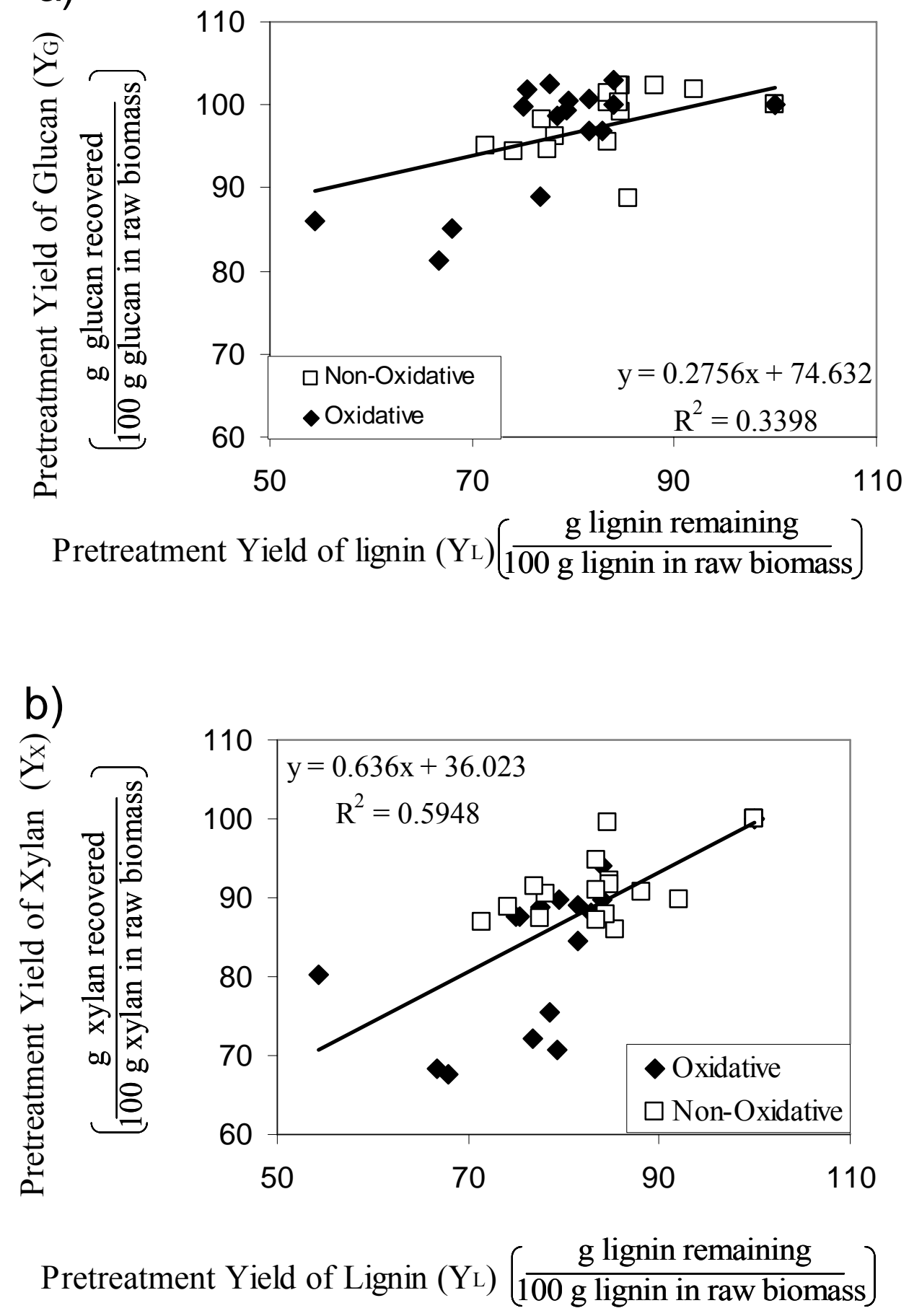

Fig. 31. Relation between pretreatment yield of lignin and pretreatment yield of carbohydrates. a) Cellulose case. b) Hemicellulose case. 
Furthermore, in the case of 4-week pretreatment, not only the analytical measurements were repeated but also the pretreatment itself in all conditions of oxidation and temperatures.

In the cases were the scales in the graph allow an error bar to be seen, it was plotted. For these and all other cases, the averages of the results and their respective standard deviation are presented in Appendix L.

\subsection{Conclusion}

Delignification and sugar degradation were the major contributors to the solubilization of biomass during pretreatment; however, the level of delignification of poplar wood after 4 weeks of oxidative pretreatment at mild temperatures was small compared to the results obtained after 4 weeks of lime pretreatment of other lignocellulose sources (Kim, 2004; Granda, 2004).

The acetyl removal was complete during the first week of pretreatment. The preservation of sugars was well accomplished. The impact of these results on the overall effectiveness of the long-term lime pretreatment of poplar wood must be determined by measuring enzymatic hydrolysis yields. 


\section{CHAPTER VII \\ ENZYMATIC HYDROLYSIS}

\subsection{Introduction}

In the traditional process of converting biomass to ethanol (Fig. 1), the pretreated biomass is hydrolyzed through the synergistic action of a complex mixture of enzymes to produce soluble monosacharides (glucose, xylose, arabinose, and mannose).

Several biomass features are considered important in effecting enzymatic digestibility: lignin content, the presence of acetyl groups, cellulose crystallinity, degree of polymerization, surface area/pore volume of cellulose fiber, and particle size (Converse et al., 1990; Sewalt et a.l, 1997; Wong et al., 1988). The focus of the pretreatment step is to methodically change these key features favoring enzymatic hydrolysis; however, researchers have reported conflicting results regarding the relationship between the features mentioned above and enzymatic hydrolysis yields. Attempts have been made to develop mathematical models that relate the chemical composition and physical characteristics of biomass with its enzymatic yields (Walseth, 1952; Sullivan, 1959; Mansfield et al., 1999; Chang and Holtzapple, 2000; Kong et al., 1992; Lee and Fan, 1982 O’Dwyer, 2005; Zhu, 2005). Unfortunately, even though these studies have been conducted since the 1950 s, there is not a conclusive, uniform result available.

The effectiveness of a pretreatment is often reported in terms of enzymatic digestibility rather than in terms of the chemical composition and physical characteristics of the biomass after pretreatment. Accordingly, this study includes exploratory research of enzymatic hydrolysis of long-term lime pretreated poplar wood as a tool to assess the pretreatment performance.

Efficient hydrolysis of lignocellulosic biomass requires the cooperative action of three types of enzymes collectively termed "cellulase": cellobiohydrolases (1,4- $\beta$-D-glucan cellobiohydrolase, exoglucanase), endoglucanases (endo-1,4- $\beta$-D-glucan 4glucanohydrolase), and cellobiase ( $\beta$-glucosidase). According to the widely accepted view, cellobiohydrolases act as exoglucanases, releasing cellobiose as the main product by attacking both the reducing and the non-reducing ends of the cellulose chain, 
endoglucanases cleave glycosidic bonds randomly along the cellulose chains, producing new binding sites for the cellobiohydrolases, and $\beta$-glucosidase hydrolyzes cellobiose to glucose and removes glucosyl residues from the nonreducing end of the soluble cellooligosaccharides (Medve et al., 1998; Srishdsuk et al., 1998).

\subsection{Materials and methods}

After pretreatment, in all conditions specified in Table 6, the biomass was neutralized (Appendix G), washed (Appendix $\mathrm{H}$ ), and stored wet in the freezer at $-20^{\circ} \mathrm{C}$. This biomass and the untreated biomass were the substrates for the enzymatic hydrolysis. The enzyme used, provided by NREL, was Spezyme ${ }^{\circledR}$ CP Genecor ${ }^{\circledR}$ Cellulase, lot \# 301-04075-054. It had an average activity of $59 \mathrm{FPU} / \mathrm{mL}$ as measured by NREL Standard Procedure "Measurement of Cellulase Activities" (FPU is defined on Appendix J)

Genecor International Inc., the company that produces the enzyme, reported enzyme activity of $82 \mathrm{GCU} / \mathrm{g}$ (minimum), where GCU stands for Genecor Cellulase Units. Their assay measures the amount of glucose released during the incubation of enzyme solution with a specified type of filter paper at $50^{\circ} \mathrm{C}$ in 60 minutes and is compared against an internal standard.

Also, NREL reported that the enzyme has a protein content of $123 \mathrm{mg} / \mathrm{mL}$ measured using the $\mathrm{BCA}^{\mathrm{TM}}$ protein assay which is a detergent-compatible formulation based on bicinchoninic acid (BCA) for the calorimetric detection and quantification of protein.

According to Coward-Kelly et al. (2003), the NREL assay used to measure enzyme activity lacks of precision due to inhibition of the enzyme by cellubiose. Thus, it is necessary to use a $0.5-\mathrm{mL}$ supplemental cellobiase loading during this experiment to relieve cellobiose inhibition. This method is important because it allows accurate comparisons between enzyme cocktails with inherently different activity; however, it is not a standard used assay. Based on this assay, the true enzyme activity was measured as 92 FPU/mL. To maintain uniformity with other members of the CAFI group, this last value was not used in any calculation and is referred to here for comparison purposes only. 
The enzyme loading to make comparable data among all members of the CAFI group was chosen to be $15 \mathrm{FPU} / \mathrm{g}$ glucan in the raw biomass.

In addition to Spezyme, $\beta$-glucosidase (Novozyme 188) activity $284 \mathrm{CBU} / \mathrm{g}$ (determined by Novo Nordisk Biochem) was added to complete the hydrolysis of cellobiose in an excess loading of $60 \mathrm{CBU} / \mathrm{g}$ cellulose.

The procedure to perform enzymatic hydrolysis was based on NREL Standard Method "Enzymatic saccharification of lignocellulosic biomass." A brief explanation follows: The appropriate amount of thawed substrate was mixed with sodium citrate buffer and antibiotics (tetracycline and cycloheximide) to prevent changes in $\mathrm{pH}$ and to avoid microbial growth, respectively. Water was added to complete $10 \mathrm{~mL}$ of mixture and it was preheated at $50^{\circ} \mathrm{C}$ in a rotary incubator (Amerex Instruments Inc, Laffayette, CA). The required quantity of enzymes to achieve a loading of $15 \mathrm{FPU} / \mathrm{g}$ glucan in raw biomass and $60 \mathrm{CBU} / \mathrm{g}$ glucan was added to the preheated mixture and the enzymatic hydrolysis occurred for a period of 72 hours. The concentration of glucan and xylan was measured by HPLC analysis using Aminex HPX-87P column (BioRad USA) and RI detector (Schambeck, SFD GMBH). The details on this procedure are in Appendix I.

\subsection{Total yield and hydrolysis yield}

The overall yields and hydrolysis yields have already been defined as (see Fig. 9 and pages 35 and 36):

Overall yield:

$$
\mathrm{Y}_{\mathrm{g}}^{\mathrm{T}}=\frac{A g}{A g+B g+C g} \text { and } \mathrm{Y}_{\mathrm{x}}^{\mathrm{T}}=\frac{A x}{A x+B x+C x}
$$

Hydrolysis yield:

$$
\mathrm{Y}_{\mathrm{g}}=\frac{A g}{A g+B g} \text { and } \mathrm{Y}_{\mathrm{x}}=\frac{A x}{A x+B x}
$$


They are related with the pretreatment yields of glucan and xylan $\left(\mathrm{Y}_{\mathrm{G}}\right.$ and $\mathrm{Y}_{\mathrm{X}}$ respectively) as: $Y^{T}{ }_{g}=Y_{G} \times Y_{g}$ and $Y^{T}{ }_{x}=Y_{X} \times Y_{x}$.

\subsection{Results and discussion}

Conditions of the pretreatment such as time, oxidation, and temperature strongly affected the biomass enzymatic digestibility. Glucan and xylan hydrolysis yields consistently increased with time and temperature and were more significant for the oxidative condition. The results are summarized in Figs. 32 to 35 .

Figs. 36 to 41 show results for overall yields. Increase of temperature increased the yields, but for the overall yield of xylan almost no difference was observed between the oxidative and non-oxidative condition up to $55^{\circ} \mathrm{C}$. The effect of the oxidation was important for the overall yield of xylan at $65^{\circ} \mathrm{C}$ and for all the overall yields of glucan. The most important overall yield of glucan was $80.7 \mathrm{~g}$ glucan hydrolyzed/100 g glucan in raw biomass (equivalent to a hydrolysis yield of $94.0 \mathrm{~g}$ glucan hydrolyzed/100 g glucan in treated biomass) and was obtained for the 4 -week pretreatment at $65^{\circ} \mathrm{C}$ and oxidative condition. Kim (2004) reported an overall yield of $91.3 \mathrm{~g}$ glucan hydrolyzed/100 g glucan in raw biomass for corn stover lime pretreated in oxidative condition for 4 weeks at $55^{\circ} \mathrm{C}$. Therefore, the results obtained in this study show that poplar wood is more recalcitrant than corn stover. This low hydrolysis yields result because a significant amount of lignin was not removed in the lime pretreatment.

Presumably, the presence of large amounts of lignin interfere with the direct physical contact between enzyme and cellulose required to effectively accomplish enzymatic hydrolysis. However, the tendency is for digestibility to increase with pretreatment time and temperature. The rate is still significant because the slope in the plots of enzymatic hydrolysis yield vs pretreatment time is high. Consequently, further study must be completed for longer pretreatment times and higher temperatures.

For xylan, the most important overall yield was $66.9 \mathrm{~g}$ xylan hydrolyzed/100 $\mathrm{g}$ xylan in raw biomass (equivalent to a hydrolysis yield of $83.5 \mathrm{~g}$ xylan hydrolyzed/100 $\mathrm{g}$ xylan in treated biomass) and was obtained for the 4 -week pretreatment at $65^{\circ} \mathrm{C}$ and oxidative condition. 
a)

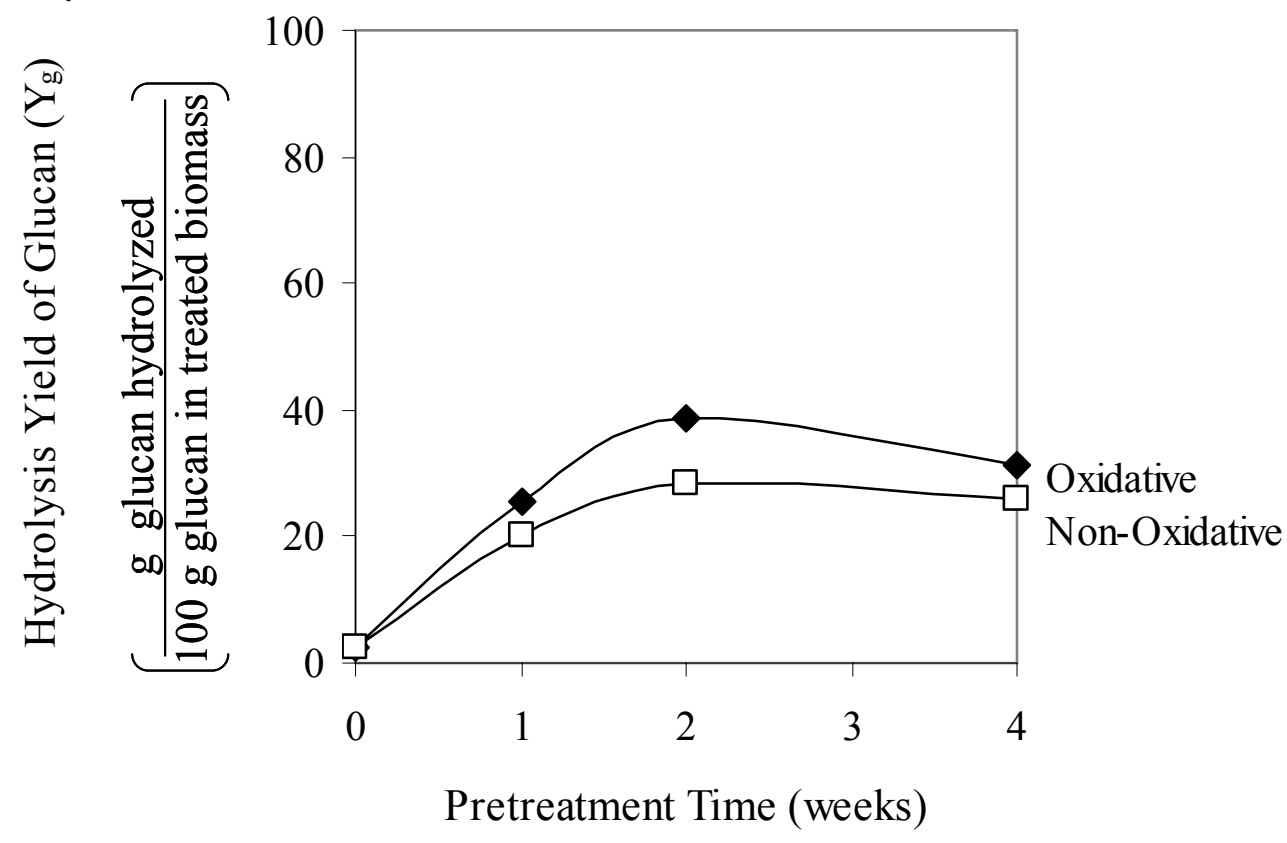

b)

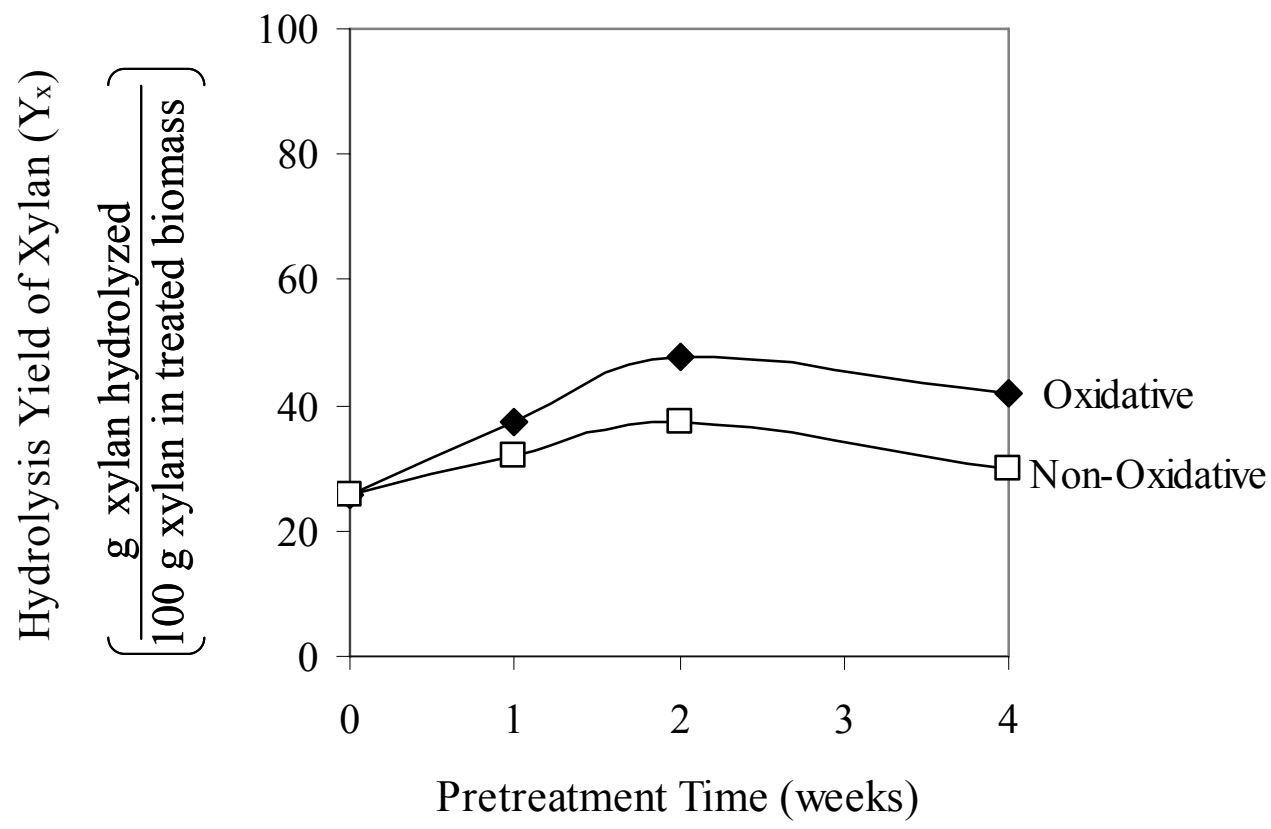

Fig. 32. Hydrolysis yields of a) glucan and b) xylan for pretreated poplar wood in oxidative and non-oxidative conditions at $25^{\circ} \mathrm{C}$. 
a)

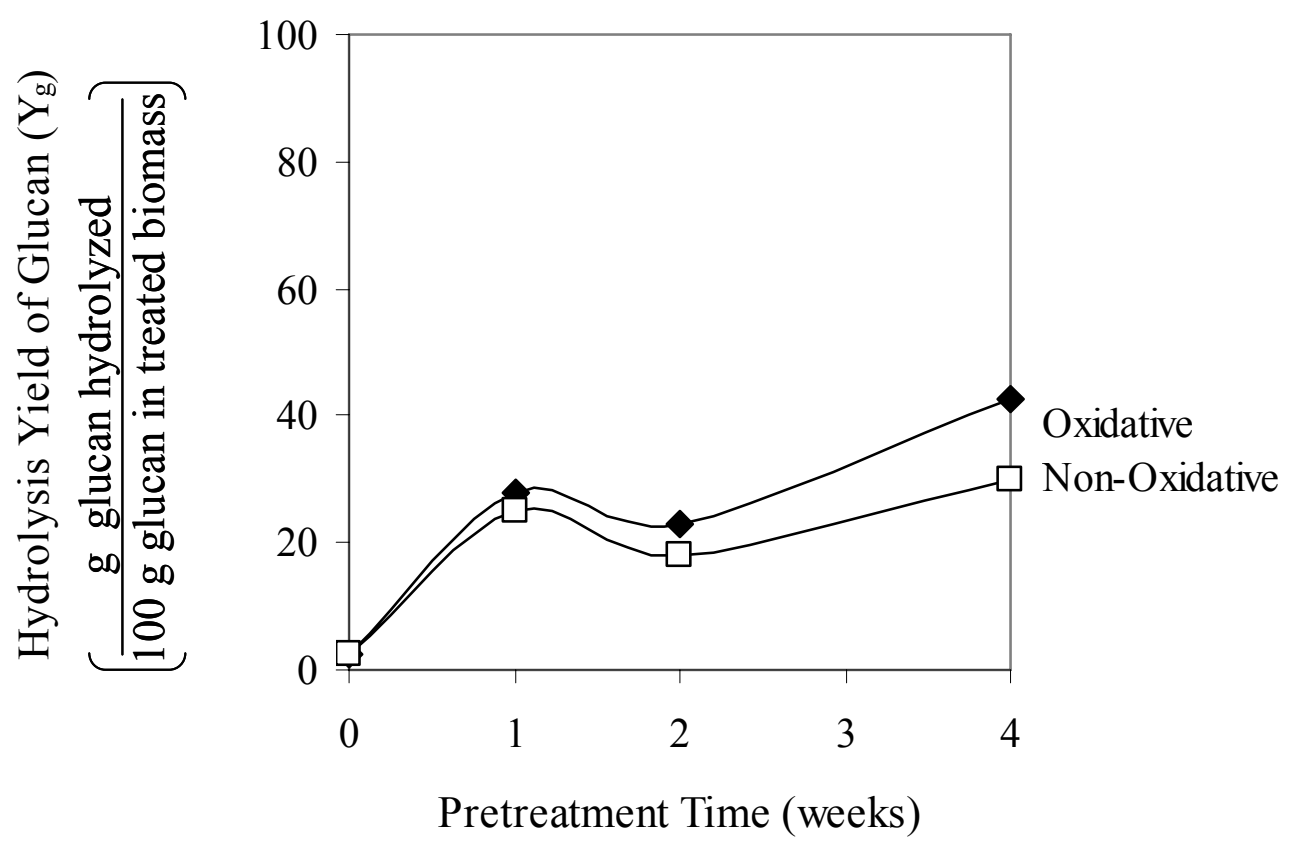

b)

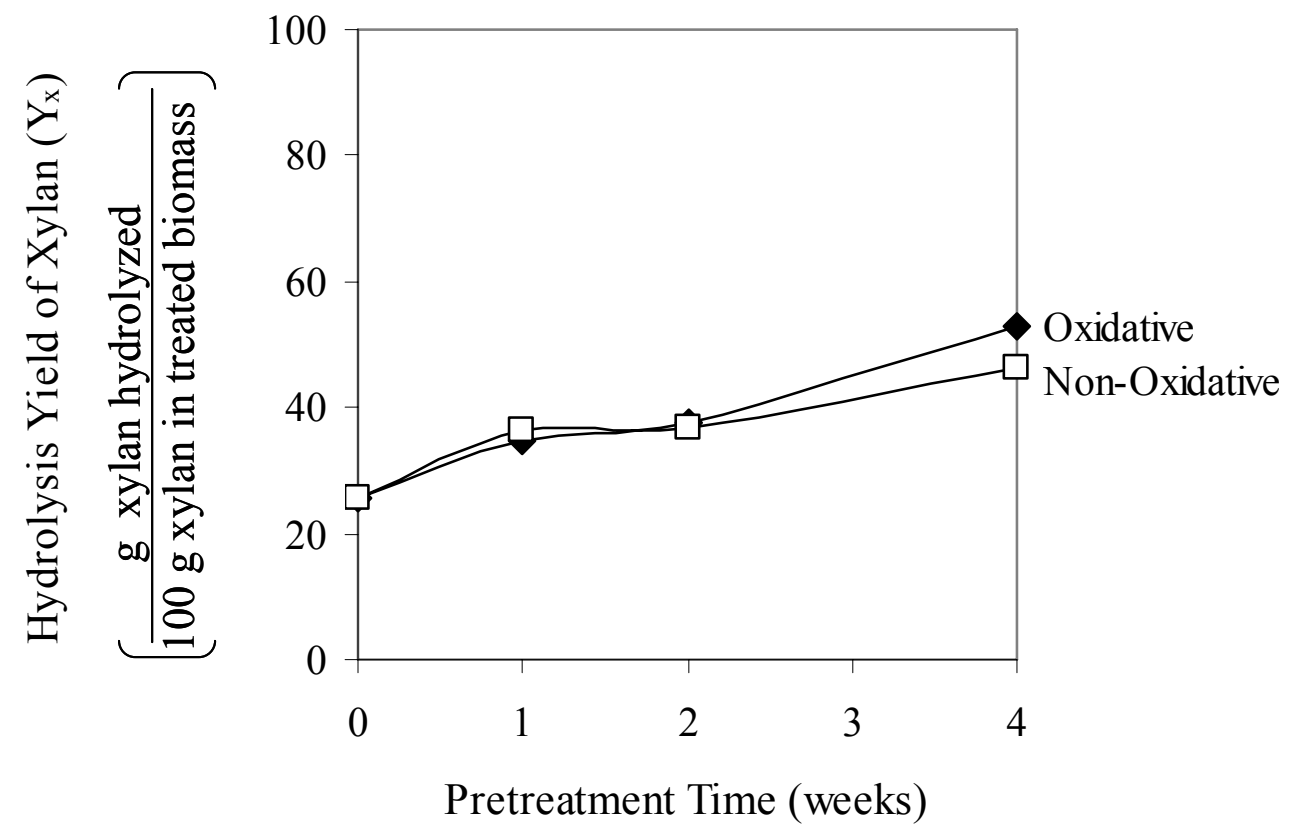

Fig. 33. Hydrolysis yields of a) glucan and b) xylan for pretreated poplar wood in oxidative and non-oxidative conditions at $35^{\circ} \mathrm{C}$. 
a)

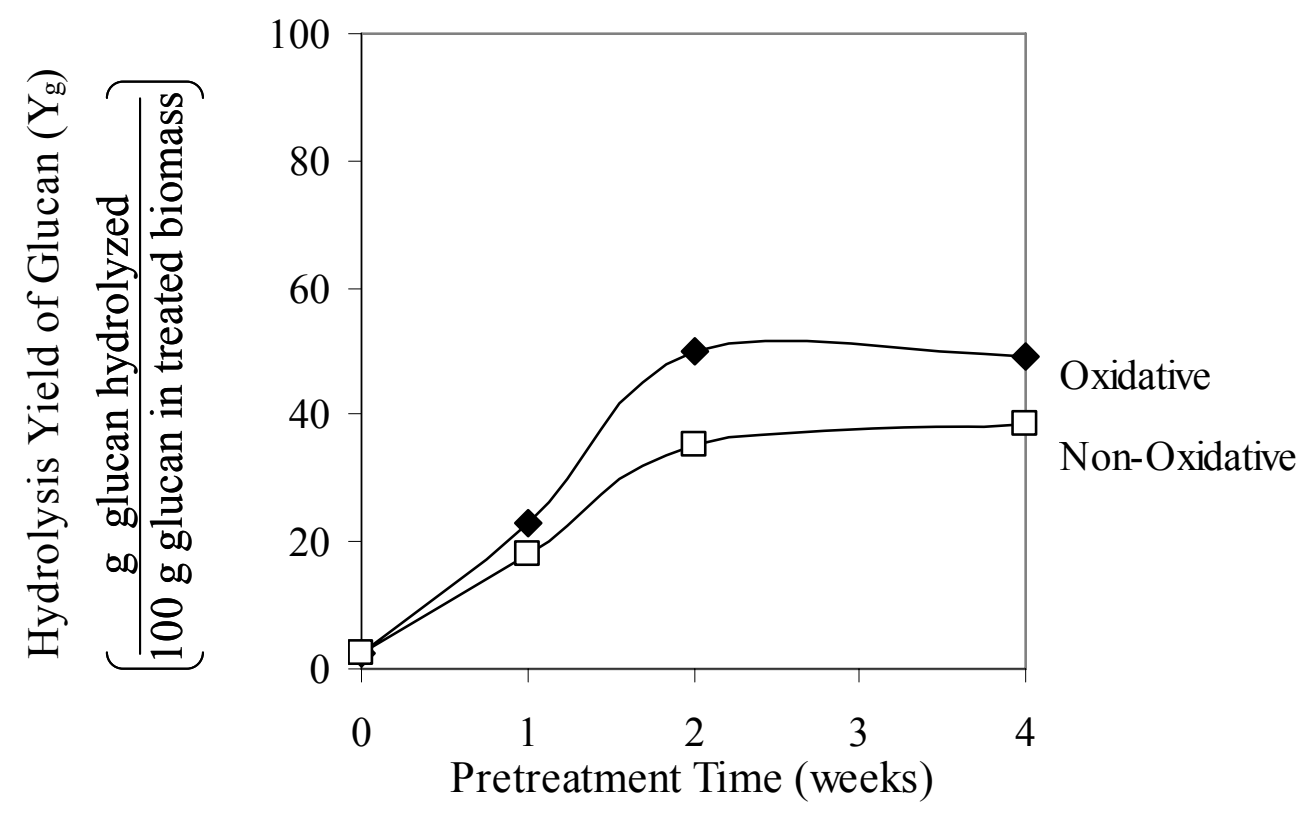

b)

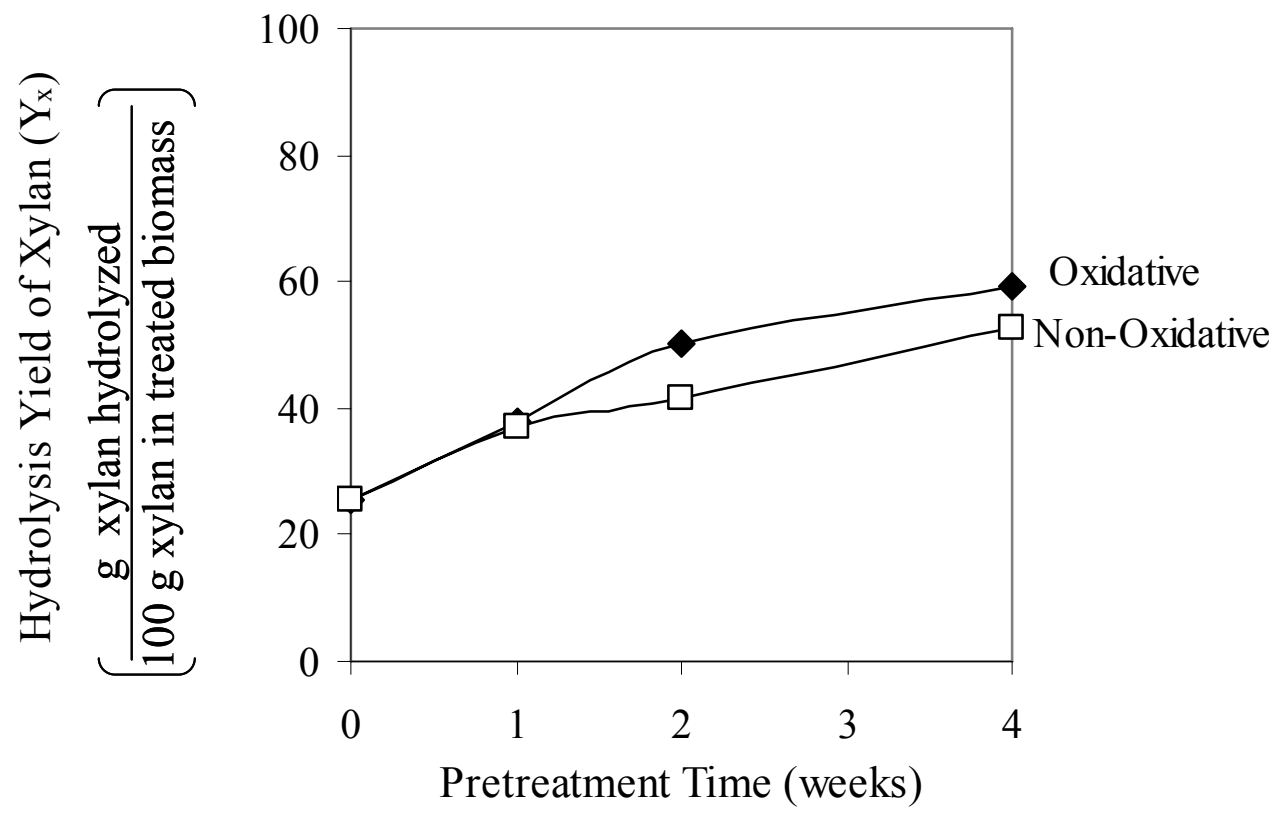

Fig. 34. Hydrolysis yields of a) glucan and b) xylan for pretreated poplar wood in oxidative and non-oxidative conditions at $45^{\circ} \mathrm{C}$. 
a)

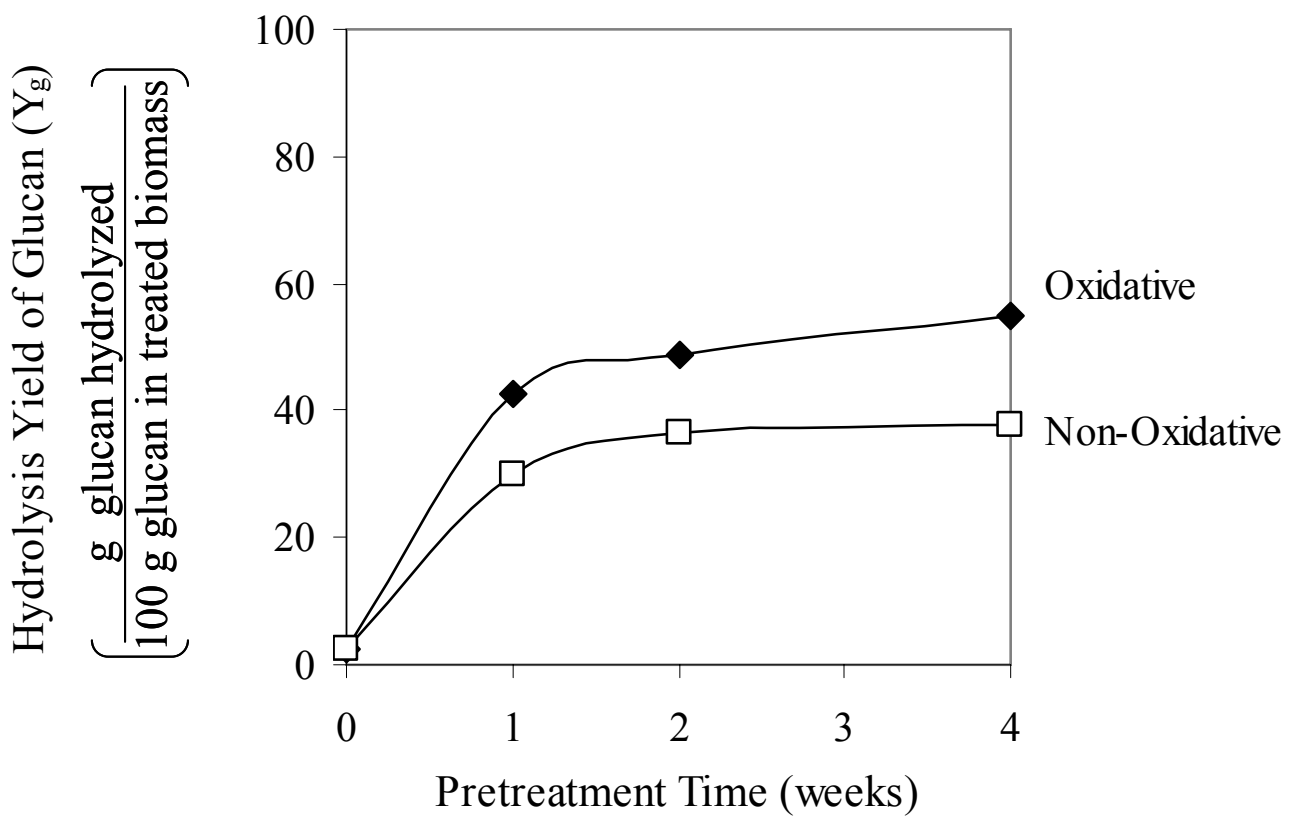

b)

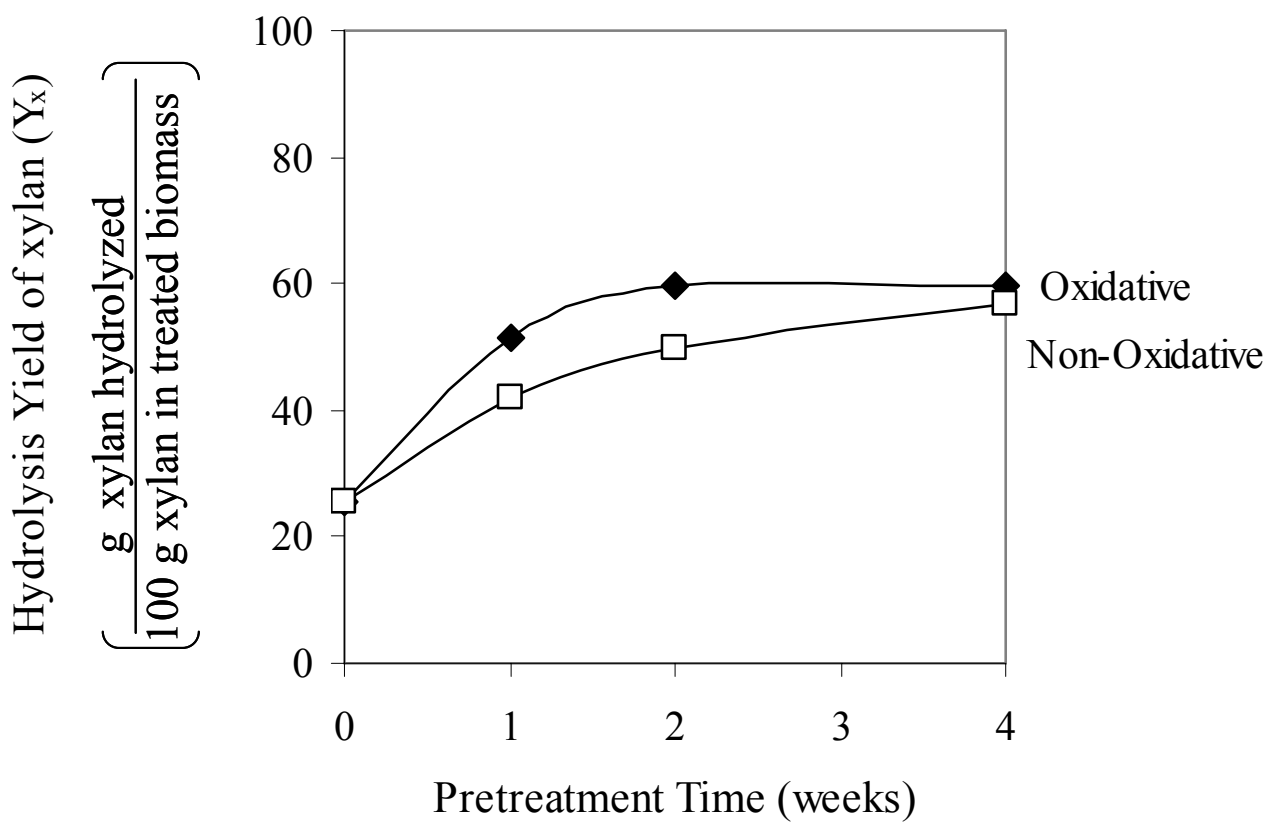

Fig. 35. Hydrolysis yields of a) glucan and b) xylan for pretreated poplar wood in oxidative and non-oxidative conditions at $55^{\circ} \mathrm{C}$. 
a)

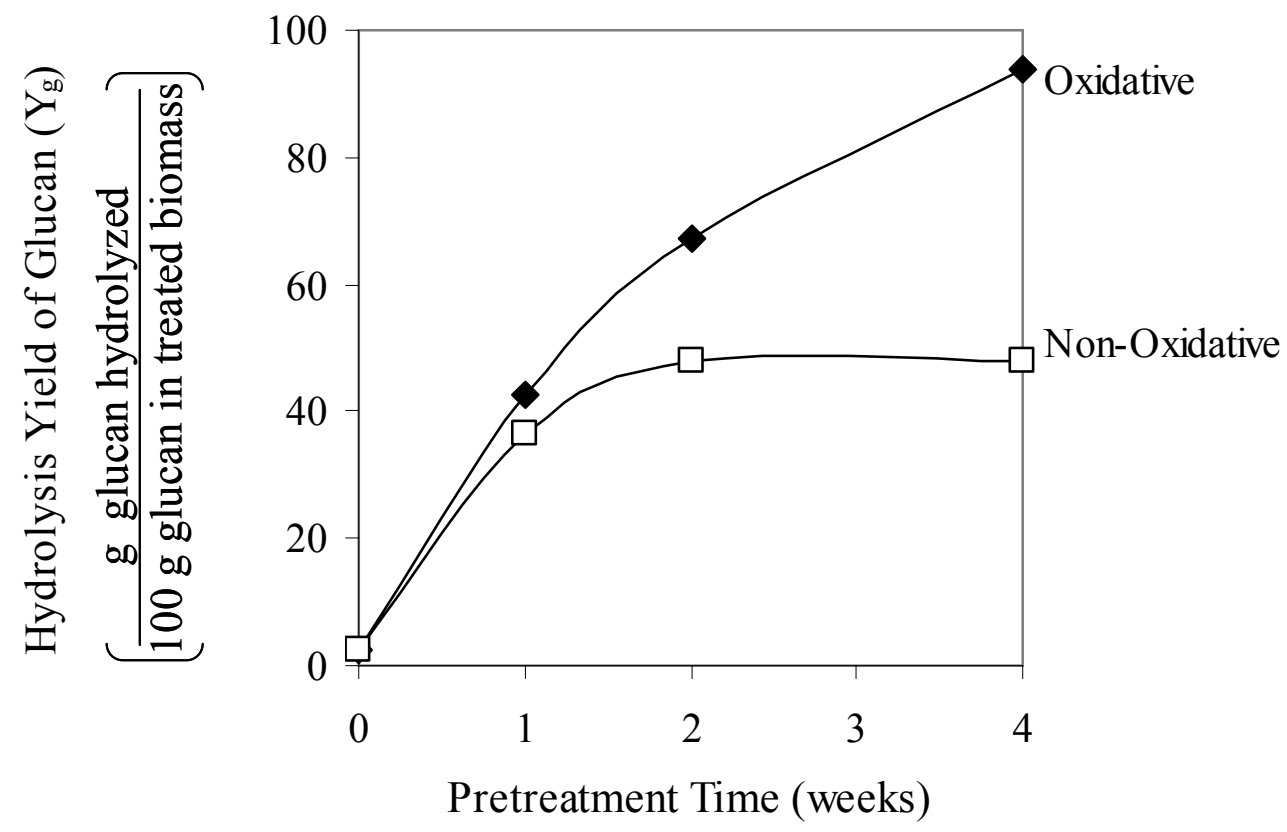

b)

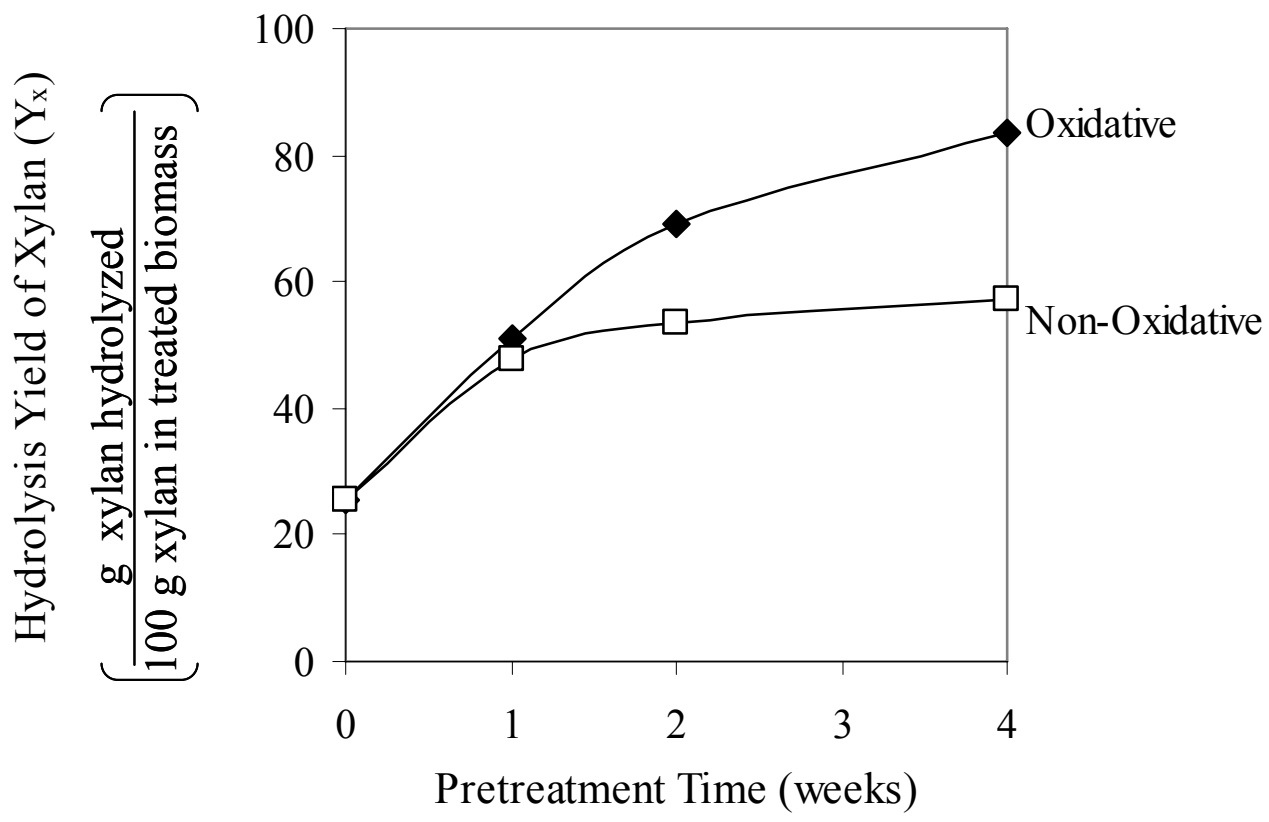

Fig. 36. Hydrolysis yields of a) glucan and b) xylan for pretreated poplar wood in oxidative and non-oxidative conditions at $65^{\circ} \mathrm{C}$. 
a)

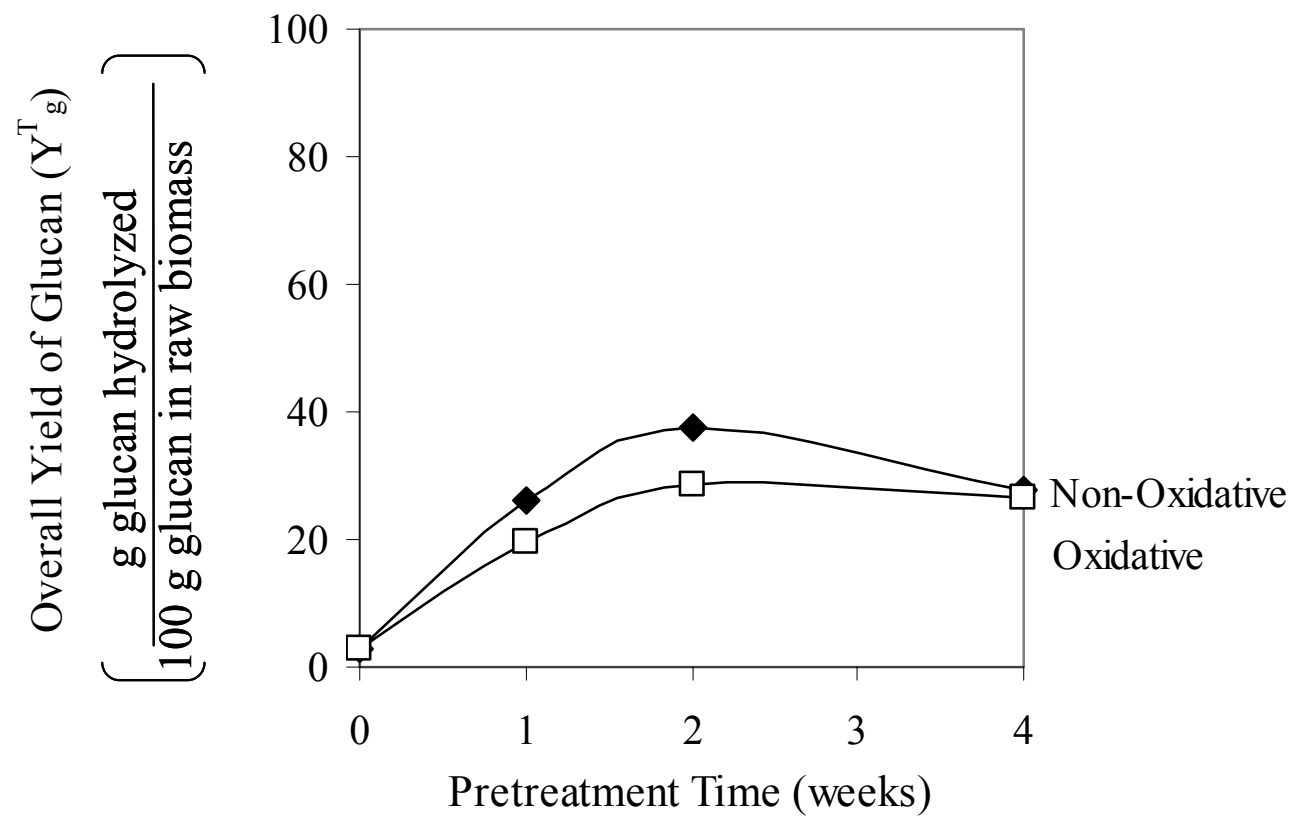

b)
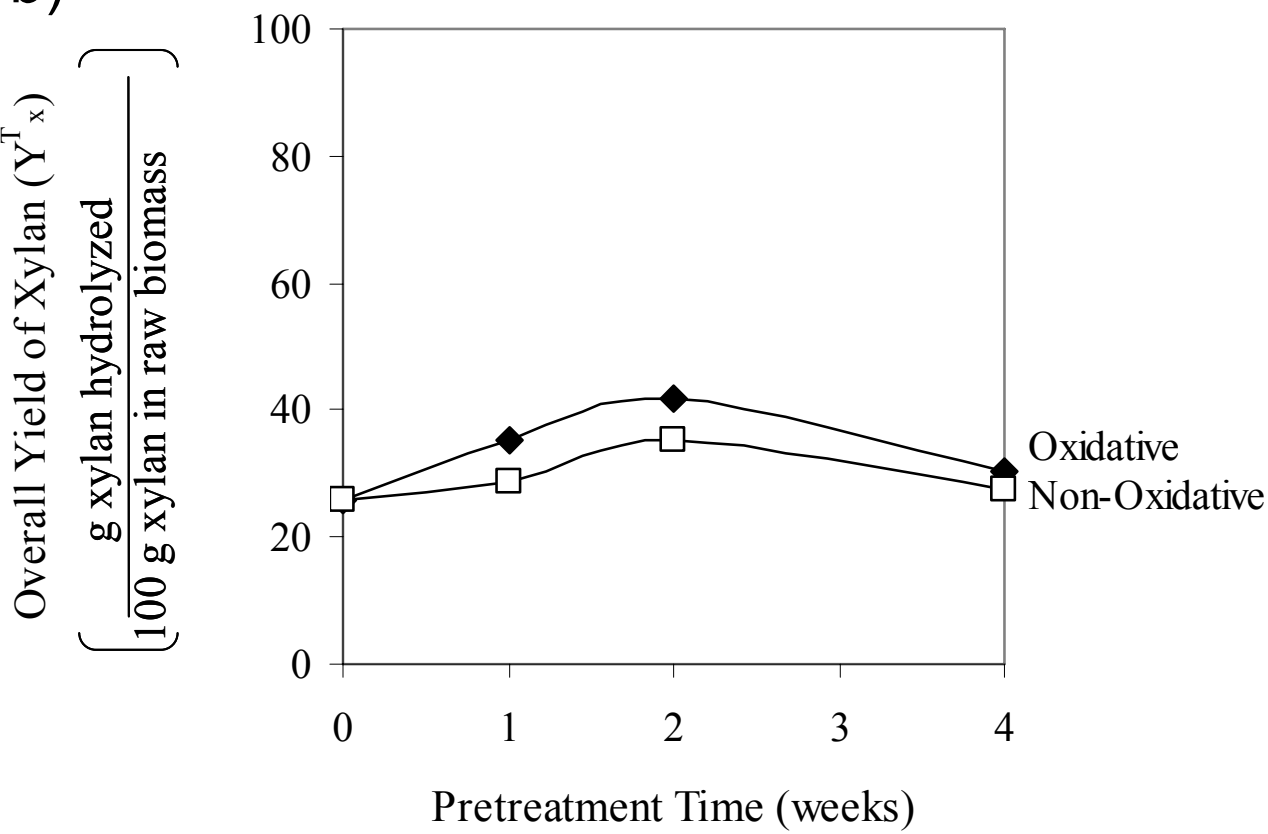

Fig. 37. Overall yields of a) glucan and b) xylan for pretreated poplar wood in oxidative and non-oxidative conditions at $25^{\circ} \mathrm{C}$. 
a)

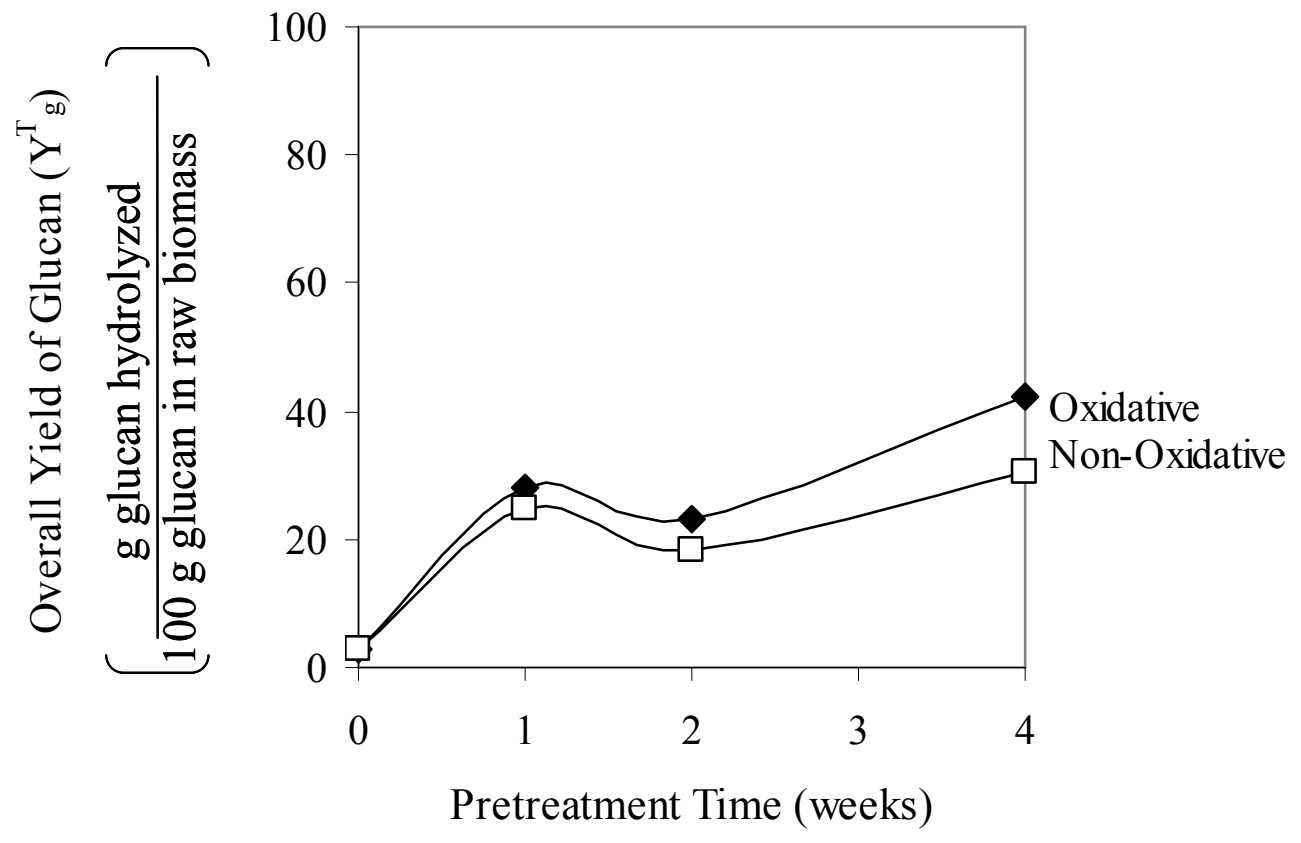

b)
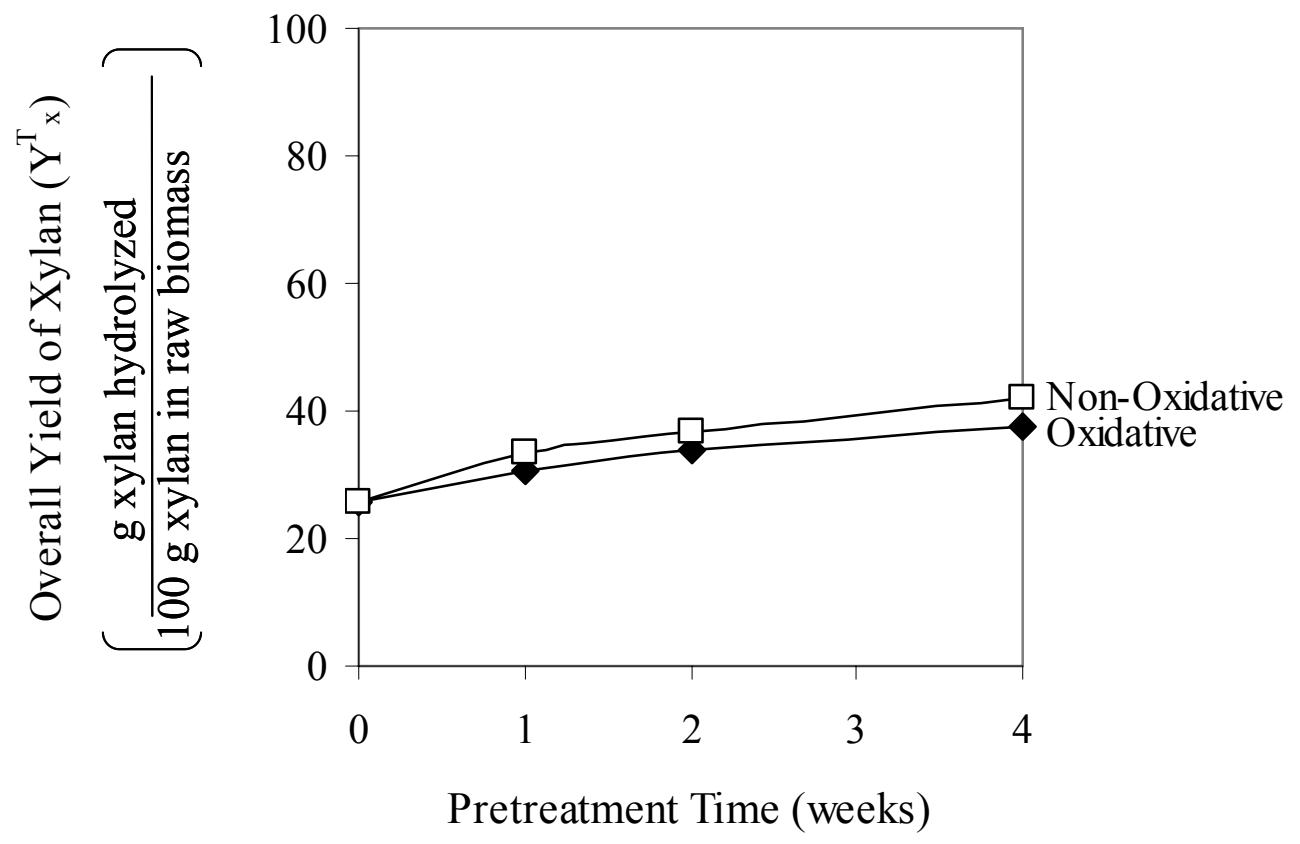

Fig. 38. Overall yields of a) glucan and b) xylan for pretreated poplar wood in oxidative and non-oxidative conditions at $35^{\circ} \mathrm{C}$. 
a)
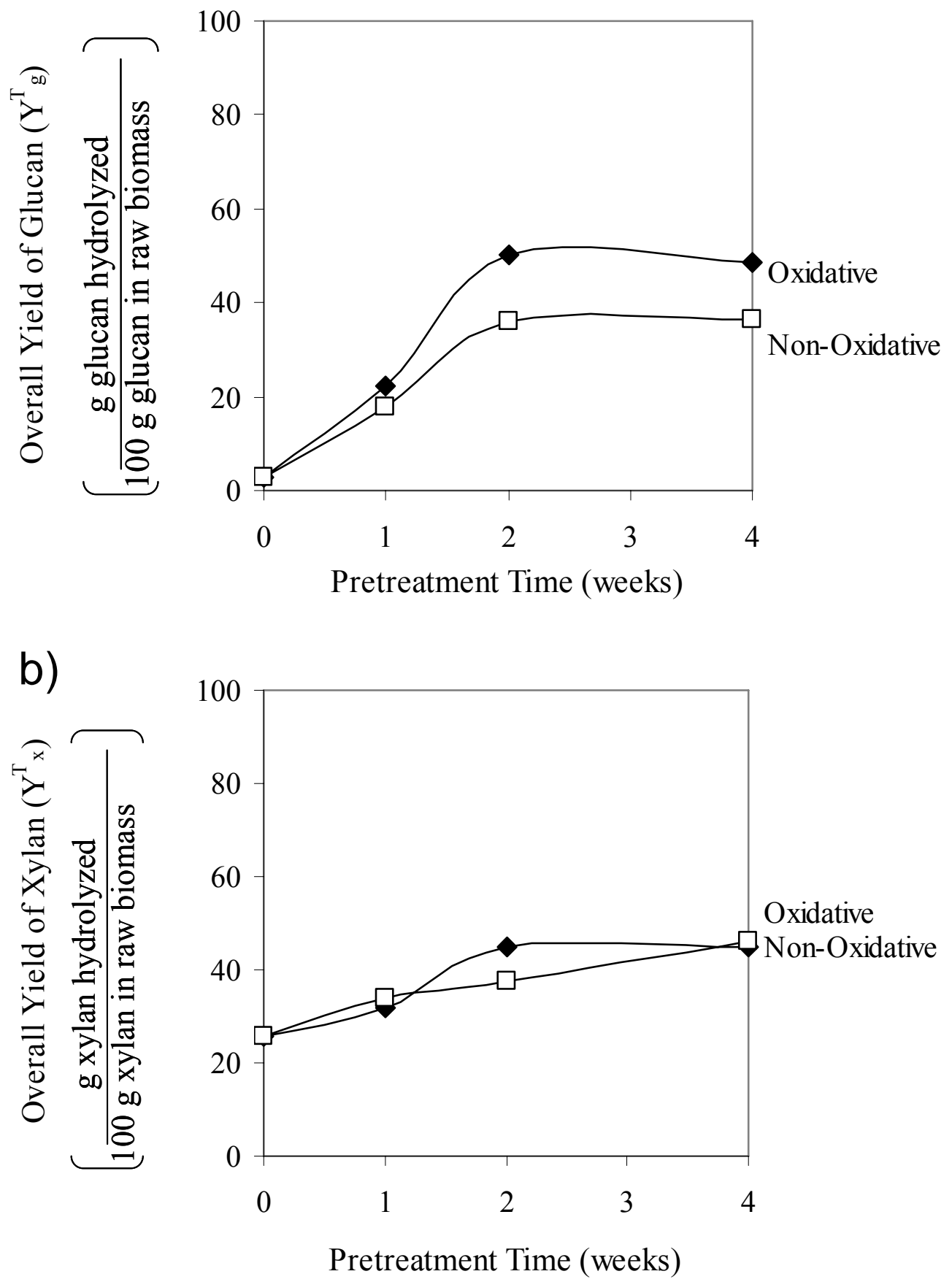

Fig. 39. Overall yields of a) glucan and b) xylan for pretreated poplar wood in oxidative and non-oxidative conditions at $45^{\circ} \mathrm{C}$. 
a)

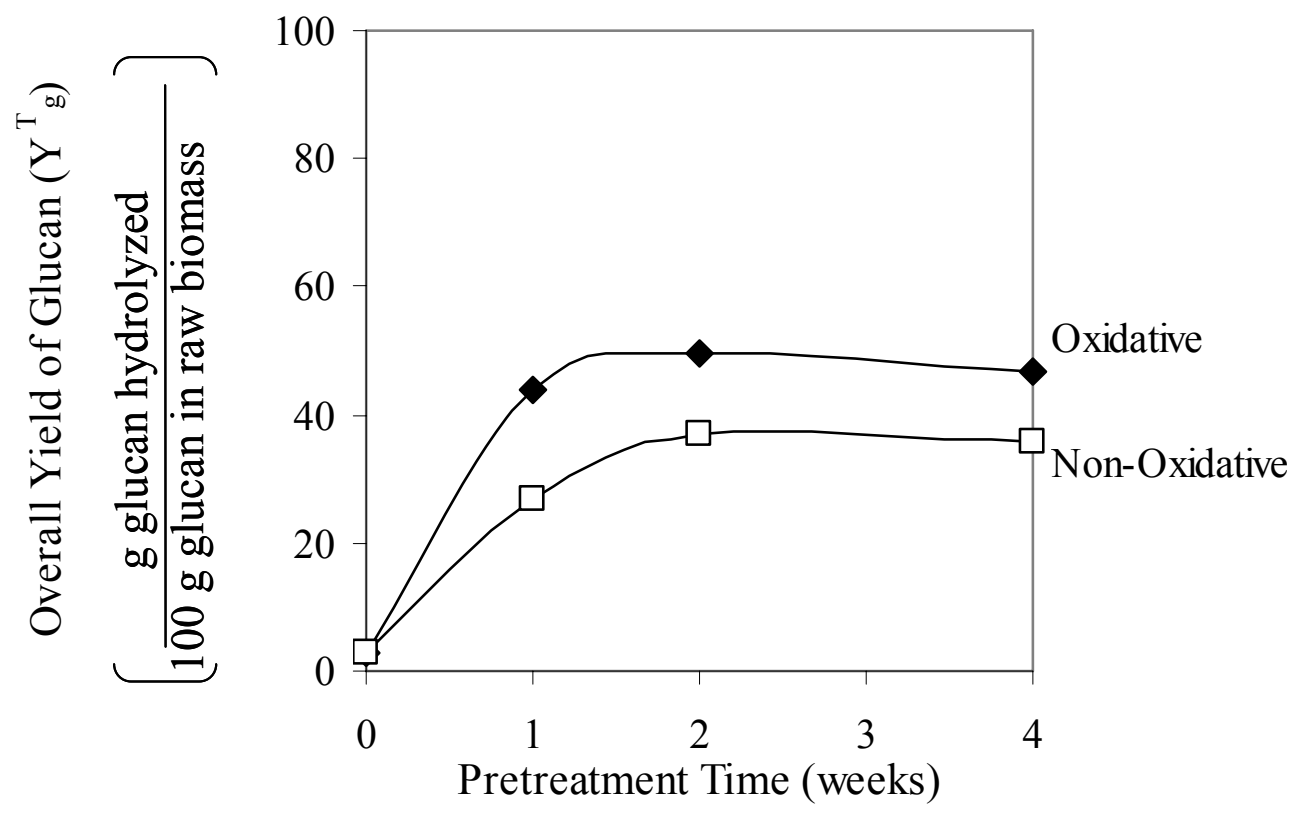

b)

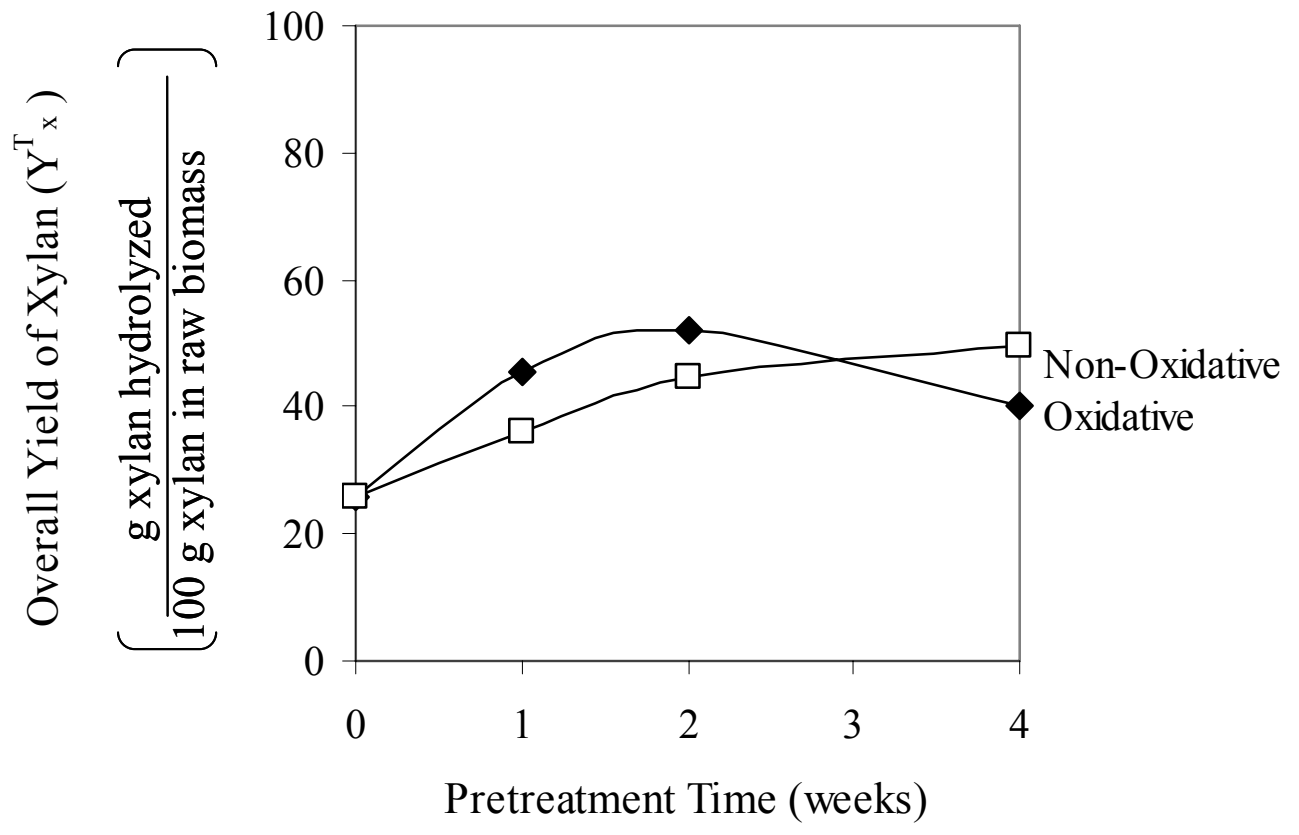

Fig. 40. Overall yields of a) glucan and b) xylan for pretreated poplar wood in oxidative and non-oxidative conditions at $55^{\circ} \mathrm{C}$. 
a)

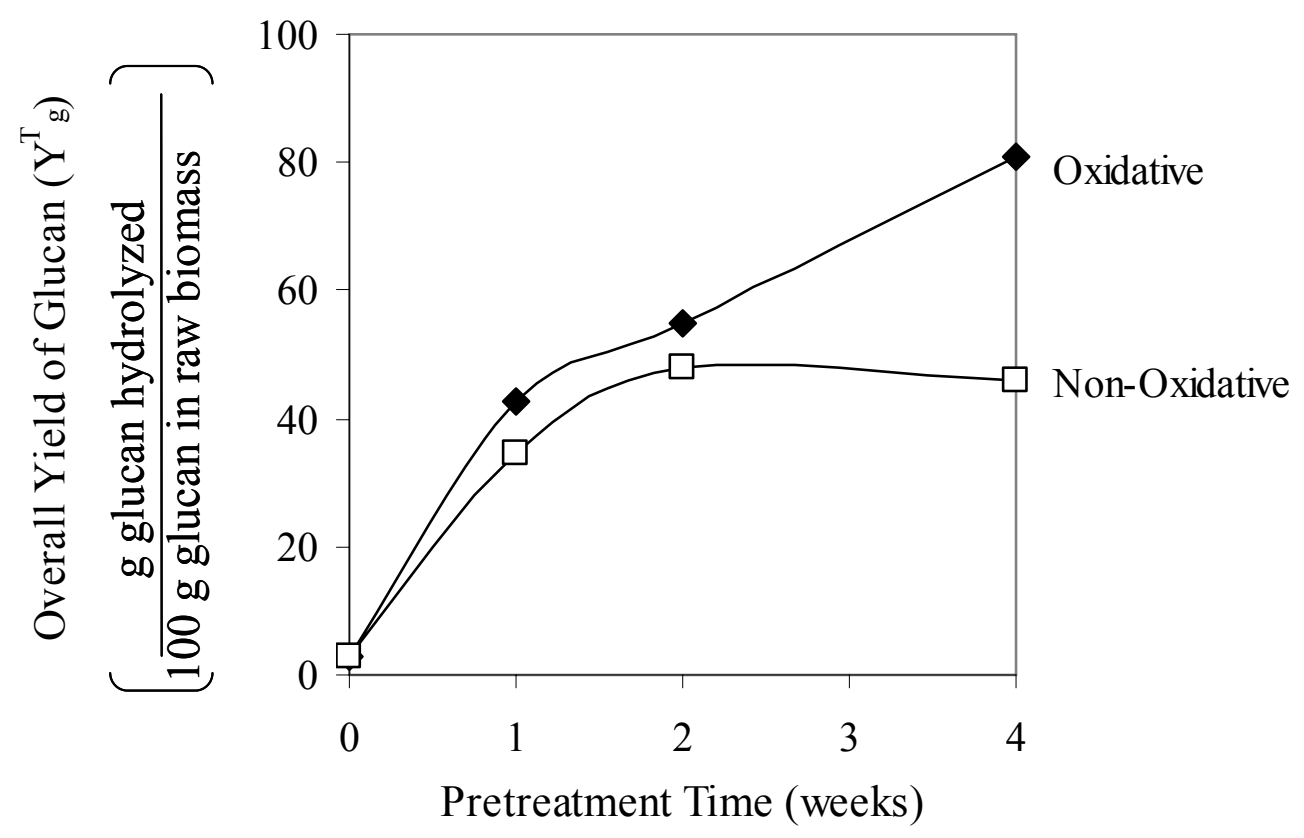

b)

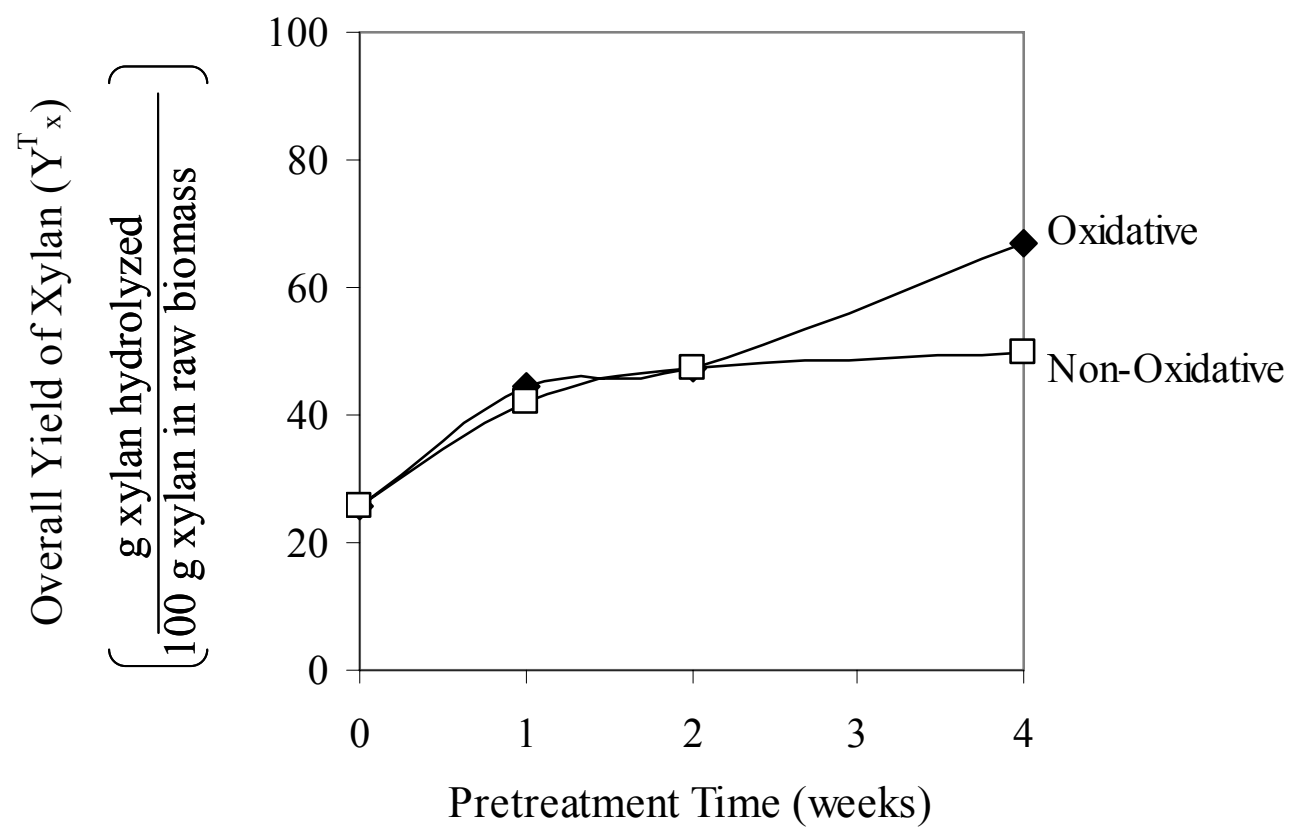

Fig. 41. Overall yields of a) glucan and b) xylan for pretreated poplar wood in oxidative and non-oxidative conditions at $65^{\circ} \mathrm{C}$. 
Interestingly, Kim (2004) reported a lower overall yield of $51.8 \mathrm{~g}$ xylan hydrolyzed/100 g xylan in raw biomass for corn stover lime pretreated in oxidative conditions for 4 weeks at $55^{\circ} \mathrm{C}$.

\subsection{Conclusion}

The enzymatic digestibility (glucan and xylan yields) of long-term lime pretreated poplar wood is directly related to pretreatment variables such as time, oxidative condition, and temperature. The optimum pretreatment condition has not yet been determined, but it is expected to be a high-temperature, oxidative condition with pretreatment time of more than 4 weeks. 


\section{CHAPTER VIII \\ CONCLUSION AND FUTURE STUDIES}

Long-term lime pretreatment of poplar wood was evaluated at $25,35,45,55$, and $65^{\circ} \mathrm{C}$ and pretreatment times of $0,1,2$, and 4 weeks in oxidative and non-oxidative conditions.

In general, oxidative pretreatment showed more sugar degradation but also more lignin removal than non-oxidative pretreatment. Xylan was less preserved than glucan and xylan degradation was more related with lignin removal. The most important pretreatment yield of lignin was $54 \mathrm{~g}$ lignin remaining/100 $\mathrm{g}$ lignin in raw biomass, and was accomplished for the 4-week lime pretreatment at $65^{\circ} \mathrm{C}$ and oxidative conditions. The corresponding pretreatment yield of glucan was $85.9 \mathrm{~g}$ glucan recovered/100 g glucan in raw biomass and pretreatment yield of xylan was $80.2 \mathrm{~g}$ xylan recovered/100 $\mathrm{g}$ xylan in raw biomass. A lower pretreatment yield of xylan was observed for 4 -week pretreatment at $55^{\circ} \mathrm{C}$. It was $67.6 \mathrm{~g}$ xylan recovered/100 $\mathrm{g}$ xylan in raw biomass.

The 3-day enzymatic hydrolysis, assessed with an enzyme loading of $15 \mathrm{FPU} / \mathrm{g}$ glucan in raw biomass, showed the most important overall yield and hydrolysis yield of glucan for the 4 -week pretreatment at $65^{\circ} \mathrm{C}$. The results were $80.7 \mathrm{~g}$ glucan hydrolyzed $/ 100 \mathrm{~g}$ glucan in raw biomass corresponding to $94.0 \mathrm{~g}$ glucan hydrolyzed/100 g glucan in treated biomass respectively. The overall and hydrolysis yields of xylan for the same pretreatment condition were $66.9 \mathrm{~g}$ xylan hydrolyzed/100 g xylan in raw biomass and $85.3 \mathrm{~g}$ xylan hydrolyzed/100 g xylan in treated biomass respectively.

It is important to compare all these results with the results obtained in the study performed by Kim (2004) on corn stover, because in both of these studies, the biomass was submitted to the same pretreatment and the same assays and methodology of reporting results were used. The comparison is very meaningful and help to understand the adaptability of long-term lime pretreatment to different feedstocks. In the case of poplar wood, it was required more severe conditions of pretreatment, since it is harder to delignify, this feature motivated an increase of temperature up to $65^{\circ} \mathrm{C}$ in opposition to a highest temperature of $55^{\circ} \mathrm{C}$ in the corn stover case.

For corn stover lime pretreated at $55^{\circ} \mathrm{C}$ in oxidative conditions, Kim (2004) reported a higher overall yield of glucan (91.3 g glucan hydrolyzed/100 g glucan in raw biomass) and 
a lower overall yield of xylan (51.8 g xylan hydrolyzed/100 g xylan in raw biomass). The corresponding hydrolysis yields were $91 \mathrm{~g}$ glucan hydrolyzed/100 g glucan in treated biomass and $52 \mathrm{~g}$ xylan hydrolyzed/100 g xylan in treated biomass respectively. This corn stover had a pretreatment yield of lignin of about $30 \mathrm{~g}$ lignin remaining/100 $\mathrm{g}$ lignin in raw biomass, pretreatment yield of glucan $93 \mathrm{~g}$ glucan recovered/100 g glucan in raw biomass and pretreatment yield of xylan $75 \mathrm{~g}$ xylan recovered/100 g xylan in raw biomass. (Table $8)$.

More lignin was removed and less carbohydrates were degraded during pretreatment in the corn stover case, ending with the same pretreatment yield as in the case of poplar wood where less lignin was removed but more carbohydrates were degraded.

Interestingly, the hydrolysis yields of glucan were not very different, and the results in the case of poplar wood are very promising because it is shown that even though the lignin content is still very high, the hydrolysis can be performed in an acceptable extend.

However, the overall yield of glucan is significantly lower for poplar wood. The difference is due to the low pretreatment yield of glucan in the poplar wood case, however it is not known if the glucan solubilized during pretreatment is still useful (not degraded). Very high yields of xylan were observed for poplar wood. Consequently, long-term lime pretreatment of poplar wood shows promising for woody biomass such as poplar wood, but it is necessary to include in the mass balances the carbohydrates solubilized in the pretreatment liquor to conclude if the overall yields are higher. Additionally the following studies must be performed:

1. Find an optimum condition of pretreatment evaluated in terms of maximum digestibility of cellulose. To accomplish this goal, it is necessary to

a) Pretreat poplar wood for longer times, because the cellulose yields have been shown to still increase at appreciable rates.

b) Pretreat poplar wood at little higher temperatures (e.g., $75^{\circ} \mathrm{C}$ ).

c) Pretreat other batches of poplar wood for comparison.

2. The effect of cellulase was evaluated at only one enzyme loading. It is necessary to determine the effect of cellulase and hemicellulase loadings on sugar yields from hemicellulose and cellulose to define the best conditions. 
3. Develop models to relate digestibility of cellulose and hemicellulose to chemical and physical characteristics of pretreated poplar wood.

4. Define conditions for hydrolysis and fermentation methods to realize high yields of ethanol from hemicellulose. 
Table 8

Comparation between this study and a previous study on long term pretreatment of corn stover (Kim, 2004).

See explanations and definitions of yields on pages 32 to 36

\begin{tabular}{|l|c|c|}
\hline \multicolumn{1}{|c|}{$\begin{array}{c}\text { 4-week Long-Term Lime Pretreatment in oxidative } \\
\text { conditions }\end{array}$} & $\mathbf{6 5}^{\mathbf{0}} \mathbf{C}$ & $\mathbf{5 5}^{\mathbf{0}} \mathbf{C}$ \\
\hline Feedstock & Poplar wood & Corn Stover \\
\hline Recovery yield of total mass (Pretreatment yield, $\left.\mathrm{Y}_{\mathrm{p}}\right)$ & 71 & 70 \\
\hline $\begin{array}{l}\text { Pretreatment yield of lignin }\left(\mathrm{Y}_{\mathrm{L}}\right) \\
\text { g lignin remaining/100 g lignin in raw biomass }\end{array}$ & 86 & 30 \\
\hline $\begin{array}{l}\text { Pretreatment yield of glucan }\left(\mathrm{Y}_{\mathrm{G}}\right) \\
\text { g glucan recovered/100 g glucan in raw biomass }\end{array}$ & $80^{(1)}$ & 75 \\
\hline $\begin{array}{l}\text { Pretreatment yield of xylan }\left(\mathrm{Y}_{\mathrm{X}}\right) \\
\text { g xylan recovered/100 g xylan in raw biomass }\end{array}$ & 94 & 97 \\
\hline $\begin{array}{l}\text { Hydrolysis yield of glucan }\left(\mathrm{Y}_{\mathrm{g}}\right) \\
\text { g glucan hydrolyzed/100 g glucan in treated biomass }\end{array}$ & 85 & 75 \\
\hline $\begin{array}{l}\text { Hydrolysis yield of xylan }\left(\mathrm{Y}_{\mathrm{x}}\right) \\
\text { g xylan hydrolyzed/100 g xylan in treated biomass }\end{array}$ & 81 & 91 \\
\hline $\begin{array}{l}\text { Overall yield of glucan }\left(\mathrm{Y}_{\mathrm{g}}^{\mathrm{T}} \text { ) }\right. \\
\text { g glucan hydrolyzed/100 g glucan in raw biomass }\end{array}$ & 67 & 52 \\
\hline $\begin{array}{l}\text { Overall yield of xylan }\left(\mathrm{Y}_{\mathrm{x}}^{\mathrm{T}} \text { ) }\right. \\
\text { g xylan hydrolyzed/100 g xylan in raw biomass }\end{array}$ & & \\
\hline
\end{tabular}

(1) A lower pretreatment yield of xylan was observed at $55^{\circ} \mathrm{C}$. The value was $67.6 \mathrm{~g}$ xylan recovered/100 g xylan in raw biomass. 


\section{REFERENCES}

Aden, A., Ruth, M., Ibsen, K., Jechura, J., Neeves, K., Sheehan, J., Wallace, B., Montague, L., Slayton, A., Lukas, J., 2002. Lignocellulosic biomass to ethanol process design and economics utilizing co-current dilute acid prehydrolysis and enzymatic hydrolysis for corn stover. NREL Technical Report 510-32438. National Renewable Energy Laboratory. Golden, Colorado.

Alén, R., 2000. Basic chemistry of wood delignification. Forest Products Chemistry. Per Stenius, (Eds.), Helsinki: Fapet Oy.

Blasig, J.D., Holtzapple, M.T., Dale, B.E., Engler, C.R., and Byersm, F.M., 1992. Resource conservative recycling 7, 95-114.

Brown, R., 2003. The Biorenewable resource base. In: Biorenewable resources. Iowa State Press.

Chadha, B.S., Kanwar, S.S., Saini, H.S., Garcha, H.S., 1995. Hybrid process for ethanol production from rice straw. Acta Microbiologica et Immunologica Hungarica, 42(1), $53-59$.

Chang, V.S., Burr, B., Holtzapple, M.T., 1997. Lime pretreatment of switchgrass. Applied Biochemistry and Biotechnology. 63-65, 3-19.

Chang, V.S., Nagwani, M., Holtzapple, M.T., 1998. Lime pretreatment of crop residues: bagasse and wheat straw. Applied Biochemistry and Biotechnology. 74(3), 135-159.

Chang V.S., 1999. Lime pretreatment of lignocellulosic biomass. Ph.D. Dissertation. Texas A\&M University, College Station, TX.

Chang V.S., Holtzapple, M.T., 2000. Fundamental factors affecting biomass enzymatic reactivity. Applied Biochemistry and Biotechnology, 84-86, 1-37.

Colin, C., 2003. The coming oil crisis. New York: Multi-Science Publishing Company. 
Converse, A.O., Ooshima, H., Burns D., 1990. Kinetics of enzymatic hydrolysis of lignocellulosic materials based on surface area of cellulose accessible to enzyme and enzyme adsorption on lignin and cellulose. Applied Biochemistry and Biotechnology. 24/25, 67-73.

Dale, B.E., Moreira, M.J., 1982. A freeze explosion technique for increasing cellulose hydrolysis. Biothecnology and Bioengineering Symposium 12, 31-43.

Dolk, M., Yan, J.F., McCarthy, J.L., 1989. Kinetics of delignification of western hemlock in flow-through reactors under alkaline conditions. Holzforschung.43(2), 91-98.

Double, J., 1987. A Techno-economic assessment of processes for producing liquid fuels from biomass in Europe. Proceedings of the International Conference on Biomass for Energy and Industry held in Lisbon, Portugal, 9-13 October, 1989.

Eaglesham, A., Brown, W., Hardy, R., 2000. The biobased economy of the twenty-first cemtury: agriculture expanding into health, energy, chemicals, and materials. NABC Report 12. New York: National Agricultural Biotechnology Council.

Eggeman, T., Elander, R., 2005. Process and economic analysis of pretreatment technologies. Bioresource Technology. 96(18):2019-2025.

Granda, C.B., 2004. Sugarcane juice extraction and preservation, and long-term lime pretreatment of bagasse. PhD dissertation, Texas A\&M University, College Station, Texas.

Holtzapple, M.T, Davison, R.R., 1999. Methods of biomass pretreatment. U.S. Patent number $5,865,898$

Holtzapple, M.T., Davison, R.R., Ross, M.K., Aldrett-Lee, S., Nagwani, M., Lee, C.M., Andelson, S.K., Kaar, W., Gaskin, D., Shirage, H., Chang, N.S., Chang, V.S., Loescher, M.E., 1999. Biomass conversion to mixed alcohol fuels using the MixAlco process. Applied Biochemistry and Biotechnology. 77-79, 609-631. 
Holtzapple, M.T., Ross, M.K., Chang, N.S., Chang, V.S., Adelson, S.K., Brazel, C., 1997. Biomass conversion to mixed alcohol fuels using the MixAlco process. Fuels and Chemicals from Biomass. American Chemical Society, Washington, DC.

Holtzapple, M. T., (1993a). Cellulose. In: Macrae, R., Robinson, R. K., and Sadler, M. J., (Eds.), Encyclopedia of Food Science, Food Technology and Nutrition, vol. 2, 2731-2738.

Holtzapple, M.T., (1993b). Hemicellulose. In: Macrae R., Robinson R.K, Sadler M.J., (Eds.), Encyclopedia of food science, food technology, and nutrition. London: Academic Press. 2324-2334.

Holtzapple, M.T., (1993c). Lignin. In: Macrae R., Robinson, R.K., Sadler, M.J., (Eds.), Encyclopedia of food science, food technology, and nutrition. London: Academic Press. 2731-2738.

Hsu, T., Ladish, M., Tsao, G., 1980. Alcohol from cellulose. Chemical Technology 10(5), $315-319$.

Kaar W.E., Holtzapple M.T., 2000. Using lime pretreatment to facilitate the enzyme hydrolysis of corn stover. Biomass and Bioenergy 00,1-11.

Kheshgi, H.S., Prince, R.C., Marland, G., 2000. The potential of biomass fuels in the context of global climate change: Focus on transportation fuels. Annual Reviews Energy \& Environment. 25, 199-244.

Kim, S., 2004. Lime pretreatment and enzymatic hydrolysis of corn stover. PhD dissertation, Texas A\&M University, College Station, Texas.

Kleinert, T.N., 1966. Mechanisms of alkaline delignification: 1. The overall reaction pattern, Tappi 49(2), 53-57. 
Klinke, H. L., Ahring, B., Schmidt, A., Thomsen, A., 2002. Characterization of degradation products from alkaline wet oxidation of wheat straw, Bioresource Technology. 82, $15-26$.

Knapper, H., Grethlein, H., Converse, A., 1981. Partial acid hydrolysis of poplar wood as a pretreatment for enzymatic hydrolysis. Biotechnology and Bioengineering Symposium $11,67-77$.

Kong, R., Engler, C., Soltes, E., 1992. Effects of cell wall acetate, xylan backbone, and lignin on enzymatic hydrolysis of aspen wood. Appl Biochem Biotechnol 34, 23-35.

Ladish, M.R., 2002. Bioprocess Engineering (Biotechnology), Van Nostrand's Scientific Encyclopedia, ninth ed., vol 1, 434-459.

Ladish, M.R., Flickinger, M.C., Tsao, G.T., 1979. Fuels and chemicals from biomass. Energy. The International Journal 4 (20), 135-164.

Ladish, M., Lin, K., Voloch, M., Tsao, G., 1983. Process considerations in enzymatic hydrolysis of biomass. Enzyme and Microbial Technology 5, 82-102.

Lai, Y.Z., 2001. Chapter 10 Chemical degradation. In: Wood and Cellulose Chemistry. Hon, D.N.-S., and Shirishi, N. (Eds.), 443-512, Marcel Dekker, Inc,. New York Basel.

Landucci, R., Goodman, B., Wyman, C., 1996. Methodology of evaluating the economics of biologically producing chemicals and materials from alternative feedstocks. Applied biochemistry and biotechnology 57/58, 741-761.

Lee, Y., Fan, L., 1982. Kinetic studies of enzymatic hydrolysis of insoluble cellulose: analysis of the initial rates. Biotechnoly and Bioengineering 24, 2383-2406.

Lightfoot, H.D., 2004. Future world energy constraints and the direction for solutions. McGill University Centre for Climate and Global Change Research. 
Loescher, M.E., 1996. Volatile fatty acid fermentation of biomass and kinetic modeling using the CPDM method. PhD dissertation, Texas A\&M University, College Station, Texas.

López, R., Poblano, V.M., Licea-Claverie, A., Alvalos, M., Alvarez-Castillo, A., Castaño, V.M., 2000. Alkaline modification of sugar cane bagasse. Adv. Compos. Matter. 9(2), 99-108.

Lynd, L., Cushman, J., Nichols, R., Wyman, E., 1991. Fuel ethanol from cellulosic biomass. Science 251, 1318-1323.

Lynd, L.R, Elander, R., Wyman, C., 1996. Likely features and costs of mature biomass ethanol technology. Applied Biochemistry and Biotechnology 57/58, 741-761.

Mansfield, S., Saake, B., Gubitz, G., De-Jong, E., Puls, J., Saddler, J., 1998. Identification, purification, and characterization of the predominant endoglucanases from two brown-rot fungal strain of Gloeophyllum. In Carbohydrates from Trichoderma reesei and other microorganisms: structures, biochemistry, genetics and applications. Cambridge: The Royal Society of Chemistry. 227-244.

Medve, J., Karlsson, J., Lee, D., Tjerneld, F., 1998. Hydrolysis of microcrystalline cellulose by cellobiohydrolase I and endoglucanase II from Trichoderma reesei: adsorption, sugar production pattern, and synergism of the enzymes. Biotechnology and Bioengineering 59, $621-633$.

Montgomery, R., 1953. Observation of alkaline degradation sugars. Industrial and Engineering Chemistry. 45(5), 1144-1147.

Mosier, N., Hall, P., Ladisch, C., Ladish, M., 1999. Reaction kinetics, molecular action, and mechanisms of cellulolytic proteins. Advances in Biochemical Engineering 65, 24-40.

Mosier, N., Wyman, C., Dale, B., Elander, R., Lee, Y.Y., Holtzapple, M., Ladish, M., 2005. Features of promising technologies for pretreatment of lignocellulosic biomass. Bioresource Technology 96, 673-686. 
Nagieb, Z.A., El-Sayed, E.S.A., 2000. Two-stage alkali-oxygen (AO) pulping of bagasse. In: Fourth International Non-Wood Fiber Pulping and Papermaking.

O’Dwyer, J.P., 2005. Developing a fundamental understanding of biomass structural features responsible for enzymatic digestibility. $\mathrm{PhD}$ dissertation, Texas A\&M University, College Station, Texas.

Ranney, J.W.; Mann, L.K., 1994. Environmental considerations in energy crop production, Biomass and Bioenergy 6, 211-228.

Reynolds, R.E., 2002. Infrastructure requirements for an expanded fuel ethanol industry,prepared for Oak Ridge National Laboratory Ethanol Project, subcontract 4500010570. Available form <http://www.afdc.doe.gov/pdfs/6235.pdf $>$.

Robert, A., Traynard, P., Martin-Borrete, O., 1968. Delignification and bleaching of chemical and semichemical cellulose pulps with oxygen and catalyst. U.S. Patent $3,384,533$.

Sewalt V., Glasser W., Beauchemin K., 1997. Lignin impact on fiber degradation III: reversal of inhibition of enzymatic hydrolysis by chemical modification of lignin and by additives. J Agri Food Chem 45, 1823-1828.

Smil, V., 1994. Energy in world history. Boulder:Westview Press.

Spath, P., Mann, M., 2004. Biomass power and conventional fossil systems with and without $\mathrm{CO}_{2}$ Sequestration - comparing the energy balance, greenhouse gas emissions and economics. NREL Technical Report 510-32575. National Renewable Energy Laboratory. Golden, Colorado.

Srishdsuk, M., Kleman-Leyer, K., Keranen, S., Kirk, T., Teeri, T., 1998. Modes of action on cotton and bacterial cellulose of a homologous endoglucanase-exoglucanase pair from Trichoderma reesei. European Journal of Biochemistry 251, 885-892. 
Sullivan, J.T., 1959. A rapid method for the determination of acid-insoluble lignin in forages and its relation to digestibility. Journal of Ani Science. 18, 1292-1298.

Trivedi, M.K., Murthy, T.S., 1982. Delignification of bagasse pulps using oxygen and alkali. IPPTA 19(2), 15-18.

USDA (U.S. Department of Agriculture), Economic Research Service, Agricultural Resources and Environmental Indicators, 1996-1997, Agricultural Handbook No. 712, Washington, D.C.

USDA (U.S. Department of Agriculture), Forest Service, Forest Inventory and Analysis Timber Product Output Database Retrieval System, 1998. $<$ http://srsfia.usfs.msstate.edu/rpa/tpo $>$.

Voloch, M., Jansen, N.B., Ladish, M.R., Tsao, G.T., Narayan, R., Rodwell, V.W., 1985. 2,3Butanediol. In: Cooney, Comprenhensive Biotechnology. C.L. Humphrey, A.E. (Eds.), Pergamon Press, Oxford. 934-947.

Walseth, C.S., 1952. The influence of the fine structure of cellulose on the action ofcellulases. Tappi 35, 233-238.

Walsh, M.E., Perlack, R.L., Turhollow A., De la Torre D., Becker D.A., Graham R.L., Slinsky S.E., Ray D.E., 2000. Biomass feedstock availability in the United States: 1999 State Level Analysis. <http://bioenergy.ornl.gov/resourcedata>.

Wayman, M., Parekh, S., 1990. Biotechnology of biomass conversion: fuels and chemicals from renewable resources. Philadelphia: Open University Press.

Wooley, R., Ruth, M., Glassner, D., Sheehan, J., 1999. Process design and costing of bioethanol technology: a tool for determining the status and direction of research and development. Biotechnology Progress 15, 794-803. 
Wong K., Deverell, K., Mackie, K., Clark, T., Donaldson, L., 1988. The relationship between fiber porosity and cellulose digestibility in steam exploded Pinus radiata. Biotechnol Bioeng 31, 447-456.

Wright, L., Hohenstein, L., 1994. Dedicated feedstock supply systems: Their current status in the USA. Biomass and Bioenergy, 6 (3).

Wyman, C., Dale, B., Elander, R., Holtzapple, M., Ladish, M., Lee, Y., 2005a. Comparative sugar recovery data from laboratory scale application of leading pretreatment technologies to corn stover. Bioresource Technology. 96(18), 2026-2032.

Wyman, C., Dale, B., Elander, R., Holtzapple, M., Ladish, M., Lee, Y.Y., 2005 b. Coordinated development of leading biomass pretreatment technologies. Bioresource Technology. 96(18), 1959-1966.

Wyman, C.E., 1999. Biomass ethanol: technical progress, opportunities, and commercial challenges. Annual Review Energy Environment 24, 189-226.

Yoon, H.H., Wu, Z.W., Lee, Y.Y., 1995. Ammonia-recycled percolation process for pretreatment of biomass feedstock. Applied Biochemistry and Biotechnology 51/52, $5-19$.

Zhu, L., 2005. Fundamental study of Structural features affecting enzymatic hydrolysis of lignocellulosic biomass. PhD dissertation, Texas A\&M University, College Station, Texas. 


\section{APPENDIX A \\ DETERMINATION OF PARTICLE SIZE DISTRIBUTION IN THE FEEDSTOCK}

This procedure is based on the NREL standard procedure "Preparation of Samples for Compositional Analysis." The purpose is to convert a variety of biomass samples into a uniform material suitable for compositional analysis in a reproducible way, and determine the particle size distribution along the way.

\section{Dry}

The biomass material is spread out on a long rectangular stainless steel pan. It is allowed to air-dry (conditioning air) in a hood (controlled air velocity $100 \mathrm{ft} / \mathrm{min}$ ) prior to any milling. Do not pile the material deeper than $5 \mathrm{~cm}$. Turn the material at least once per day to ensure even drying. After at least 4 days of drying, measure the solids content of the biomass sample following NREL "LAP Determination of Total Solids in Biomass" (Appendix J). If the moisture content is less than $10 \%$ and the subsequent measurements of the moisture content report a change in weight of less than $1 \%$ in $24 \mathrm{~h}$, the biomass can be considered dried.

\section{Mill}

Feed the air-dried biomass into the knife mill and mill until the entire sample passes through the 2-mm screen in the bottom of the mill. Let the mill cool down between batches because the heat generated in the process may damage the sample.

\section{Sieve}

Stack the sieves in the following order, starting at the bottom: the bottom pan, 80, 50, 40, 30, and 20-mesh sieve. Place the milled biomass in the 20-mesh sieve. The sample should be no more than $7 \mathrm{~cm}$ deep in the 20 -mesh sieve. The milled sample may be 
processed in batches if necessary. Place the cover on the sieve stack and secure the stack in the sieve shaker. Shake the sieves for $15 \pm 1 \mathrm{~min}$.

The fraction retained on the 20 -mesh sieve (+20 mesh fraction) should be milled and sieved again or stored separately to weigh. The fraction retained on the 30 to $80+$ mesh sieve (-20/+80 mesh fraction) should be retained for compositional analysis. The material in the bottom pan is the fines (-80 mesh) fraction. Retain this material for ash analysis. It is not used in any other pretreatment or analytical procedure.

\section{Collect}

Each mesh fraction is separated into appropriate vessels and labeled as $\mathrm{W}_{+20}$, for particles retained on the 20 mesh $\mathrm{W}_{-20}$, for particles that pass the 20 mesh and are retained on the 30 mesh $\mathrm{W}_{-30}$, for particles that pass the 30 mesh and are retained on the 40 mesh $\mathrm{W}_{-40}$, for particles that pass the 40 mesh and are retained on the 50 mesh $\mathrm{W}_{-50}$, or $\mathrm{W}_{+80}$ for particles that pass the 50 mesh and are retained on the 80 mesh $\mathrm{W}_{-80}$, for particles that pass the 80 mesh or fines.

\section{Weigh and record}

All mesh fractions are weighed to the nearest $0.1 \mathrm{~g}$. Determine the moisture content taking small samples of each fraction and using NREL Standard Procedure "Determination of Total Solids in Biomass" (2004) (Appendix J).

\section{Combine}

Combine all of the $-20 /+80$ mesh by pouring all the $-20 /+80$ mesh fractions into the same pan used to dry the biomass and mix it carefully by hand for 30 minutes. 


\section{Calculate}

Use the following equation to determine the weight fractions (example for the fraction that passes the $20 \mathrm{mesh})$ :

$$
\text { Fraction }_{-20} \%=\left(\frac{\mathrm{WC}_{-20}}{\mathrm{WC}_{+20}+\mathrm{WC}_{-20}+\mathrm{WC}_{-30}+\mathrm{WC}_{-40}+\mathrm{WC}_{+80}+\mathrm{WC}_{-80}}\right) \times 100
$$

where $\mathrm{WC}_{-i}$ represents the weight fraction that passes mesh $i$, corrected by its moisture content. 


\section{APPENDIX B EXTRACTIVES IN BIOMASS}

This procedure is based on the NREL standard procedure "Determination of extractives in biomass." It has two purposes: quantify extractives for compositional analysis and remove non-structural material (ethanol soluble) from poplar wood prior to analysis to prevent interference with later analytical steps. Ethanol-soluble material includes chlorophyll, waxes, or other minor components. Historically, ethanol-benzene has been used to extract waxes, fats, some resins, and portions of wood gums. Soxhlet extraction with 190-proof ethanol has been found to be an effective, non-toxic alternative to extractions employing benzene.

\section{Preparation}

Determine the moisture content of the sample (NREL Standard Procedure "Determination of Total Solids and Moisture in Biomass") (Appendix J) and dry boiling flasks in a $105( \pm 5)^{\circ} \mathrm{C}$ drying oven for a minimum of 15 hours.

After cooling in a desiccator, add boiling stones to the boiling flask, label it, and record its oven-dry weight (ODW) to the nearest $0.1 \mathrm{mg}$. Add $6-8 \mathrm{~g}$ of sample to a labeled cellulose extraction thimble (single thickness, Whatman ${ }^{\circledR}$ ) and record the weight to the nearest $0.1 \mathrm{mg}$. The height of the biomass in the thimble must not exceed the height of the Soxhlet siphon tube. Assemble the Soxhlet apparatus and insert the thimble into the Soxhlet tube.

\section{Analyze the sample for ethanol extractives}

Add 190 ( $\pm 5 \mathrm{~mL}$ ) 190-proof ethyl alcohol to the tared ethanol receiving flask. Place the receiving flask on the Soxhlet apparatus. Adjust the heating mantles to provide a minimum of 6-10 siphon cycles per hour and reflux for 16-24 hours. When reflux time is complete, turn off the heating mantles and allow the glassware to cool to room temperature. Remove the thimble and transfer the extracted solids, as quantitatively as possible, onto 
cellulose filter paper in a Buchner funnel. Wash the solids with approximately $100 \mathrm{~mL}$ of fresh 190-proof ethanol. Allow the solids to dry using vacuum filtration or air dry. Combine any solvent from the Soxhlet tube with the solvent in the receiver flask.

\section{Remove solvent from the extractives}

Use a rotary evaporator equipped with a water bath set to $40( \pm 5)^{\circ} \mathrm{C}$ and a vacuum source. The vacuum source should be sufficient to remove solvent without extreme bumping. Continue to remove solvent until all visible solvent is gone. Place the flask in a vacuum oven at $40( \pm 2)^{\circ} \mathrm{C}$ for 24 hours. Cool to room temperature in a desiccator. Weigh the flask or tube and record the weight to the nearest $0.1 \mathrm{mg}$.

\section{Calculate}

Use the following equation to obtain the extractives content:

$$
\% \text { Extractives }=\frac{\mathrm{WFR}-\mathrm{WF}}{\mathrm{ODW}} \times 100
$$

where

WFR $=$ Weight of the flask plus residue

$\mathrm{WF}=$ Weight of the flask

ODW $=$ Weight of the sample corrected by its moisture content (or dry weight) 


\section{APPENDIX C \\ DETERMINATION OF CARBOHYDRATES, LIGNIN AND ACETYL CONTENT IN BIOMASS}

This procedure is based on the NREL standard procedure "Determination of Structural Carbohydrates and Lignin in Biomass (2004)". The purpose is quantify the following components of biomass: cellobiose, glucose, xylose, galactose, arabinose, mannose, lignin (insoluble lignin and soluble lignin), and acetic acid.

\section{Sample preparation}

Determine the moisture content of the sample according to NREL Standard Procedure "Determination of Total Solids and Moisture in Biomass" (Appendix J). The moisture content must be $10 \%$ or less, otherwise further air drying is necessary prior running this procedure. The particle size must be in the range $-20 /+80$ mesh. Deviation to a larger or smaller particle size may result in bias in both the lignin and the carbohydrates content. It is also important to have the sample extractives free, running the procedure "Extractives in biomass" explained in Appendix B before this procedure.

\section{Crucibles preparation}

Filtering crucibles (25-mL, porcelain, medium porosity, Coors \#60531 or equivalent) are necessary in this procedure. An appropriate number of filtering crucibles must have been prepared at least one day before running this procedure. The preparation of the crucibles starts by ignition of the crucibles in a muffle furnace at $575( \pm 25){ }^{\circ} \mathrm{C}$ for a minimum of 4 hours. After ignition, the crucibles must be removed from the furnace directly into a desiccator. Let them cool for exactly $1 \mathrm{~h}$ and weigh them to the nearest 0.1 $\mathrm{mg}$ and record this weight. Place them back in the furnace and ash to constant weight defined as less than $\pm 0.3 \mathrm{mg}$ change in the weight upon $1 \mathrm{~h}$ of reheating. The correct preparation of the crucibles and permanent supervision of the calibration of the analytical balance during the weighing, are fundamental to obtain an accurate, consistent result. 


\section{Preparation of the samples for the calibration curve}

The calibration curve samples may be prepared either in advance or after running this procedure, but they have to be ready for the analysis of carbohydrates in the HPLC. They are a series of sugar solutions of known concentration that are run in the HPLC to obtain the respective area. The results are then used to calculate an unknown concentration of sugars given an area.

The range of the concentration of the calibration standards, for poplar wood is suggested as $0.1,0.5,1,2,3,4,5 \mathrm{mg} / \mathrm{mL}$ for D-cellobiose, D-(+)glucose, D-(+)xylose, and D-(+)mannose. The samples for the sugar calibration curve may be prepared in a large batch that is stored frozen. Thaw and vortex frozen standards prior to use.

\section{Concentrated acid hydrolysis}

Weigh $0.3( \pm 0.01) \mathrm{g}$ of the sample and place it into a labeled $16 \times 100 \mathrm{~mm}$ test tube and record the weight to the nearest $0.1 \mathrm{mg}$. Run the NREL Standard Procedure "Determination of Total Solids in Biomass" (Appendix J) at the same time, to accurately measure the percent solids for correction. Add $3.00( \pm 0.01 \mathrm{~mL})$ of $72 \%$ sulfuric acid to each pressure tube. Place the pressure tube in a water bath set at $30( \pm 3)^{\circ} \mathrm{C}$ and incubate the sample for 60 $( \pm 5)$ minutes. Using a Teflon stir rod, stir the sample every 5 to 10 min without removing the sample from the bath.

\section{Sugar Recovery Standards (SRS) preparation}

The sugar recovery standards is a set of sugars that are used to correct for losses due to destruction of sugars during dilute acid hydrolysis. For poplar wood, SRS should include D-(+)glucose, D-(+)xylose, and D-(+)mannose. SRS sugar concentrations should be chosen to most closely resemble the concentrations of sugars in the test sample (i.e., for a sample with $43 \%$ of glucan, $15 \%$ of xylan and $3 \%$ of mannose, it is necessary to weigh about 
$0.130 \mathrm{~g}$ glucose, $0.045 \mathrm{~g}$ xylose and $0.009 \mathrm{~g}$ mannose). The SRS may be prepared during the concentrated acid hydrolysis step. Weigh out the required amount of sugar (to the nearest $0.1 \mathrm{mg}$ ), transfer it to a pressure glass bottle, add $84.0 \mathrm{~mL}$ deionized water and 3 $\mathrm{mL}$ of $72 \%$ sulfuric acid.

Immediately shake vigorously and transfer an aliquot of $20 \mathrm{~mL}$ into a $50-\mathrm{mL}$ Erlenmeyer flask and neutralize this sample as explained below in the section "neutralization." This will allow the analysis on HPLC of the initial sugar concentration of the SRS. This analysis has two purposes: check the HPLC calibration and avoid errors such as balance calibration when comparing SRS concentration before and after dilute hydrolysis.

\section{Dilute acid hydrolysis}

Once the time for the concentrated acid hydrolysis has elapsed, remove the tubes from the water bath and dilute the acid to a $4 \%$ concentration by adding $84.00( \pm 0.04) \mathrm{mL}$ deionized water with an automatic burette. Seal the bottles and place them in an autoclave. Autoclave the sealed samples and sugar recovery standards for $1 \mathrm{~h}$ at $121^{\circ} \mathrm{C}$. After that, allow the hydrolyzates to slowly cool to room temperature before removing the caps.

\section{Acid insoluble lignin analysis}

Vacuum filter the autoclaved hydrolysis solution through one of the prepared filtering crucibles. Capture the filtrate in a filtering flask. Transfer an aliquot, approximately $50 \mathrm{~mL}$, into a sample storage bottle. This sample will be used to determine acid-soluble lignin as well as carbohydrates and acetyl content. Use a minimum of $50 \mathrm{~mL}$ of hot deionized water to quantitatively transfer all remaining solids out of the pressure bottle into the filtering crucible. Dry the crucible and acid insoluble residue at $105( \pm 3){ }^{\circ} \mathrm{C}$ until a constant weight is achieved, minimum overnight, better 24 hours or more. Remove the samples from the oven and cool in a desiccator. As accurately as possible, record the weight of the crucible and dry the residue to the nearest $0.1 \mathrm{mg}$. Place the crucibles and residue in the muffle furnace at $575( \pm 25){ }^{\circ} \mathrm{C}$ for $24( \pm 6)$ hours. Carefully remove the crucible from the furnace 
directly into a desiccator and cool for exactly $1 \mathrm{~h}$. Weigh the crucibles and ash to the nearest $0.1 \mathrm{mg}$ and record the weight. Place the crucibles back in the furnace and ash to a constant weight.

\section{Acid soluble lignin analysis}

It must be performed within $6 \mathrm{~h}$ of hydrolysis on a UV-Visible spectrophotometer (background, deionized water) using the hydrolysis liquor aliquot obtained after vacuum filter the autoclaved hydrolysis solution. Measure the absorbance of the sample at $320 \mathrm{~nm}$ on a UV-Visible spectrophotometer. Using deionized water dilute the sample as necessary (a dilution factor of 3 is recommended) to bring the absorbance into the range of $0.2-1.0$, recording the dilution. Record the absorbance to three decimal places.

\section{Carbohydrates analysis}

Transfer $20 \mathrm{~mL}$ of the hydrolysis liquor obtained after the filtering step to a $50-\mathrm{mL}$ Erlenmeyer flask. Use calcium carbonate to neutralize each sample to $\mathrm{pH} 5-6$. Allow the sample to settle and decant off the supernatant. The $\mathrm{pH}$ of the liquid after settling will be approximately 7. Centrifuge the sample to eliminate the calcium carbonate, and prepare the

sample for HPLC analysis by passing the decanted liquid through a $0.2-\mu \mathrm{m}$ filter into an autosampler vial. Seal and label the vial. Analyze the calibration standards, SRS before and after hydrolysis, and samples by HPLC using a Biorad Aminex HPX-87P column equipped with the appropriate guard column. HPLC conditions follow:

Injection volume: $20 \mu \mathrm{L}$

Mobile phase: HPLC grade water, $0.2 \mu \mathrm{m}$ filtered and degassed

Flow rate: $0.55 \mathrm{~mL} / \mathrm{min}$

Column temperature: $85^{\circ} \mathrm{C}$

Detector temperature: room temperature

Detector: refractive index

Run time: 20 minutes 
If cellobiose and oligomeric sugars are detected in levels greater than $3 \mathrm{mg} / \mathrm{mL}$, incomplete hydrolysis occurred and fresh samples should be hydrolyzed and analyzed. Peaks before cellobiose may indicate high levels of sugar degradations products in the previous sample, which indicates over hydrolysis. All samples from batches showing evidence of over-hydrolysis should have fresh samples hydrolyzed and analyzed.

\section{Acetyl content}

Prepare 0.01-N sulfuric acid for use as a HPLC mobile phase. (278 $\mu$ l concentrated sulfuric acid in a 1-L volumetric flask, bringing to volume with HPLC grade water). Filter this mobile phase through a $0.2-\mu \mathrm{m}$ filter and degas before use. Prepare a series of calibration standards containing acetic acid in a range of 0.005 to $0.5 \mathrm{mg} / \mathrm{mL}$. Prepare the sample for HPLC analysis by passing a small aliquot of the liquor through a $0.2-\mu \mathrm{m}$ filter into an autosampler vial. Seal and label the vial. Analyze the calibration standards, CVS, and samples by HPLC using a Biorad Aminex HPX-87H column equipped with the appropriate guard column. HPLC conditions follow:

Sample volume: $50 \mu \mathrm{L}$

Mobile phase: $0.01-\mathrm{N}$ sulfuric acid, $0.2-\mu \mathrm{m}$ filtered and degassed

Flow rate: $0.55 \mathrm{~mL} / \mathrm{min}$

Column temperature: $65^{\circ} \mathrm{C}$

Detector temperature: room temperature

Detector: refractive index

Run time: 45 minutes

\section{Calculations}

Acid-insoluble lignin: 


$$
\% \mathrm{AIL}=\frac{(\mathrm{WCR}-\mathrm{WC})+(\mathrm{WCA}-\mathrm{WC})}{\mathrm{ODW}} \times 100
$$

where:

$\%$ AIL $=$ Percentage of acid insoluble lignin

$\mathrm{WCR}=$ Weight of crucible plus residue

$\mathrm{WC}=$ Weight of crucible

WCA $=$ Weight of crucible plus ash

ODW $=$ Dry weight of the sample (or weight corrected by moisture content)

Acid-soluble lignin

$$
\% \mathrm{ASL}=\frac{\mathrm{UV} \cdot 87 \cdot \mathrm{DF}}{11.4 \cdot \mathrm{ODW}} \times 100
$$

where:

$\% \mathrm{ASL}=$ Percentage of acid insoluble lignin

$\mathrm{UV}=$ Average UV-Vis absorbance of the sample at $320 \mathrm{~nm}$

$\mathrm{DF}=$ Dilution factor

ODW = Dry weight of the sample (or weight corrected by moisture content)

The values 87 and 11.4 stand for volume of the filtrate and absorptivity of poplar wood at $320 \mathrm{~nm}$, respectively

$$
\% \text { Total Lignin }=\% \text { AIL }+\% \text { ASL }
$$

Percentage of recovery of SRS

$$
\mathrm{PR}=\frac{\mathrm{SRS}_{\mathrm{A}}}{\mathrm{SRS}_{\mathrm{B}}}
$$

where: 
$\mathrm{PR}=$ percentage of recovery of SRS

$\mathrm{SRS}_{\mathrm{A}}=$ Concentration of sugar as measure by HPLC before dilute acid hydrolysis

$\mathrm{SRS}_{\mathrm{B}}=$ Concentration of sugar as measure by HPLC after dilute acid hydrolysis

Concentration of carbohydrates:

$$
\mathrm{C}_{\mathrm{i}}=\frac{\mathrm{C}_{\mathrm{HPLC}} \cdot \mathrm{AC} \cdot 87}{\mathrm{PR} \cdot \mathrm{ODW} \cdot 10}
$$

where:

$\mathrm{C}_{i}=$ Concentration of Sugar $i$

$\mathrm{C}_{\mathrm{HPLC}}=$ Concentration of Sugar $i$ as given by HPLC

$\mathrm{PR} \quad=$ Percentage of recovery of SRS

$\mathrm{AC}=$ Anhydro correction to calculate the concentration of polymeric sugars from the corresponding concentration of monomeric sugars. It is 0.88 for glucose and mannose and 0.9 for xylose.

ODW $=$ Dry weight of the sample (or weight corrected by moisture content)

The values 87 and 10 stand for volume of the sample and conversion units factor, respectively.

Acetate content

$$
\% \mathrm{ACE}=\frac{\mathrm{C}_{\mathrm{AHPLC}} \cdot 87 \cdot 0.683}{\mathrm{ODW}} \times 100
$$

$\mathrm{C}_{\mathrm{AHPLC}}=$ Concentration of acetic acid as given by HPLC

ODW $=$ Dry weight of the sample (or weight corrected by moisture content)

The values 87 and 0.683 stand for volume of the sample and conversion factor from acetic acid to acetate respectively. 


\section{APPENDIX D DETERMINATION OF ASH IN BIOMASS}

This procedure is based on the NREL standard procedure "Determination of Ash Biomass." The purpose is to measure the amount of inorganic material in biomass, either structural or extractable, as part of the total composition.

\section{Preparation of materials and samples}

Determine the moisture content of the samples using the NREL Standard Procedure "Determination of Total Solids and Moisture in Biomass" (Appendix J) at the time when the sample is weighed. Label the appropriate number of crucibles (ashing crucibles, 50-

$\mathrm{mL}$, porcelain) with a porcelain marker and place them in the muffle furnace at $575( \pm 25)$ ${ }^{\circ} \mathrm{C}$ for a minimum of 4 hours. Remove the crucibles from the furnace directly into a desiccator. Cool for exactly $1 \mathrm{~h}$. Weigh the crucibles to the nearest $0.1 \mathrm{mg}$ and record this weight. Place the crucibles back into the muffle furnace at $575( \pm 25)^{\circ} \mathrm{C}$ and dry to constant weight.

\section{Ignite and ash}

Weigh 0.5 to $2.0 \mathrm{~g}$, to the nearest $0.1 \mathrm{mg}$, of the sample into the tared crucible. Record the sample weight. Using a burner and clay triangle with stand, place the crucible over the flame and let the sample burn until no more smoke or flame appears. Place the crucibles in the muffle furnace at $575( \pm 25){ }^{\circ} \mathrm{C}$ for $24( \pm 6)$ hours. When handling the crucible, protect the sample from drafts to avoid mechanical loss of sample. Carefully remove the crucible from the furnace directly into a desiccator and cool for exactly $1 \mathrm{~h}$. Weigh the crucibles and ash to the nearest $0.1 \mathrm{mg}$ and record the weight. At $575( \pm 25)^{\circ} \mathrm{C}$ ash to constant weight. 


\section{Calculations}

$$
\% \mathrm{Ash}=\frac{\mathrm{WCA}-\mathrm{WC}}{\mathrm{ODW}} \times 100
$$

where

$\%$ Ash $=$ Percentage of ash

WCA $=$ Weight of the crucible plus ash

WC $=$ Weight of the crucible

ODW = Dry weight of the sample (corrected by moisture) 
APPENDIX E

EQUATIONS TO CALCULATE OXYGEN CONCENTRATION IN THE AIR AT TEMPERATURE $T$

$$
\begin{gathered}
P a=P-P v(T) \\
Y_{A}=\frac{P a}{P} \\
Y_{O_{2}}=0.21 \cdot Y_{A}
\end{gathered}
$$

where:

$\mathrm{Pa} \quad=$ Partial pressure of air

$P v(T)=$ Pressure of saturated vapor at temperature $T$

$P \quad=$ Atmosferic pressure

$Y_{A}=$ Molar fraction of dry air in the air at temperature $T$

$Y_{O 2}=$ Molar fraction of oxygen in the air 


\section{APPENDIX F \\ STARTING UP PROCEDURE FOR THE PRETREATMENT REACTOR SYSTEM}

The purpose of this procedure is to bring the reactor system to operating conditions. The steps are summarized as follows:

1. Fill water into the water tank. Nearly full level is recommended.

2. Turn on the centrifugal pump to circulate water. Refill sufficient water into the tank to maintain a nearly full level.

3. Check for leaks in the system and correct them as needed.

4. Turn on the temperature controller to heat up the circulating water to the set temperature.

5. Operate the whole system to reach a steady state. Steps 1 through 5 can be omitted in the case of pretreatment at $25^{\circ} \mathrm{C}$.

6. Transfer a mixture of $15.0 \mathrm{~g}$ dry weight of the raw biomass and $7.5 \mathrm{~g}$ of calcium hydroxide and $110 \mathrm{~mL}$ of water to the reactors using a funnel. Use $40 \mathrm{~mL}$ of distilled water to rinse the spatula and the container of the mixture and transfer all remnants to the reactor.

7. Tightly cap the reactor and connect the bubble indicator (previously filled with 20 $-25 \mathrm{~mL}$ of distilled) to measure the gas flow rate.

8. Slowly open the appropriate valve to supply nitrogen for non-oxidative pretreatment or air for oxidative pretreatment. Confirm bubble formation in the bubble indicator. Adjust the gas flow rate to achieve at $2-3$ bubbles/second using clamp placed in the inlet tube at the bottom of the reactor.

9. Regularly check gas flow rate, seals, water levels in the cylinder filled with water and in the tank, and working temperatures in all reactors.

10. After the pretreatment time has elapsed, remove the reactors and cool down to room temperature. 


\section{APPENDIX G NEUTRALIZATION OF LIME AFTER PRETREATMENT}

This procedure has a double purpose: determine the lime consumption during pretreatment and neutralize the sample to render it ready for analytical procedures that may be affected for $\mathrm{pH}$.

\section{Preparation of the sample}

Once the pretreatment time is elapsed, let the reactor cool to room temperature, transfer its contents to a 1-L centrifuge bottle, using distilled water to rinse and move all the material as completely as possible. The volume of slurry in the bottle after this step is about $750 \mathrm{~mL}$.

\section{Procedure}

Set up titration apparatus (buret, clamp, magnetic stirrer and a well-calibrated $\mathrm{pH}$ meter). Place a magnetic bar into the centrifuge bottle containing pretreated biomass slurry and place the bottle on the magnetic stirrer. Dip the $\mathrm{pH}$ probe inside of the bottle to measure the $\mathrm{pH}$ of the slurry. Fill 5- $\mathrm{N} \mathrm{HCl}$ solution in the buret and clamp it over the bottle. Record the volume $\left(V_{i}\right)$. Slowly drop the acid into the bottle up to the end point ( $\mathrm{pH}$ 7.00). Provide enough time ( $\geq 1 \mathrm{~h}$ ) to ensure the $\mathrm{pH}$ of the slurry is stabilized. Record the volume left in the buret $(V f)$. Be prepared to continue the neutralization after a few washes as explained in appendix $\mathrm{H}$.

\section{Calculation}

Use the following equation to determine the lime consumption during pretreatment:

$$
\mathrm{W}_{\mathrm{ca}(\mathrm{OH})_{2}}=\frac{1 \mathrm{~mol} \mathrm{Ca}(\mathrm{OH})_{2}}{2 \mathrm{~mol} \mathrm{HCl}} \times \frac{\mathrm{N}_{\mathrm{HCl}} \cdot\left(\mathrm{V}_{\mathrm{i}}-\mathrm{V}_{\mathrm{f}}\right)^{1000}}{100 \mathrm{M}_{\mathrm{Ca}(\mathrm{OH})_{2}}}
$$

where, 
$\mathrm{W}_{\mathrm{Ca}(\mathrm{OH}) 2}=$ The amount of lime, $\mathrm{Ca}(\mathrm{OH}) 2$, unreacted $(\mathrm{g})$

$\mathrm{NHCl}=$ Normality of $\mathrm{HCl}$ solution

$\mathrm{V}_{\mathrm{i}}-\mathrm{V}_{\mathrm{f}}=$ Total volume of $\mathrm{HCl}$ solution to titrate the biomass slurry $(\mathrm{mL})$

$\mathrm{M}_{\mathrm{Ca}(\mathrm{OH}) 2}=$ Molecular weight of $\mathrm{Ca}(\mathrm{OH}) 2,74.092 \mathrm{~g} / \mathrm{mol}$ 


\section{APPENDIX $\mathrm{H}$ WASHING BIOMASS PROCEDURE AND RECOVERY YIELD OF TOTAL MASS}

This procedure is run immediately after the neutralization of the sample. Its purpose is to eliminate the pretreatment liquor from the sample. The weight loss of biomass due to pretreatment (recovery yield of total mass) is also determined.

\section{Preparation of materials}

Dry a plastic container (about $500 \mathrm{~mL}$ capacity) and Whatman 934/AH glass fiber filter paper (particle retention $=1.5 \mu \mathrm{m}$, Fisher Scientific Co., Pittsburgh PA) in a $45^{\circ} \mathrm{C}$ oven for $24 \mathrm{~h}$ or longer. Let them cool in a dessicator. Record their weights to the nearest $0.1 \mathrm{mg}$.

\section{Washing}

After neutralizing the sample as explained in the Appendix G, continue stirring for 15 min. Centrifuge the water/poplar wood mixture at $4000 \mathrm{rpm}$ for $15 \mathrm{~min}$. A vacuum filtration apparatus should be set up before hand using a Buchner funnel and one of the predried/pre-weighed filter papers. After centrifuging, carefully decant the water into the Buchner funnel with vacuum filtration. Decant as much water as possible being careful not to lose much solids. Fill the centrifuge bottle with $750 \mathrm{~mL}$ of fresh distilled water. Observe the filtrate color. Stir, centrifuge, decant, and fill the centrifuge bottle with fresh distilled water as many times as necessary until the filtrate becomes clear. If it takes too long to filter, replace the old filter with one of the other previously dried-and-weighed filter papers.

It is very important to measure the $\mathrm{pH}$ of the washed biomass during the stirring step. It has been observed that no matter how carefully the neutralization has been done, the $\mathrm{pH}$ increases again and further neutralization may be required.

\section{Determination of weight loss}


After completing the washing, transfer all the poplar wood from the centrifuge bottle to the prepared $500-\mathrm{mL}$ container. Transfer all the solids as quantitatively as possible to the container using water. Dry the biomass and the filter papers at $45^{\circ} \mathrm{C}$ for $24 \mathrm{~h}$ or longer. Cool the biomass and filters in a desiccator until they reach room temperature. Weigh them and record the values to the nearest $0.1 \mathrm{mg}$. After subtracting the weight of the containers and filter paper, the net weight of the poplar wood is obtained $\left(W_{2}\right)$. Immediately after, using about $0.3-0.5 \mathrm{~g}$ of this $45^{\circ} \mathrm{C}$-dried washed biomass, determine the moisture content as described in the NREL Standard Procedure "Determination of Total Solids and Moisture in Biomass" (Appendix J) $\left(X_{2}\right)$.

$$
Y=\frac{W_{2} \times\left(1-X_{2}\right)}{W_{1} \times\left(1-X_{1}\right)}
$$

where

$Y=$ Total yield, $\mathrm{g}$ treated bagasse/g untreated bagasse

$W_{1}=$ Weight of the washed raw biomass before pretreatment

$X_{1}=$ Moisture content of the washed and air dried raw biomass (W $), \mathrm{g} \mathrm{H}_{2} \mathrm{O} / \mathrm{g}$ total weight

$W_{2}=$ Weight of the $45^{\circ} \mathrm{C}$-dried poplar wood in the $500-\mathrm{mL}$ container and filter papers

$X_{2}=$ Moisture content of the $45^{\circ} \mathrm{C}$-dried biomass $\left(W_{2}\right), \mathrm{g} \mathrm{H}_{2} \mathrm{O} / \mathrm{g}$ total $45^{\circ} \mathrm{C}$-dried weight. 


\section{APPENDIX I}

\section{ENZYMATIC HYDROLYSIS}

This procedure is based on the NREL standard procedure "Enzymatic Saccharification of Lignocellulosic Biomass." The purpose is to determine the maximum extent of digestibility possible after the enzymatic saccharification of cellulose from untreated or pretreated lignocellulosic biomass.

\section{Determination of biomass and enzyme quantity}

Determine the moisture content of the samples using the NREL Standard Procedure "Determination of Total Solids and Moisture in Biomass." (Appendix J) in advance. Also, measure glucan content of the sample according to the method described in Appendix $\mathrm{C}$ prior to this analysis. The recovery yield of total mass must be known beforehand. The enzyme activity should be measured to assure good conservation during the storage (use NREL Standard Procedure "Measurement of Cellulase Activities"). Using these data, calculate the amount of biomass equivalent to $0.1 \mathrm{~g}$ of glucan in raw biomass as follows:

$$
B=\frac{0.1}{G \cdot T S}
$$

where:

$B=$ Biomass to be weighed

$G=$ Glucan fraction in the treated biomass

$Y=$ Percentage of recovery yield of total mass

$\mathrm{TS}=$ Solid fraction in the sample (equivalent to 1 minus moisture content)

Also calculate the amount of enzyme to be added as:

$$
E 1=\frac{\left(\frac{0.1}{Y_{G}}\right) \cdot E L}{E A}
$$


E1 = Amount of enzyme to be added

$E L=$ Enzyme loading $=15 \mathrm{FPU} / \mathrm{g}$ glucan in raw biomass

$E A=$ Enzyme activity

$Y_{G}=$ Pretreatment yield of glucan

\section{Preparation of citrate buffer and the sample}

Citrate buffer is prepared as follows: dissolve $210 \mathrm{~g}$ of citric acid monohydrate in 1000 $\mathrm{mL}$ of distilled water, then adjust the $\mathrm{pH}$ to 4.5 by adding $\mathrm{NaOH}$. Before running this procedure, make sure the biomass has been neutralized and washed since deviations in the $\mathrm{pH}$ (too acidic or alkaline) affect the enzymatic hydrolysis yields greatly.

Weigh $B \mathrm{~g}$ of biomass into a labeled 20 -mL glass scintillation vial. Add sodium citrate buffer $(5 \mathrm{~mL}, 0.1 \mathrm{M}, \mathrm{pH} 4.8)$, tetracycline $(40 \mu \mathrm{L}, 10 \mathrm{mg} / \mathrm{mL}$ in $70 \%$ ethanol), cycloheximide (30 $\mu \mathrm{L}, 10 \mathrm{mg} / \mathrm{mL}$ in distilled water) and an amount of distilled water $(W)$, HPLC grade, equal to

$$
W=5-B-E 1-E 2
$$

where $B$ and $E 1$ were defined before and $E 2$ is the required amount of cellobiase to obtain $60 \mathrm{CBU} / \mathrm{g}$. This is to bring the volume in the vial to $10 \mathrm{~mL}$ (after adding enzymes). Measure the $\mathrm{pH}$ in the vials and adjust to 4.8 with either a saturated solution of sodium hydroxide or acetic acid as necessary. Close the vials and preheat them in a rotary incubator (Amerex Instruments Inc, Lafayette, CA) at a speed of $105 \mathrm{rpm}$ and a temperature of $50^{\circ} \mathrm{C}$ for $1 \mathrm{~h}$. The vials should be held in the incubator at a minimum angle of $45^{\circ}$ to assure good mixing.

\section{Enzymatic hydrolysis}

Take the vial briefly out of the incubator, add the enzymes, both at a time and place the vial back in the incubator. Record the time. If more than a sample is run in a batch, it is 
advisable to add the enzymes at specific intervals of time between the samples, $30 \mathrm{~s}$ to 1 min are recommended.

\section{Analysis}

Once the enzymatic hydrolysis time has elapsed, take the samples out of the incubator in the same order as the enzyme was applied and with the same interval of time between the samples. Put the closed vials in a boiling water bath to denature the enzymes and let them heat for $15 \mathrm{~min}$. Place the vials in a mixture of ice and water and let them cool down for $10 \mathrm{~min}$.

Transfer the vials contents to labeled $15-\mathrm{mL}$ centrifuge tubes and centrifuge for $10 \mathrm{~min}$ at $4000 \mathrm{rpm}$ to eliminate the solid residue. Dilute the decanted liquid (if necessary) with distilled water (HPLC grade) recording the dilution factor. Prepare the sample for HPLC analysis by passing the decanted diluted liquid through a $0.2-\mu \mathrm{m}$ filter into an autosampler vial. Seal and label the vial. Analyze calibration standards (to prepare calibration standards use guidelines in Appendix C) and samples by HPLC using a Biorad Aminex HPX-87P column equipped with the appropriate guard column. HPLC conditions follow:

Injection volume: $20 \mu \mathrm{L}$, dependent on concentration and detector limits

Mobile phase: HPLC grade water, 0.2- $\mu \mathrm{m}$ filtered and degassed

Flow rate: $0.55 \mathrm{~mL} / \mathrm{min}$

Column temperature: $85^{\circ} \mathrm{C}$

Detector temperature: Room temperature

Detector: refractive index

Run time: 35 minutes

\section{Calculations:}

$$
\% \text { digestion }=\frac{\mathrm{C}_{\mathrm{HPLC}} \cdot 10 \cdot \mathrm{AC}}{0.1}
$$

where:

$\mathrm{C}_{\mathrm{HPLC}}=$ Concentration of the sugar as given by HPLC in $\mathrm{g} / \mathrm{mL}$ 
$\mathrm{AC}=$ Anhydro correction to calculate the concentration of polymeric sugars from the corresponding concentration of monomeric sugars. It is 0.88 for glucose and mannose and 0.9 for xylose.

The values 10 and 0.1 stand for volume of the sample and grams of cellulose added, respectively. 


\section{APPENDIX J \\ DEFINITION OF FPU}

FPU stands for "filter paper units" per milliliter of original (undiluted) enzyme solution and are the units to measure enzyme activity using Whatman No. 1 filter paper strips as substrate. For quantitative results the enzyme preparations must be compared on the basis of significant and equal conversion. The value of $2.0 \mathrm{mg}$ of reducing sugar as glucose from $50 \mathrm{mg}$ of filter paper ( $4 \%$ conversion) in 60 minutes has been designated as the intercept for calculating filter paper cellulose units (FPU) by IUPAC. Thus, the procedure involves finding a dilution of the original enzyme stock such that a $0.5 \mathrm{~mL}$ aliquot of the dilution will catalyze $4 \%$ conversion in 60 minutes and then calculating the activity (in FPU/mL) of the original stock from the dilution required. According to Ghose (1987), the required calculations are based on the International Unit (IU), more specifically:

$1 \mathrm{IU}=0.1 \mu \mathrm{mol} \mathrm{min} \mathrm{m}^{-1}$ of substrate converted

$=1 \mu \mathrm{mol} \mathrm{min} \mathrm{m}^{-1}$ of "glucose" (reducing sugars as glucose) formed during the hydrolysis reaction

$=0.18 \mathrm{mg} \mathrm{min} \mathrm{m}^{-1}$ when product is glucose

The absolute amount of glucose released in the FPU assay at the critical dilution is 2.0 $\mathrm{mg}$ (equivalent to $2 / 0.18 \mu \mathrm{mol}$ ). This amount of glucose was produced by $0.5 \mathrm{ml}$ enzyme in 60 min, i.e., in the FPU reaction:

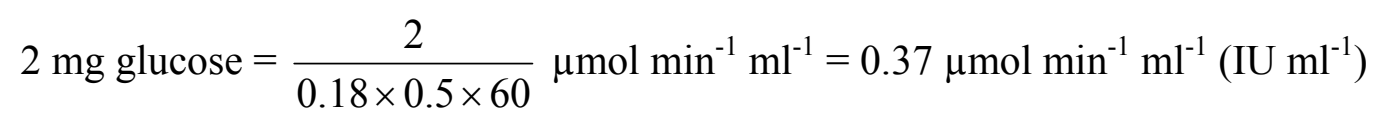

Therefore, the estimated amount of enzyme ( $=$ critical enzyme concentration $=\mathrm{ml} \mathrm{ml}^{-1}$ ) which releases $2.0 \mathrm{mg}$ glucose in the FPU reaction contains 0.37 units, and:

$$
\text { FPU } \equiv \frac{0.37}{\text { enzyme concentration to release } 2.0 \mathrm{mg} \text { glucose }} \text { units } \mathrm{ml}^{-1}
$$

This last one is the defining equation for FPU. The purpose of the procedure is to accurately find the denominator. 


\section{APPENDIX K \\ DETERMINATION OF MOISTURE CONTENT IN BIOMASS}

This procedure is based on the NREL standard procedure "Determination of Total Solids and Moisture in Biomass." The purpose is to measure the amount of water and other components volatilized at $105^{\circ} \mathrm{C}$ present in a biomass sample.

\section{Procedure}

Accurately weigh a predried aluminum foil weighing dish to the nearest $0.1 \mathrm{mg}$ and record this weight (WD). Thoroughly mix the sample and then weigh 1 to 5 grams $( \pm 0.1$ $\mathrm{mg}$ ) into the weighing dish. Record the weight of the sample plus the weighing dish (WWS). Place the sample into a convection oven at $105^{\circ} \mathrm{C}( \pm 3)^{\circ} \mathrm{C}$ and dry to constant weight $( \pm 0.1 \%$ change in the amount of moisture present upon $1 \mathrm{~h}$ of reheating). It is advisable to dry at least $24 \mathrm{~h}$. Remove the sample from the oven and place in a desiccator; cool to room temperature. Weigh the dish containing the oven-dried sample to the nearest $0.1 \mathrm{mg}$ and record this weight (WDS). All the samples must be run in replicate (duplicates, at minimum).

\section{Calculation}

$$
\% \quad \text { Moisture }=1-\frac{\mathrm{WDS}-\mathrm{WD}}{\mathrm{WWS}-\mathrm{WD}} \times 100
$$

All the abbreviations used in this equation are explained in the text under "Procedure".

Conversely, the total solids content of the sample is calculated as:

$$
\% \text { Total Solids }=\frac{\mathrm{WDS}-\mathrm{WD}}{\mathrm{WWS}-\mathrm{WD}} \times 100 \text { or } \% \text { Total solids }=1-\text { Moisture content }
$$




\section{APPENDIX L}

\section{EXPERIMENTAL DATA FOR MASS BALANCES}

Carbohydrates and lignin composition was analyzed at least twice for poplar wood taken from the same pretreated batch. In the 4-week pretreatment case, the pretreatment was repeated at all conditions and then analyzed in duplicates. Extractives and ash were measured only once, and acetyl content was $<0.1 \mathrm{~g} / 100 \mathrm{~g}$ treated biomass in all cases.

\begin{tabular}{|c|c|c|c|c|c|c|}
\hline SAMPLE & \multicolumn{2}{|c|}{$\begin{array}{c}\text { 1-WEEK } \\
\text { PRETREATMENT }\end{array}$} & \multicolumn{2}{|c|}{$\begin{array}{c}\text { 2-WEEK } \\
\text { PRETREATMENT }\end{array}$} & \multicolumn{2}{|c|}{$\begin{array}{c}\text { 4-WEEK } \\
\text { PRETREATMENT }\end{array}$} \\
\hline \multicolumn{7}{|c|}{ GLUCAN (g/100 $\mathrm{g}$ treated biomass) } \\
\hline & AVERAGE & STDEV & AVERAGE & STDEV & AVERAGE & STDEV \\
\hline $25 \mathrm{~A}$ & 46.62 & 0.34 & 44.18 & 1.91 & 39.11 & 2.43 \\
\hline $25 \mathrm{~N}$ & 46.16 & 0.13 & 46.16 & 2.62 & 47.29 & 1.64 \\
\hline $35 \mathrm{~A}$ & 47.09 & 0.15 & 47.10 & 0.33 & 41.71 & 4.51 \\
\hline $35 \mathrm{~N}$ & 46.46 & 0.86 & 47.61 & 1.68 & 47.66 & 1.34 \\
\hline $45 \mathrm{~A}$ & 47.43 & 0.40 & 47.61 & 0.33 & 49.87 & 0.35 \\
\hline $45 \mathrm{~N}$ & 47.63 & 1.51 & 48.83 & 1.85 & 48.15 & 0.96 \\
\hline $55 \mathrm{~A}$ & 47.78 & 1.00 & 47.97 & 0.56 & 44.16 & 1.01 \\
\hline $55 \mathrm{~N}$ & 42.81 & 2.15 & 48.62 & 1.35 & 48.50 & 0.11 \\
\hline $65 \mathrm{~A}$ & 45.67 & 1.47 & 42.96 & 1.72 & 43.35 & 2.80 \\
\hline $65 \mathrm{~N}$ & 46.38 & 1.71 & 50.38 & 1.31 & 48.66 & 0.24 \\
\hline \multicolumn{7}{|c|}{ XYLAN (g/100 g treated biomass) } \\
\hline $25 \mathrm{~A}$ & 16.10 & 0.34 & 15.15 & 1.17 & 12.29 & 0.32 \\
\hline $25 \mathrm{~N}$ & 16.40 & 0.50 & 16.46 & 0.73 & 15.92 & 0.78 \\
\hline $35 \mathrm{~A}$ & 15.69 & 0.37 & 15.62 & 0.63 & 12.65 & 0.83 \\
\hline $35 \mathrm{~N}$ & 16.19 & 0.07 & 17.47 & 0.01 & 15.89 & 0.82 \\
\hline $45 \mathrm{~A}$ & 15.62 & 0.30 & 16.03 & 0.48 & 14.15 & 0.43 \\
\hline $45 \mathrm{~N}$ & 16.71 & 0.09 & 16.34 & 0.64 & 16.28 & 0.41 \\
\hline $55 \mathrm{~A}$ & 15.58 & 0.24 & 15.58 & 0.50 & 12.84 & 0.26 \\
\hline $55 \mathrm{~N}$ & 15.64 & 1.32 & 16.16 & 0.36 & 16.58 & 0.28 \\
\hline $65 \mathrm{~A}$ & 15.14 & 0.18 & 13.30 & 0.42 & 13.43 & 3.58 \\
\hline $65 \mathrm{~N}$ & 16.46 & 0.22 & 16.27 & 1.19 & 16.58 & 0.31 \\
\hline
\end{tabular}




\begin{tabular}{|c|c|c|c|c|c|c|}
\hline \multirow{2}{*}{ SAMPLE } & \multicolumn{2}{|c|}{$\begin{array}{c}\text { 1-WEEK } \\
\text { PRETREATMENT }\end{array}$} & \multicolumn{2}{|c|}{$\begin{array}{c}\text { 2-WEEK } \\
\text { PRETREATMENT } \\
\end{array}$} & \multicolumn{2}{|c|}{$\begin{array}{c}\text { 4-WEEK } \\
\text { PRETREATMENT }\end{array}$} \\
\hline & \multicolumn{6}{|c|}{ LIGNIN (g/100 g treated biomass) } \\
\hline $25 \mathrm{~A}$ & 23.94 & 0.30 & 23.72 & 2.24 & 22.21 & 0.09 \\
\hline $25 \mathrm{~N}$ & 23.61 & 0.09 & 24.13 & 1.59 & 27.38 & 0.18 \\
\hline $35 \mathrm{~A}$ & 23.93 & 0.73 & 24.32 & 3.20 & 24.71 & 0.22 \\
\hline $35 \mathrm{~N}$ & 24.93 & 1.77 & 24.77 & 1.75 & 27.28 & 0.23 \\
\hline $45 \mathrm{~A}$ & 25.10 & 1.62 & 23.66 & 1.38 & 25.30 & 0.40 \\
\hline $45 \mathrm{~N}$ & 23.41 & 0.01 & 26.43 & 3.49 & 26.64 & 0.25 \\
\hline $55 \mathrm{~A}$ & 23.50 & 0.00 & 22.35 & 2.20 & 23.85 & 0.07 \\
\hline $55 \mathrm{~N}$ & 25.00 & 2.40 & 27.60 & 0.04 & 25.03 & 0.12 \\
\hline $65 \mathrm{~A}$ & 23.16 & 0.31 & 21.64 & 0.42 & 20.04 & 0.01 \\
\hline $65 \mathrm{~N}$ & 21.32 & 3.35 & 26.04 & 1.14 & 28.02 & 1.09 \\
\hline \multicolumn{7}{|c|}{ MANAN (g/100 $\mathrm{g}$ treated biomass) } \\
\hline $25 \mathrm{~A}$ & 2.73 & 0.02 & 3.30 & 0.29 & 2.74 & 0.34 \\
\hline $25 \mathrm{~N}$ & 2.73 & 0.02 & 3.42 & 0.02 & 3.24 & 0.03 \\
\hline $35 \mathrm{~A}$ & 2.53 & 0.10 & 3.24 & 0.34 & 2.70 & 0.00 \\
\hline $35 \mathrm{~N}$ & 2.41 & 0.08 & 3.12 & 0.02 & 2.33 & 0.08 \\
\hline $45 \mathrm{~A}$ & 2.47 & 0.08 & 3.22 & 0.00 & 2.67 & 0.16 \\
\hline $45 \mathrm{~N}$ & 2.18 & 0.04 & 3.39 & 0.83 & 1.68 & 0.15 \\
\hline $55 \mathrm{~A}$ & 2.14 & 0.10 & 2.76 & 0.02 & 2.05 & 0.26 \\
\hline $55 \mathrm{~N}$ & 1.19 & 0.16 & 2.21 & 0.37 & 1.57 & 0.01 \\
\hline $65 \mathrm{~A}$ & 1.61 & 0.03 & 2.60 & 0.19 & 2.01 & 1.32 \\
\hline $65 \mathrm{~N}$ & 0.99 & 0.11 & 1.98 & 0.39 & 1.52 & 0.20 \\
\hline \multicolumn{7}{|c|}{ ASH (g/100 g treated biomass) } \\
\hline $25 \mathrm{~A}$ & 1.33 & & 1.1 & & 1.2 & \\
\hline $25 \mathrm{~N}$ & 1.33 & & 1.1 & & 1.2 & \\
\hline $35 \mathrm{~A}$ & 1.67 & & 1.3 & & 1.2 & \\
\hline $35 \mathrm{~N}$ & 1.70 & & 1.4 & & 1.2 & \\
\hline $45 \mathrm{~A}$ & 1.70 & & 1.6 & & 1.1 & \\
\hline $45 \mathrm{~N}$ & 0.82 & & 1.5 & & 1.1 & \\
\hline $55 \mathrm{~A}$ & 1.77 & & 1.0 & & 1.2 & \\
\hline $55 \mathrm{~N}$ & 1.19 & & 0.9 & & 1.2 & \\
\hline $65 \mathrm{~A}$ & 1.46 & & 1.2 & & 1.3 & \\
\hline
\end{tabular}




\begin{tabular}{l|c|c|c}
\hline SAMPLE & $\begin{array}{c}\text { 1-WEEK } \\
\text { PRETREATMENT }\end{array}$ & $\begin{array}{c}\text { 2-WEEK } \\
\text { PRETREATMENT }\end{array}$ & $\begin{array}{c}\text { 4-WEEK } \\
\text { PRETREATMENT }\end{array}$ \\
\hline \multicolumn{3}{c}{ ASH (g/100 g treated biomass) } \\
\hline $65 \mathrm{~N}$ & 1.46 & 1.16 & 1.41 \\
\multicolumn{3}{c}{ EXTRACTIVES (g/100 g treated biomass } \\
\hline \multicolumn{3}{c}{1.19} & 0.54 \\
$25 \mathrm{~A}$ & 1.89 & 1.87 & 1.35 \\
$35 \mathrm{~N}$ & 1.37 & 1.46 & 1.44 \\
$35 \mathrm{~N}$ & 1.71 & 1.46 & 1.44 \\
$45 \mathrm{~A}$ & 1.71 & 2.10 & 1.44 \\
$45 \mathrm{~N}$ & 1.35 & 1.46 & 1.37 \\
$55 \mathrm{~A}$ & 1.71 & 1.46 & 1.44 \\
$55 \mathrm{~N}$ & 1.71 & 1.46 & 1.44 \\
$65 \mathrm{~A}$ & 1.05 & 0.67 & 1.95 \\
$65 \mathrm{~N}$ & 2.92 & 1.46 & 1.98 \\
\hline
\end{tabular}

The number in the name of the sample indicates the temperature in degrees celcius and the $\mathrm{N}$ stands for non-oxidative pretreatment, whereas the A stands for oxidative pretreatment (air). 


\section{VITA}

Rocio Sierra Ramirez received a B.S. in chemical engineering from Universidad de America, Bogotá, Colombia. She worked as a research assistant in the development of the brown sugar industry in Colombia. Rocio received a M.S. in mechanical engineering from Universidad de Los Andes, Bogotá, Colombia. She worked as a professor at Universidad de Los Andes. In August 2003, she started her M.S. in the Department of Chemical Engineering at Texas A\&M University, completing this degree in December 2005.

\section{Address:}

Texas A\&M University

Department of Chemical Engineering

TAMU M.S. 3122

College Station, TX 77843 